\title{
WestVirginiaUniversity
}

THE RESEARCH REPOSITORY @ WVU

Graduate Theses, Dissertations, and Problem Reports

2007

\section{Finite element analysis of composite bridge deck joints}

Amit Valmick Desai

West Virginia University

Follow this and additional works at: https://researchrepository.wvu.edu/etd

\section{Recommended Citation}

Desai, Amit Valmick, "Finite element analysis of composite bridge deck joints" (2007). Graduate Theses, Dissertations, and Problem Reports. 4296.

https://researchrepository.wvu.edu/etd/4296

This Thesis is protected by copyright and/or related rights. It has been brought to you by the The Research Repository @ WVU with permission from the rights-holder(s). You are free to use this Thesis in any way that is permitted by the copyright and related rights legislation that applies to your use. For other uses you must obtain permission from the rights-holder(s) directly, unless additional rights are indicated by a Creative Commons license in the record and/ or on the work itself. This Thesis has been accepted for inclusion in WVU Graduate Theses, Dissertations, and Problem Reports collection by an authorized administrator of The Research Repository @ WVU. For more information, please contact researchrepository@mail.wvu.edu. 
Finite Element Analysis of Composite Bridge Deck Joints

\author{
Amit Valmick Desai \\ Thesis Submitted to the \\ College of Engineering and Mineral Resources \\ at West Virginia University \\ in partial fulfillment of the requirements \\ for the degree of \\ Master of Science \\ in \\ Mechanical Engineering
}

Nithi T. Sivaneri, Ph.D., Chair

Hota V. Ganga Rao, Ph.D.

Bruce Kang, Ph.D.

Department of Mechanical and Aerospace Engineering

Morgantown, West Virginia

2007

Keywords: Bridge deck, ANSYS, Joints, Finite Element Modeling. 


\section{ABSTRACT \\ Finite Element Analysis of Composite Bridge Deck Joints}

\section{Amit Desai}

Pultruded FRP bridge decks have many advantages compared to conventional concrete decks. Joints are an integral part of composite bridge decks and modular decks with field joints normally lead to lower efficiency than monolithic decks. The joints should be designed to provide higher efficiency to transfer loads and moments from one component to another.

In this study a finite element model of a 4"-thick low-profile FRP bridge deck (Prodeck 4) made of E-glass fiber and vinyl ester resin, having a fiber volume fraction of approximately $50 \%$ and weighing about $10 \mathrm{lb} / \mathrm{ft}^{2}$, is developed using the software ANSYS. The design also incorporates various joint systems such as an adhesively connected joint, mechanically riveted joint and a combined riveted and bonded joint. These modeled joints are subjected to compressive and bending loads to evaluate results such as strain profiles across the joint sections. The obtained results are compared with previous experimental results. A good correlation is found to exist between the finite element and experimental results of Prodeck 4. 


\section{ACKNOWLEDGEMENTS}

The road to my graduate degree has been long and winding, so I would like to thank some people. Firstly, I would like to thank my advisor Dr. Nithi T. Sivaneri, who gave me an opportunity to work under him and under whose supervision I chose this topic and began the thesis. He is the best advisor I could have wished for, without whose guidance and support this thesis would not have been possible. He is actively involved in the work of all of his students, and clearly has their best interest in mind.

I would also like to thank the members in my committee: Dr. Hota V. Ganga Rao and Dr. Bruce Kang for taking out time from their busy schedules to evaluate my thesis. Their suggestions are invaluable and their support throughout the entire process is greatly appreciated.

I am forever indebted to my parents and my sister for their love, support, encouragement and endless patience when it is most required. I am very grateful to my cousins, without whose inspiration this work would not have been finished.

Finally, I would also like to thank all my roommates and friends especially Aneesh who helped me in completion of my graduate work.

I am very grateful for the time and effort so many people have dedicated in helping me succeed 


\section{Table of Contents}

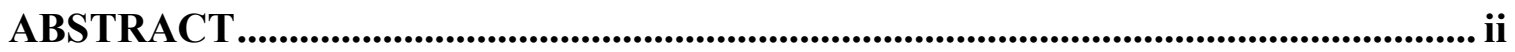

ACKNOWLEDGEMENTS .................................................................................iii

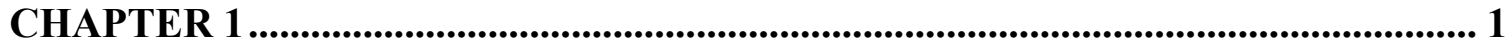

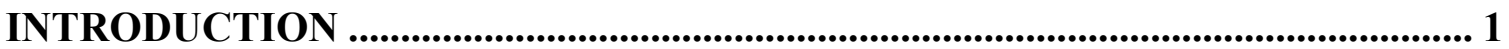

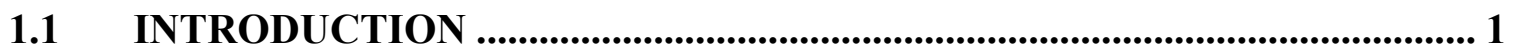

$1.2 \quad$ LITERATURE REVIEW ................................................................................... 3

1.2.1 Adhesively Bonded Composite Joints ................................................. 4

1.2.2 Mechanically Fastened Composite Joints ................................................. 8

$1.3 \quad$ NEED FOR CURRENT RESEARCH................................................................ 16

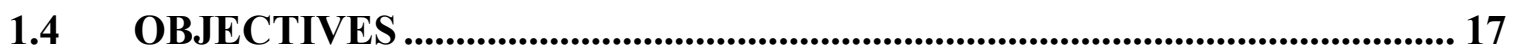

1.5 THESIS OVERVIEW ................................................................................... 17

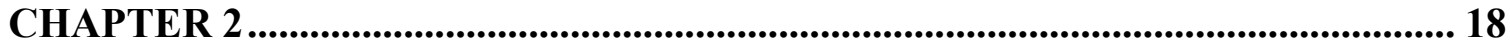

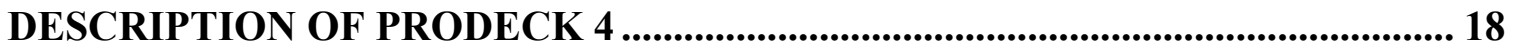

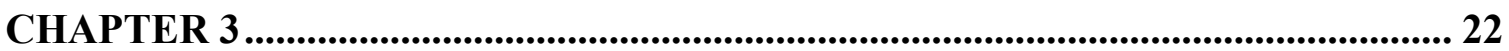

FINITE ELEMENT MODEL..................................................................................... 22

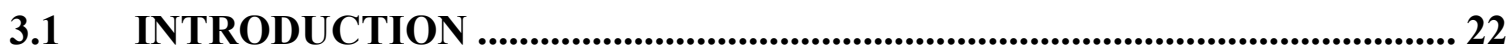

3.2 TYPE OF ELEMENT ................................................................................. 22

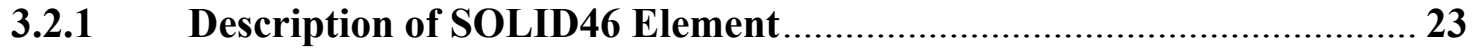

3.3 MATERIAL PROPERTIES........................................................................... 25

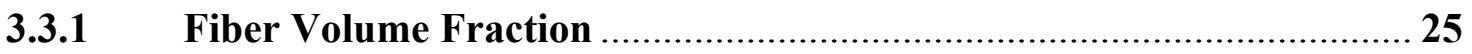

3.3.2 Lamina Properties …………………………..................................... 26

3.3.3 Material Specifications of the Laminas used in Prodeck 4 .....................30

$3.4 \quad$ FINITE ELEMENT MODEL......................................................................... 31

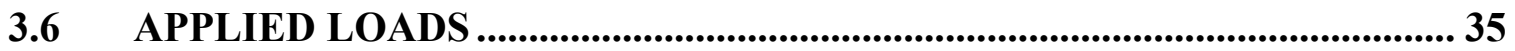

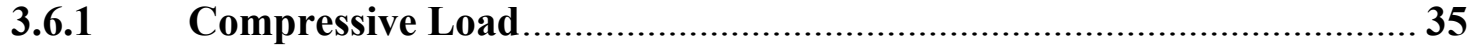

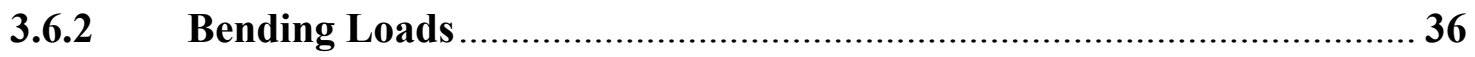

3.7 ADHESIVE MODELING .................................................................................. 37

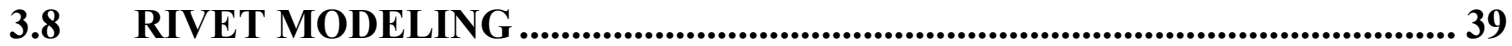




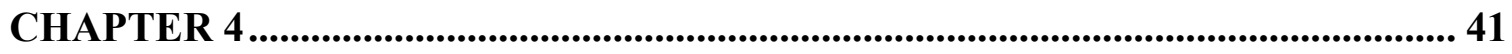

ANALYSIS OF ADHESIVELY BONDED FRP PANELS.......................................... 41

$4.1 \quad$ INTRODUCTION ............................................................................................ 41

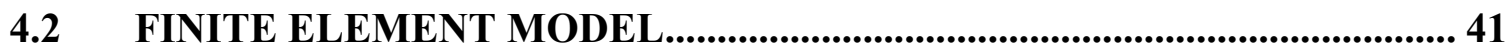

4.3 BOUNDARY CONDITIONS for COMPRESSIVE LOADING ..................... 45

4.5 RESULTS - COMPRESSIVE LOADING CASE ......................................... 47

4.5.1 Analysis of Stain Profile Across the Joint ............................................... 47

4.5.2 Analysis with varying Young's Modulus ........................................... 51

4.6 COUPON-LEVEL ADHESIVE LAP-JOINT ANALYSIS............................ 52

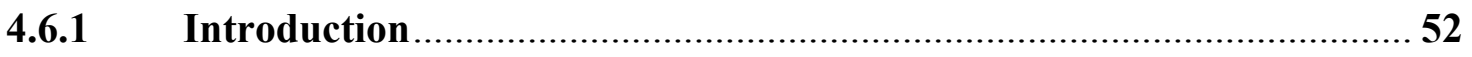

4.6.2 Analysis of Stain Profile across the Coupon-Level Joint …………….... 54

4.7 SHEAR STRESS VARIATION IN THE ADHESIVE.....................................59

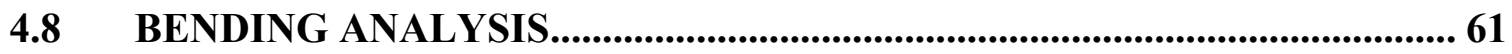

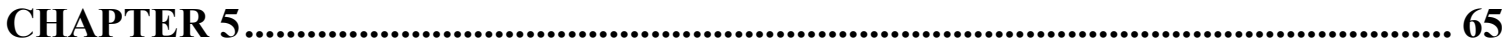

ANALYSIS OF MECHANICALLY CONNECTED FRP PANELS.......................... 65

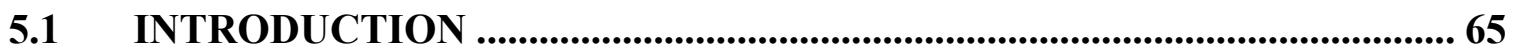

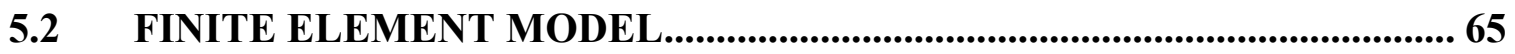

5.3 BOUNDARY CONDITIONS AND APPLIED LOADS..................................... 69

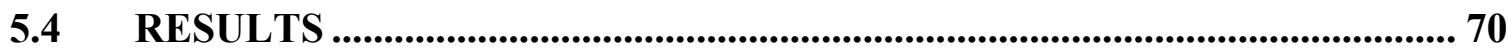

5.4.1 Analysis of Strain Profile Across the Joint ........................................... 70

5.5 COUPON-LEVEL MECHANICALLY CONNECTED LAP JOINT

ANALYSIS ........................................................................................................................... 74

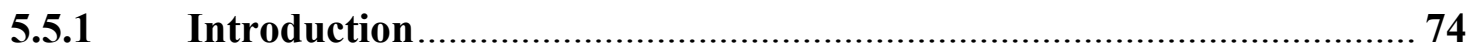

5.5.2 Analysis of Stain Profile across the Coupon-Level Joint …………….... 76

5.6 ANALYSIS OF MECHANICALLY AND ADHESIVELY-CONNECTED

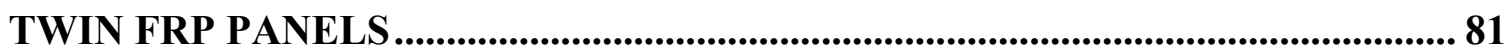

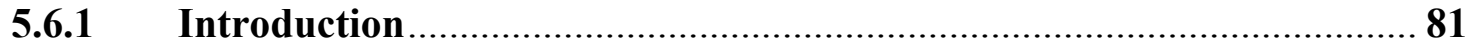

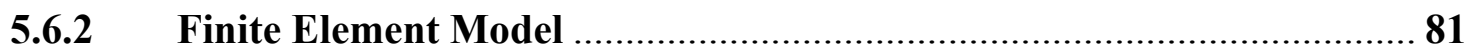

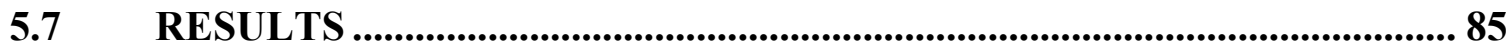

5.7.1 Analysis of Stain Profile across the Joint................................................. 85 


\subsection{COUPON-LEVEL MECHANICALLY AND ADHESIVELY BONDED}

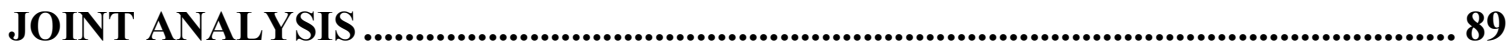

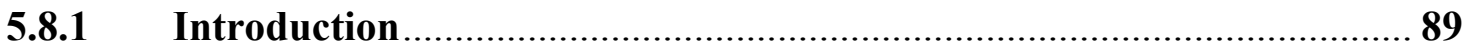

5.8.2 Analysis of Strain Profile across the Coupon-Level Joint....................... 91

CHAPTER 6........................................................................................................................ 95

CONCLUSIONS AND RECOMMENDATIONS...................................................... 95

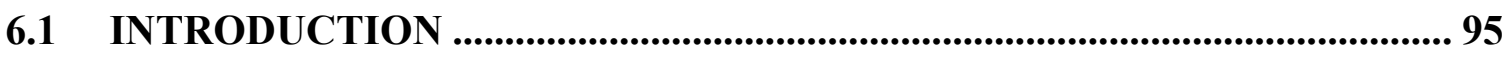

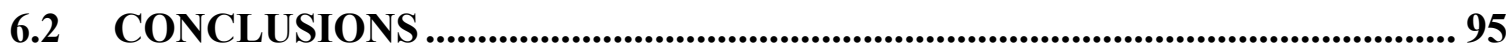

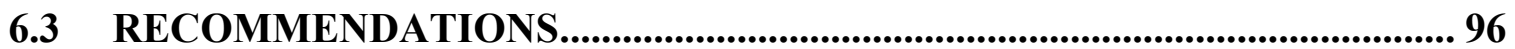

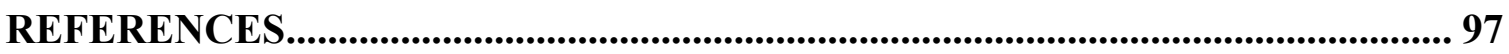




\section{LIST OF FIGURES}

Fig. 1.1 Diagram of pultrusion process....................................................

Fig. 2.1 Cross-section of Prodeck 4.....................................................19

Fig. 2.2 Orientation of global coordinate system........................................19

Fig. 2.3 Fiber architecture of Prodeck4 component ........................................20

Fig. 3.1 SOLID46 geometry..........................................................23

Fig. 3.2 Solid model of Prodeck 4.....................................................32

Fig. 3.3 Meshed model of glued twin Prodeck 4 panels........................................33

Fig. 3.4 Fiber orientations of individual layers of an element in Prodeck 4.................34

Fig. 3.5 Pictorial representation of boundary conditions applied on the Prodeck 4........35

Fig. 3.6 Pictorial Representation of 3"x 3" Surface load applied on the Prodeck 4..........36

Fig. 3.7 Four point bending analysis on an adhesively bonded twin-panel Prodeck 4.....37

Fig. 3.8 SOLSH190 geometry.........................................................38

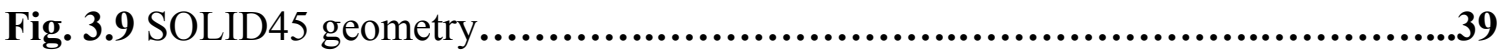

Fig. 3.10 Meshed model of a riveted Prodeck 4 connection.................................40

Fig. 4.1 Solid model of an adhesively bonded FRP twin-panel connection................42

Fig. 4.2 Map-meshed model of an adhesively bonded FRP twin-panel connection.......43

Fig. 4.3 Orientations of element coordinate systems in FRP panel connection............43

Fig. 4.4 Joint Section of the FRP twin-panel connection..................................44

Fig. 4.5 Pictorial representation of boundary conditions applied on FRP twin-panel......45

Fig. 4.6 Pictorial representation of uniform pressure applied on the adhesively bonded

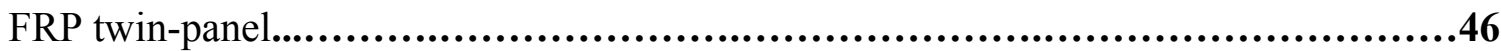

Fig. 4.7 Contour plot of longitudinal strain in the joint region for a compressive load

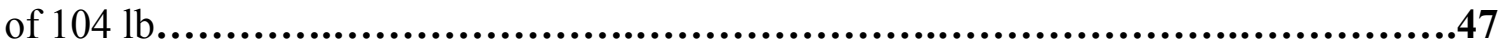

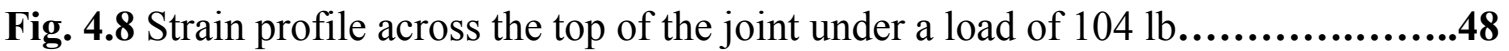

Fig. 4.9 Strain profile across the length of the glued joint.................................50

Fig. 4.10 Adhesively-bonded coupon-level single lap joint..............................51

Fig. 4.11 Adhesively-bonded coupon-level single lap joint...............................53

Fig. 4.12 Pictorial representation of uniform pressure and boundary conditions applied on the adhesively-bonded coupon-level joint................................................54 
Fig. 4.13 Contour plot of longitudinal strain in the joint region for a compressive load of

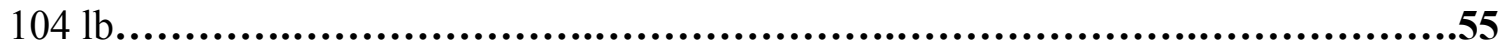

Fig. 4.14 Strain profile across the top of the joint under a load of $281 \mathrm{lb} . . . . . . . . . . . . . . .56$

Fig. 4.15 Strain Profile across the length of the coupon-level glued joint...................58

Fig. 4.16 Shear stress variation in the adhesive........................................59

Fig. 4.17 Graphical representation of shear stress variation across the adhesive...........60

Fig. 4.18 Four point bending analysis on an adhesively-bonded twin Prodeck 4 panel....61

Fig. 4.19 Contour plot of longitudinal strain in the tension region of the joint for an equivalent load of $148 \mathrm{lb}$

Fig. 4.20 Strain profile on the bottom flange of the bridge-panel under 4-point bend test.......................................................................................63

Fig. 4.21 Strain profile on the top flange of the bridge-panel joint under 4-point bend test..............................................................................64

Fig. 5.1 Solid model of a mechanically bonded FRP twin-panel........................66

Fig. 5.2 Map-meshed model of a mechanically bonded FRP twin-panel..................67

Fig. 5.3 Orientations of element coordinate systems in FRP twin-panel..................67

Fig. 5.4 Joint section of the riveted FRP twin-panel..................................68

Fig. 5.5 Pictorial representation of boundary conditions and applied load on riveted FRP twin-panel..........................................................................69

Fig. 5.6 Contour plot of longitudinal strain in the joint region for a compressive load of 400 lb...........................................................................................70

Fig. 5.7 Strain profile across the top of the joint under a load of $400 \mathrm{lb} . . . . . . . . . . . . . . . . . .71$

Fig. 5.8 Strain profile across the length of the riveted joint...............................73

Fig. 5.9 Mechanically connected coupon-level single lap joint.........................75

Fig. 5.10 Pictorial representation of uniform pressure and boundary conditions applied on the mechanically connected coupon-level joint..........................................76

Fig. 5.11 Contour plot of longitudinal strain in the joint region of the riveted coupon joint

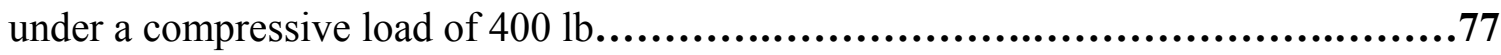

Fig. 5.12 Strain profile across the top of the joint under a load of $400 \mathrm{lb}$.................78

Fig. 5.13 Strain profile across the length of the coupon-level riveted joint................80 
Fig. 5.14 Solid model of a mechanically and adhesively bonded FRP twin-panel connection..............................................................................82

Fig. 5.15 Joint section of the riveted and adhesively bonded FRP twin-panel.............83

Fig. 5.16 Pictorial representation of boundary conditions and applied load on riveted and adhesively bonded FRP twin-panel...................................................884

Fig. 5.17 Contour plot of longitudinal strain in the joint region for a compressive load of

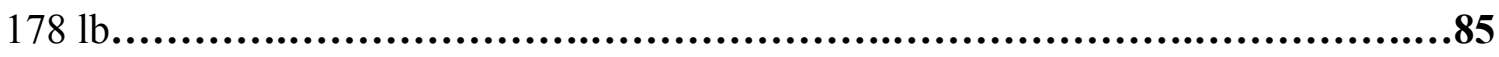

Fig. 5.18 Strain profile across the top of the joint under a load of $178 \mathrm{lb} . . . . . . . . . . . . . . .87$

Fig. 5.19 Strain profile across the length of the riveted and glued FRP panels............88

Fig. 5.20 Mechanically riveted and adhesively bonded coupon-level single lap joint.....90

Fig. 5.21 Pictorial representation of uniform pressure and boundary conditions applied on the mechanically riveted and adhesively bonded coupon-level joint......................91

Fig. 5.22 Contour plot of the longitudinal strain in the joint region of the riveted and

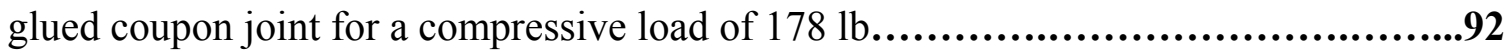

Fig. 5.23 Strain profile across the length of the riveted and glued coupon joint...........94 


\section{LIST OF TABLES}

Table 2.1 Specifications of CDBM3415 fabric used in Prodeck 4........................21

Table 2.2 Specifications of DDBM4015 fabric used in Prodeck 4........................21

Table 3.1 Layer properties of fibers and roving $\ldots \ldots \ldots \ldots \ldots \ldots \ldots \ldots \ldots \ldots \ldots \ldots \ldots \ldots \ldots \ldots \ldots . . .31$

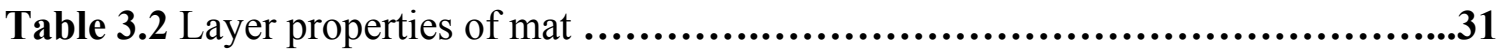

Table 4.1 Longitudinal strain values across the joint for different applied loads..........49

Table 4.2 Longitudinal strain values across the glued coupon joint for different applied

loads.............................................................................57

Table 4.3 Longitudinal strain values across the joint under tension for applied load......63

Table 5.1 Longitudinal strain values across the riveted joint for different applied loads.72

Table 5.2 Longitudinal strain values across the riveted coupon-level joint for different applied loads..........................................................................79

Table 5.3 Longitudinal strain values across the riveted and adhesively connected joint for different applied loads................................................................87

Table 5.4 Longitudinal strain values across the coupon-level joint for different applied

loads...........................................................................................93 


\section{CHAPTER 1}

\section{INTRODUCTION}

\subsection{INTRODUCTION}

Last decade has seen a significant growth in the use of fiber reinforced polymer (FRP) composite materials and structural systems in engineering applications. Also known as fiber-reinforced plastics, these materials have proven themselves to be valuable for use in the construction and rehabilitation of buildings and bridges [Bank (2006)].

FRP composite materials have a variety of applications in structural engineering ranging from strips and sheets for external strengthening of structures to internal reinforcing bars for concrete members to structural profile like cellular decks for bridge floors, which is the focus of this thesis. FRP composite materials have been developed into economically and structurally viable construction materials and structural systems for bridges over the last 20 years [Bank (2006)]. Pultruded FRP bridge decks have many advantages compared to conventional concrete decks especially in bridge engineering. Some of the advantages of FRP composite decks are:

- They are more durable, lighter-weight and easier to install than concrete decks.

- FRP bridge decks are more resistant to corrosion caused by deicing salts resulting in an increased service life of bridge.

- Electromagnetic transparency.

- Thermal insulation. 
- Capacity to carry increased live load due to the reduction in the dead load.

- Superior fatigue performance.

Due to many advantages of FRP bridge decks over reinforced concrete bridge decks, concrete bridge decks are, in a limited manner, getting replaced by FRP bridge decks. A lightweight modular FRP composite deck weighs approximately $80 \%$ less than the conventional concrete deck. This low dead load of the deck allows an increase to the allowable live load capacity of the bridge. [Alampalli and Kunin (2001)].

The most common procedure used to manufacture FRP bridge decks is based on pultrusion process. Pultrusion is a continuous manufacturing process used to manufacture constant cross-section shapes of any length. The fibers are continuously impregnated and pulled through a heated die, where they are shaped and cured. Both closed sections (e.g., a box-beam) and open sections (e.g., an I-beam) can be produced, but it is easier to produce closed sections. Closed sections, such as a box beam, are fabricated using a mandrel cantilevered behind the entrance to the die. The pultrusion line can also be fitted with a rotating winder to apply reinforcements at an angle (usually $\pm \theta$ ) around the product. This is commonly used to fabricate pipe and drive shafts. Operational costs of this process are low and this process is ideally suited for high volume applications. All the pultruded bridge decks are made of glass fibers and polyester or vinyl ester matrices (thermoset matrices). All of the systems are based on several profiles adhesively bonded together. Experiments in the laboratory have been carried out to evaluate the joint efficiency of a glued and mechanically riveted profile and a mechanically riveted profile. 


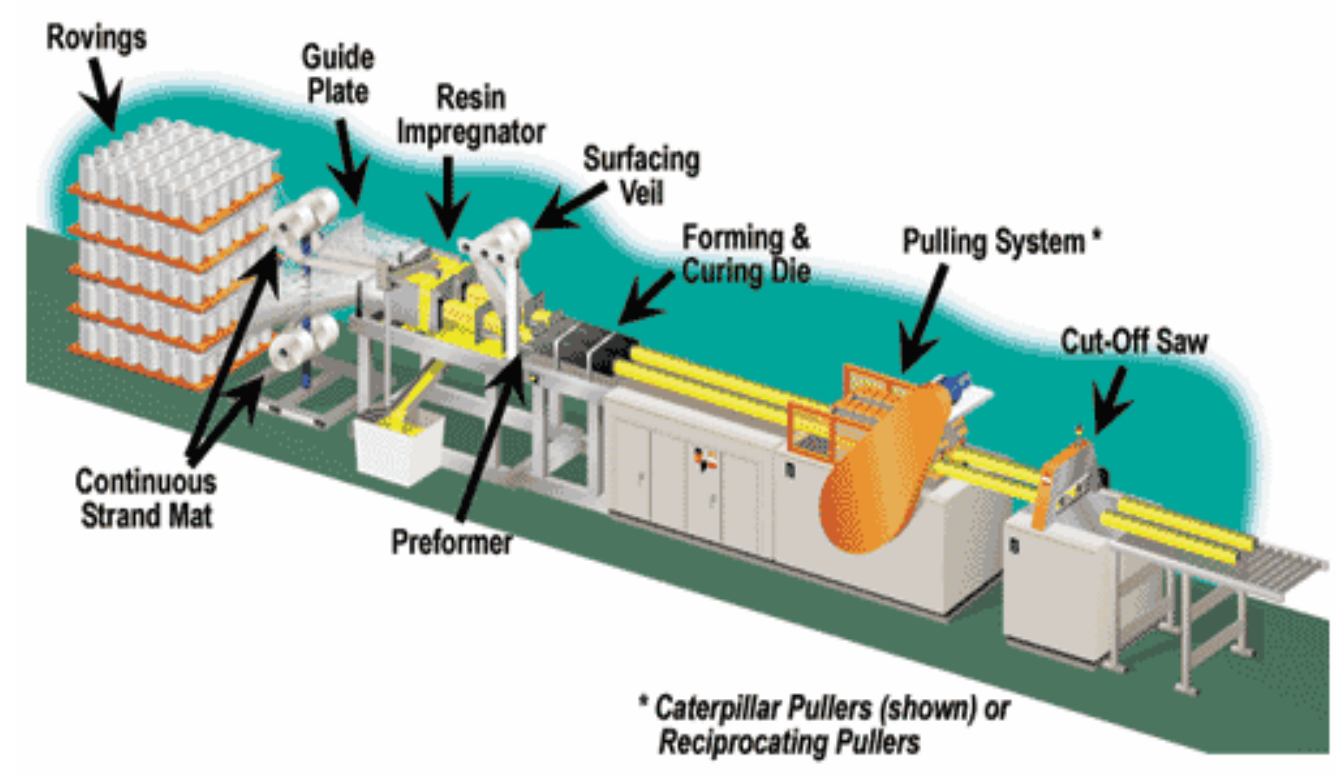

Fig. 1.1 Diagram of the pultrusion process *

Despite having many advantages, FRP materials are not widely used in the civil infrastructural community because of lack of standardized test procedures, proper design criteria and reliable failure theory. Research and development is still being carried out in order to increase the performance and application in infrastructural community.

\subsection{LITERATURE REVIEW}

A critical review on FRP connections, with civil engineering applications in mind has been presented by Hollaway (1990) and Mosallam (1994). This section reviews the theory behind adhesively bonded and mechanically bolted coupon-level joints in composites and also presents the research done at the deck level.

\footnotetext{
* http://www.pulwellpultrusions.com/applications.htm
} 


\subsubsection{Adhesively Bonded Composite Joints}

Adhesively bonded joints exhibit lower stress concentration when compared to bolted joints. It is necessary to select the right type of overlap joint in order to have more efficient joint in terms of reduced stress concentration and higher joint stiffness. The two main stress patterns that are highly critical for a reliable adhesive joint are shear and peel stresses. Peel stresses on the other hand occur at the free end of a lap joint due to eccentricities in load application, and can be eliminated by using symmetric joint geometry (i.e., double lap joint) and by tapering the adherends. According to Oplinger (1975), in theory, desired load capacities can be achieved by making the joint long enough and thick enough. However, peel stress resistance is a function of adherend thickness, and similarly shear stress is a function of adhesive length/area. The factors affecting stress concentrations are:

- Thickness of the adherend

- Overlap length of the bond

- Thickness of the adhesives

- Stacking sequence of laminates Increase in adherend thickness might induce higher peel stresses, hence not recommended. Inducement of residual stresses during the curing process is considered to be a function of adhesive thickness. Bond layer thickness [Oplinger (1975)] is generally limited to a range of $0.005-0.015$ in. $(0.127-0.38 \mathrm{~mm})$. An increase in overlap length results in lower stress concentrations. Experimental results by Dyole (1991) report an optimum overlap length of 4 in., in terms of reducing the tress concentrations. The effect the of stacking sequence of laminates making up the adherends in composite joints is 
significant. For example, a $90^{\circ}$ layer placed adjacent to the bond layer theoretically acts largely as additional thickness of the bond material, leading to lower peak stresses. On the other hand, $0^{\circ}$ layers when placed next to the bond layer give stiff adherend response with higher stress peaks. In practice, it has been observed that $90^{\circ}$ layers next to bond layer tend to seriously weaken the joint because of transverse cracking which develops in these layers.

Joint efficiency can be defined as the ratio of the ultimate joint load over the ultimate load of the unjointed material. The factors mainly affecting joint efficiency are: 1) adherend length, 2) fiber volume fraction, 3) joint geometry, 4) effective adhesive length and 5) fiber orientation. Experiments conducted by Sotiropoulos (1995), on pultruded FRP coupon joints reported a minimum length for the adhesive layer around $120 \mathrm{~mm}$ to achieve maximum joint efficiency. Prokhorov (1965) recommended a minimum value equal to 30 times the adherend thickness which has found to be $143 \mathrm{~mm}$ for the joints studied by Sotiropoulos (1995).

The development of theoretical models of the adhesive joints has taken over five decades. For single lap joints, Volkersen (1938) has proposed a simple shear lag model based on the assumptions of one dimensional bar like adherends with only shear deformations in the adhesive layer. Later, Goland and Reissner (1944) have postulated a beam on-elastic-foundation model simulating the joint as consisting of two beams bonded with shear and transverse normal-deformable adhesive layer. Hart-Smith (1987) has extended the Goland and Reissner model to treat joints with elastic-plastic adhesives. Srinivas (1975), introduced factors like, transverse shear deformation and transverse normal stresses to finite element analyses proposed by earlier researchers to study 
adhesive joint behavior. Compilation of analytical works on FRP adhesive joints can be found in review papers by Matthews et al., (1982), and Vinson (1989).

Melhem and Schlup (1994) have presented a detailed discussion on the usage of adhesives and composites in highway structures. They have presented results of research done on small scale specimens at the Kansas state university. Experiments are carried out to characterize the adhesive shear strength performance. Several joint variables such as material type, type of adhesive, temperature, pre-bond moisture, humidity, bond-line thickness and others are included in the test program.

Lap joint theories have been developed to analyze the stresses and strains in the adhesive layer based on strength of materials methods and fracture mechanics. In the strength of materials method, the maximum stresses and strains are determined using coupon tests. The data is then used to predict the ultimate stress and strain value at the critical point or over a limited zone [Adams and Wake (1984)]. Clark and McGregor (1993) suggested that failure in adhesive occurs when the maximum tensile strength exceeds its strength over a limited zone, and their failure criterion is applicable to a number of joint configurations.

In the fracture mechanics method, the critical energy release rate is measured and then used as the ultimate value for the predicted energy release rate or the value of Jintegral [Tong, 1989]. Other contributions include Delale et.al. (1981) who developed two-dimensional closed form solutions for a bonded joint. Lin and Lin (1993) derived a finite element model of single-lap adhesive joints. Oplinger (1994) developed a layered beam theory to investigate the effects of adherend deflection on the adhesive stress 
distributions. Tsai and Morton (1994) evaluated theoretical solutions using non linear finite element analysis.

The four distinct ways in which adhesively bonded composite joints can fail are:

- Failure of the adherend

- Failure of adhesive under shear stress

- Failure of the adherend under peel stress

- Failure in through-the-thickness direction of the adherends under tensile loading. When adherends are relatively thin, results of stress analyses show that for all joint types, the stresses in the bond will be enough to guarantee that the adherends reach their load capacity before failure occurs in the bond. As the adherend thickness increases, the bond stresses become relatively larger until a point is reached at which bond failure occurs at a lower load than that at which the adherends fail. Single lap joints are the least capable of all joint types in terms of efficiency. This is because the eccentricity of the geometry generates significant bending of the adherends, which in turn magnifies the peel stresses, and finally leads to premature failure of the joint.

Shear strength failure is an adhesive failure of bond between the adherend and the adhesive. The shear strength of the bonded joint is proportional to the square root of the laminate thickness [Hollaway, 1990]. The peel stress is a tensile stress that develops its maximum value near the free end of the joint. The peel stress induced failure occurs within the laminate as soon as the peel stress exceeds the inter-laminar tension in the adherends. Hart-Smith (1987) suggests that peel stress can be eliminated by adherend tapering, if the adherend thickness is limited to ensure failure of the adherends rather than the adhesive. All of the reports discussed above are focused on coupon-level specimens 
and not beam to beam connections .However they can be used as a basis for providing information on failure modes and joint efficiencies of pultruded composites.

Bank et al. (1994) presented local failures in joints between FRP structural shapes using FRP bolts and nuts and FRP angles as connectors. Tests results have shown that such a design may not be suitable for FRP material or system that is tested by Bank et al. (1994) and Bank and Mosallam (1991). A closer investigation of the failure modes observed in the pultruted sections. In addition, the shear-out failure mode observed in one of the connections tested in that work could be prevented, by using a larger end bolt distance. Even though the use of FRP bolts and nuts eliminates corrosion problems of connectors, maximum torque applied through the FRP bolts is much less than the torque applied when high strength steel bolts are used. Morsi and Cook (1984) conducted an investigation of the efficiency of joints between steel columns and beams using steel and/or FRP angles with steel and/or FRP bolts.

\subsubsection{Mechanically Fastened Composite Joints}

The review of many finite element analyses and experimental work conducted on bolted joints is presented in this section. Winter (1956) tested bolted connections covering variables such as bolt diameter, sheet thickness, mechanical properties of sheet and bolt steels, edge distance etc. All bolted connections have been tested on Baldwin testing machine for four load ranges. A connection slip is attached to the upper half of the connection and the other to the lower half. It measures autographically by means of special adapter arms. 
Cope and Lacy (2004) have developed a methodology to efficiently depict mechanical fasteners in lap joints using finite elements. A simple lap joint with three rows of mechanical fasteners has been modeled using different combinations of explicit and spring element representations of fasteners. The main objective of this study is to determine the appropriate level of model refinement that is necessary for accurate SIF solutions for cracks emanating from fastener holes. The computer code FRANC 2D/L (Fracture Analysis Code 2- Dimensional / Layered) is used in this study. The combinations of explicit and spring element representations of fasteners may be used to develop an efficient lap joint model as a function of load transfer versus deformation.

Shankar et al. (2002) investigated the effect of oily film corrosion-prevention compounds on the fatigue behavior of aluminum alloy 7075-T6 mechanically fastened joints. Double lap joints with a single bolt fastener are tested under constant-amplitude fatigue loading with and without any treatment of lubricants compound. The final fracture occurred in the middle plate for all the specimens or in the vicinity of the reduced section at the fastener hole. Bearing mode failure initiates at the bore of the hole and spreads diametrically across the fastener hole while fretting mode failure initiates from flaws created by fretting damage on the surface of the middle plate. Increasing the clamping force shifts the fracture line away from the centerline of the fastener hole towards the loaded end of the middle plate. For each load case and surface condition, higher lives are recorded for specimens that failed in fretting mode than those failed in the bearing mode. This is due to the fact that the bearing failure occurs at the edge of the fastener hole, where the stress concentrations are high, while fretting mode failures occur away from the edge of the hole, wherein stress concentrations are much lower. Increasing 
clamping force reduces the bearing stresses and the stress intensities at the two locations become comparable, shifting the failure from one mode to another. At certain levels of friction load transfer ratio, all failure occurs in the bearing mode, while at higher values of friction force, the failure occurs in fretting mode. The transition between bearing and failure modes occurs at the same load transfer ratio for both the specimens.

Failure usually initiates at the first root of the bolt thread in a bolted joint. In this paper, Fukuoka and Takaki (1998) analyzed the mechanical behavior of bolted joints in various clamping configurations using FEM as multi-body elastic contact problem, and the effects of nominal diameter, friction and pitch error upon stress concentrations are evaluated for through bolts, studs and tap bolts. The stress concentration at the thread root becomes remarkable with increase of $\mu$ (friction coefficient). On the contrary, under the bolt head subjected to pure tension, it is observed that as $\mu$ increases, the stress concentration factor decreases. This opposing phenomenon on the stress concentrations occurring under the bolt head and at thread root may be explained due to difference in the sliding directions of these two regions, i.e., the bolt thread slides relatively inwards, while the bolt head expands outwards. In the tap bolt head, the stress concentration under the bolt head increase with smaller radial coefficient of friction and larger circumferential coefficient. Mechanical behavior of studs is not sensitive to friction on the contact surface compared with through bolts. Due to imperfect geometry induced by low accuracy in machining, high stress concentration factor is likely to occur at the thread roots located in the rear of the bolt hole. Recessed internal threads are effective for reducing high stress concentrations. In the loosening process, the magnitude of the bottoming torque should 
be more than half the tightening torque in order to restrict the rotation of a bottoming stud.

Gerbert and Bastedt (1993) investigated external loaded bolted joints of different designs. The predicted mounting stiffness of the bolt and abutment is substantially higher than the bolt load. A load application factor is introduced in VDI 2230 and a new fraction is determined which is much lower than the existing ones. The application factor is independent of the location of the external load in practical design but it is influenced by the layout of the bolt joint.

Jung and Han (2000) investigated the fatigue life prediction of SUS304 stainless steel with bolted joints using the fatigue modulus concept. A modified fatigue life prediction equation as an exponential function of fatigue modulus, fatigue cycle and load transfer level is derived to consider the relaxation of stress concentration due to fasteners. The main objective of this study is to characterize the fatigue behavior of mechanically fastened joints, identifying the relaxation of stress concentration and the effect of clamping force on the fatigue strength. Fatigue tests have been conducted for plate-type specimens with bolted holes and a finite element model is used to observe the stress concentration near bolts. The extension of fatigue life is obtained due to relaxation of stress concentration due to fasteners. The gradient of the stress distribution is affected nonlinearly by the clamping force. The predicted life is close to the test data, this shows that the constants of fatigue modulus degradation model contain geometry data representing notch effects.

Pratt and Pardoen (2002) developed nonlinear Finite element models to predict the load elongation behavior of single- and dual-bolted conical-head bolted lap joints. 
This research shows that the test specimen results of conical-head bolts and the dualfastener underestimate those of the single-fastener joints up to $17 \%$ in thick panels. This underestimation of joint strength results in overly conservative joint designs with corresponding excess weight and cost. The load elongation trace is used to determine the joints stiffness and joint yield strength. "The joint yield strength is defined as the load at which a line, offset from the origin by $4 \%$ of the fastener hole size and having slope equal to the joint stiffness, intersects the load-elongation trace" [Pratt and Pardeon (2002)]. The area under the load-elongation trace, or deformation energy, provides a direct measure of resistance to joint elongation. A nonlinear finite-element code NIKE3D is used to develop the models. A bilinear elastic-plastic material model is used. The effective coefficient of friction $\mu$ for subsurface shear is given by

$$
\mu=\tau_{0} \frac{A}{P}
$$

where $P=$ normal force and $A=$ contact area. The fastener-to-panel friction coefficient and the residual fastener clamp are useful in predicting the slip resistance of experimental test specimens. The dual-fastener results have been halved to enable a comparison with single-fastener specimen results. The dual fastener results underestimate the yield strength of the single-fastener joint by up to $10 \%$ in thick panels. The slip resistance of the single-fastener lap joint is up to $17 \%$ higher than the thicker panels than that predicted with the dual-fastener test results. The experimental data is substantiated with finiteelement analyses. The model load elongation predictions are in excellent agreement with experimental test data.

Lehnhoff and Wistheuff (1996) performed axisymmetric finite element modeling of bolted joints to show the effects of the magnitude as well as the radial location of the 
externally applied load on the member separation radius and the stress on the surface between the two members. Separation of the members at a certain radial distance is a phenomenon that can be detrimental to maintaining a sealed joint. The member separation is caused by the compression of the connected members in the near vicinity of the bolt. Thus, controlling this tendency for the members to separate by proper spacing of bolts in joint group can help to prevent leakage. The separation radius is the point where the two members separate due to loading. The separation radius is a function of bolt size, external load magnitude and location, and connected material thickness ratio. Larger bolts have larger separation radii. This is due to the larger contact area between the bolt head and the member. The separation is found to be nonlinearly related to changes in the magnitude as well as position of the external load. A 27-percent decrease for 24-mm bolts to 39-percent decrease for 8-mm bolts in the separation radius resulted with changes in the load magnitude. The external load varied from zero to the maximum that could be sustained before the joint separation for steel members. The change in separation radius for the aluminum members, cast iron members, and a combination of the two materials is of the order of 2-10 percent. Changes in the stress on the surface between the members occurred with changes in magnitude as well as radial position of the external load. The stress is found to be higher near the bolt for larger external loads and also when the radial location of the external load is increased.

Ireman (1998) developed a three dimensional finite element model of composite joints to determine non-uniform stress distributions through the thickness of composite laminate in the vicinity of the bolt hole. The objective of the study is to develop a threedimensional FE model of an isolated region of the joint. The model is validated against 
experimental strain and deformation measurements. A number of joint configurations including variations of many significant joint parameters like laminate lay up, bolt diameter, bolt type, bolt pre-tension and lateral support condition are studied. The FE models are created with the general-purpose program IDEAS [Mark (1995)] and the analysis have been carried out with ABAQUS [Hibbitt et al. 1995]. The specimens used are quasi-isotropic $[( \pm 45 / 0 / 90) 4]_{\mathrm{s} 32}$, zero dominated $\left[\left( \pm 45 / 90 / 02 / 90 / 0_{2}\right) 2\right]_{\mathrm{s} 32}$ and quasiisotropic $[( \pm 45 / 0 / 90) 8]_{664}$. The aluminum plates are made from AA7475-T76 and the bolt material is Titanium Ti6A114VSTA.

The fitting between bolt and hole is ISO $\mathrm{f} 7 / \mathrm{H} 10$ for all specimen configurations. For the quasi-isotropic specimens with countersunk bolts, without lateral support and no pre tension of the bolt, there is good agreement between measured and computed strains. The measured and calculated relative displacement between parts is of the same magnitude. For protruding head bolts, with the same conditions there is good agreement between measured and computed strains in the $45^{\circ}$ direction, while for other directions the calculated strains are slightly smaller than the measured ones. There is good agreement between the measured and calculated displacements. For zero-dominated laminates with countersunk bolts, there has been good agreement between the measured and calculated strains is very good for the case without lateral support and somewhat less good for the case with lateral support. The computed and measured relative displacement curves are in good agreement for the case with lateral support, with the calculated displacement larger than the measured ones. For the case with lateral support, the experimental curves differ considerably between the two sides of the specimen and the computed curves fall between the experimental curves. This indicates that the FE models 
are too stiff in bending, which could be due to use of linear elements. The limitation of the model is that same friction coefficient had to be used in the ABAQUS [Hibbitt et al. (1995)] version. The friction coefficient may not have been accurate as it is assumed on the basis of friction coefficient measurements at fracture surfaces. Friction coefficient measurements for material combinations used in composite bolted joints are therefore proposed as an important subject for future research.

All of the above mentioned research have been done at the coupon-level. Boyapati (2006) has performed an analytical research on Prodeck 4 using ANSYS software. The analysis is done on multi panel decks and beam considering them as a single entity. The analytical results obtained in the deflection analyses show excellent correlation with experimental results obtained by previous researchers. Even the strain values present at selected locations obtained in analytical research show good correlation with experimental strain results at selected locations.

Ganga Rao et al. (2004) conducted experimental research on a Prodeck-4 FRP bridge deck. Each module is 29"x 4" and weighs about $10 \mathrm{lb} / \mathrm{ft}^{2}$, is made of E-glass with vinyl ester resin, and has a fiber volume fraction of about $50 \%$. The component tested consists of two 3" wide modules joined using 1) Glued with Pliogrip adhesive, 2) Riveted and glued with Pliogrip adhesive, 3) Riveted, 4) Glued with 1" long chopped glass strands throughout the Pliogrip adhesive only and 5) Glued with $0 / 90$ fabric between the joint. Compression and bending tests have been conducted on these panel-to-panel connections to obtain the strain profile across the joint. A second test has been performed to determine the joint efficiency of the various panel-to-panel connections. The specimens are simply supported with $\mathrm{L} / 2$ as the spacing between the loading points. To 
determine the joint efficiency the difference in strain across the joint is compared. Theoretically the strain should be identical because of the four-point bending configuration, however due to strain leakage (inefficiency) at the joint the resulting strain from one side to the other is different.

The glued and riveted joint attained the highest efficiency of $83 \%$. This is expected because the continuous bonding of the glue is enhanced by the stiffness of the rivet. Riveted only joints are second highest with an efficiency of $80 \%$. Results from the tests are compared and discussed in detail in the subsequent chapters.

\subsection{NEED FOR CURRENT RESEARCH}

Structural joints form an essential critical element of FRP bridge decks. The most pragmatic joining techniques are adhesive and mechanical joining. Adhesive bonding has the advantage of high strength and good corrosion resistance, while bolting facilitates disassembly and may be perceived as more reliable. The optimal design of these joints improves the performance and structural integrity and minimizes the weight of the structures, leading directly to increases in their load-carrying capability. From the above published work it is clear that different joints used to connect the Prodeck 4 deck have been checked experimentally. But the structural analysis of panel to panel Prodeck 4 joint connections has not yet been carried out using finite element model; the current study intends to fulfill this need for a numerical modeling and analysis. This research mainly focuses on developing a finite element model of each of the joint connections that include: 1) glued, 2) riveted and glued and 3) riveted only, and the analytical results thus obtained are then compared to the existing results. 


\subsection{OBJECTIVES}

- To model a composite bridge deck (Prodeck 4) using ANSYS software.

- To develop a finite element model of an equivalent coupon-level joint for each of the different joint configurations.

- To develop finite elements models of twin FRP panels of Prodeck 4 using adhesive, rivets and both combined as the media of connection.

- To evaluate structural properties of the twin-panel bridge deck connections, under compressive and bending loads.

\subsection{THESIS OVERVIEW}

- Chapter 2 gives a detail description of composite bridge deck (Prodeck 4) that is being analyzed.

- Chapter 3 details the finite element model of Prodeck 4 that is generated, the type of element that is used in model generation, and the loading conditions.

- Chapter 4 shows the finite element model of a coupon-level joint and twin FRP panel connection using adhesive, its loading conditions, results and comparison of those with existing experimental results.

- Chapter 5 shows the finite element model of a coupon-level joint and twin FRP panel connection using rivets only and using rivets and adhesive, its loading conditions, and results and comparison of those with existing experimental results.

- Chapter 6 presents the conclusions of this research and recommends future work. 


\section{CHAPTER 2}

\section{DESCRIPTION OF PRODECK 4}

The multi-cellular, low-profile FRP bridge deck being described in this chapter is called Prodeck 4. It is made of E-glass fiber and Vinyl ester resin. Figure 2.1 shows the schematic of the cross section of Prodeck 4. The deck is 4" high and 29"wide. The thickness of bottom and top flanges is 0.430 " each while that of the web is 0.375 ". The top and bottom flanges of the bridge deck component are made of 24 layers of $0^{0}$ fibers, $90^{\circ}$ fibers, $\pm 45^{\circ}$ fibers, continuous strand mat (CSM) and 56 Yield Rovings ( 4 per inch). The web is made of 20 layers of $0^{0}$ fibers, $90^{\circ}$ fibers, $\pm 45^{\circ}$ fibers, continuous strand mat (CSM) and 56 Yield Rovings (4 per inch). The fibers continue from flange to the web and then again to the flange. The low-profile FRP deck has fiber volume fraction of approximately 0.5 and weighs about $10 \mathrm{lb} / \mathrm{ft}^{2}$.

The material properties of Prodeck 4 obtained from the manufacturer are as follows:

$$
\begin{aligned}
& \text { Modulus of elasticity of fiber }\left(E_{f}\right)=10.5 \times 10^{6} \mathrm{psi} \\
& \text { Modulus of elasticity of matrix }\left(E_{m}\right)=4.9 \times 10^{5} \mathrm{psi} \\
& \text { Shear modulus of fiber }\left(G_{f}\right)=4.30 \times 10^{6} \mathrm{psi} \\
& \text { Shear modulus of matrix }\left(G_{m}\right)=1.8 \times 10^{5} \mathrm{psi} \\
& \text { Poisson's ratio of fiber }\left(v_{f}\right)=0.22 \\
& \text { Poisson's ratio of matrix }\left(v_{m}\right)=0.38
\end{aligned}
$$




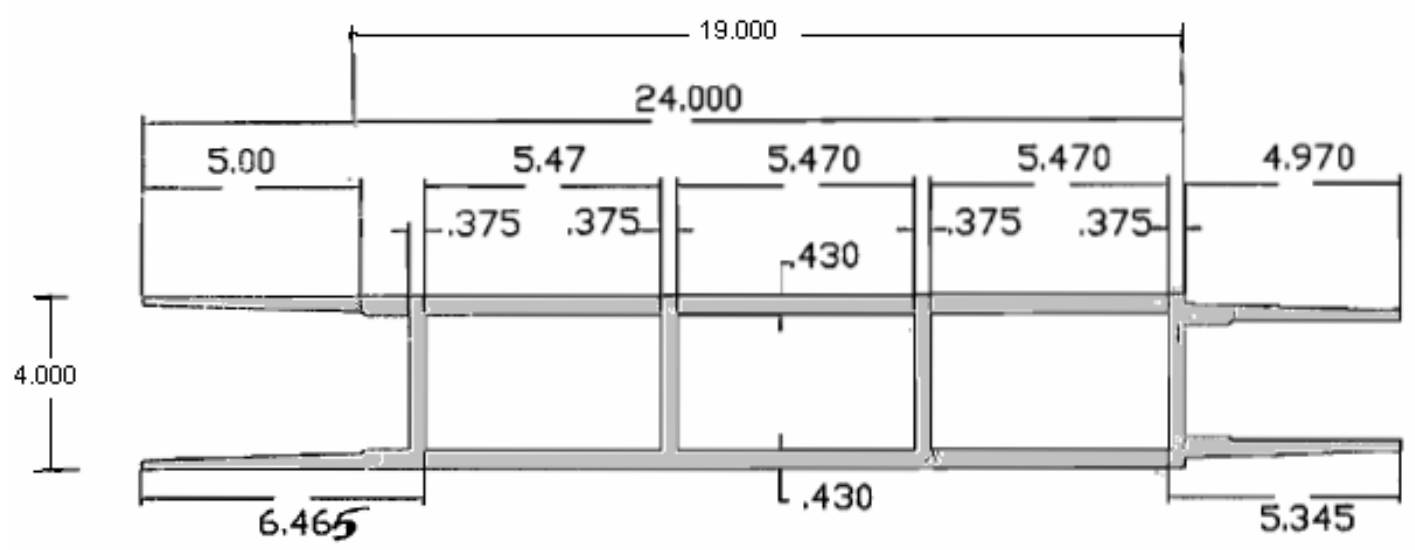

FRP Deck

All Dimensions are in Inches

Fig. 2.1 Cross-section of Prodeck 4

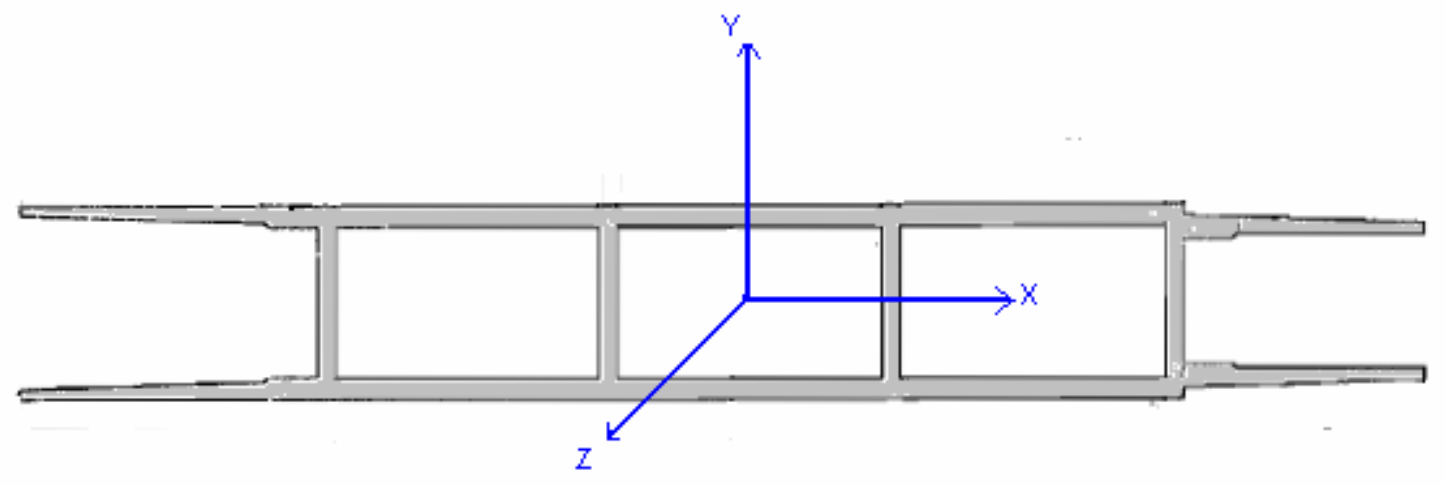

Fig. 2.2 Orientation of global coordinate system

The global coordinate system for Prodeck 4 is oriented as shown in Fig. 2.2. The traffic moves in the direction along the $X$-axis of the global coordinate system whereas the $0^{0}$ fibers run in direction perpendicular to the direction of the traffic movement. 


\section{PRO DECK 4 \\ MATERIAL CONSTRUCTION \\ MIDDLE SECTION prop. 5}

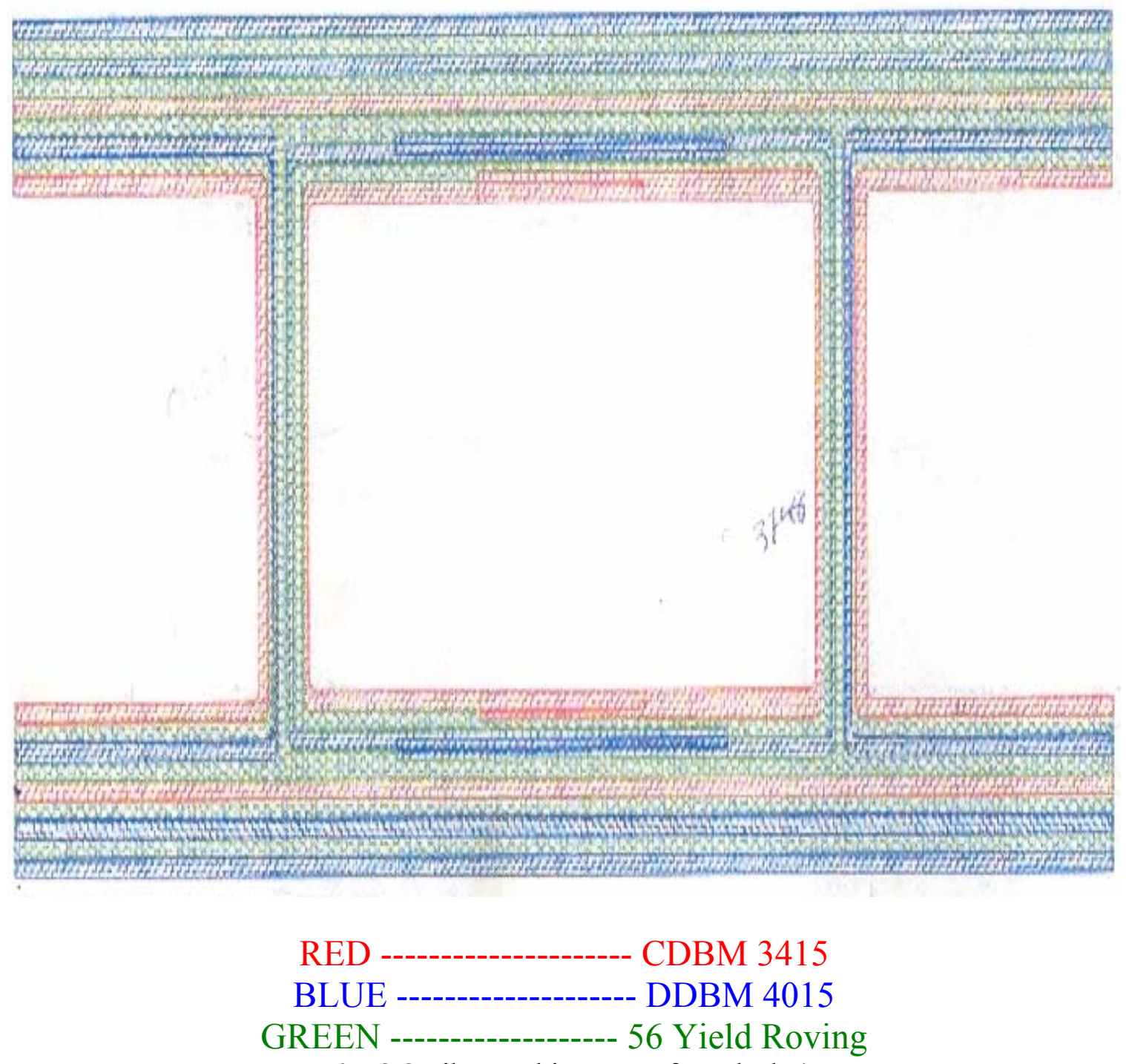

Fig. 2.3 Fiber architecture of Prodeck 4

The detailed description of CDBM3415 and DDBM4015 fabrics comprising of $0^{0}$ fibers, $\pm 45^{\circ}$ fibers and mat (CSM) are given in the Tables 2.1 and 2.2, respectively. The thickness of rovings (Green layer) is calculated to be approximately 0.04 ". 
Table 2.1 CDBM 3415 fabric specifications

\begin{tabular}{|c|c|c|c|c|}
\hline $\begin{array}{c}\text { Fiber } \\
\text { orientation }\end{array}$ & $\begin{array}{c}\text { Nominal Wt. } \\
\left.\text { (oz./yd. }{ }^{2}\right)\end{array}$ & $\begin{array}{c}\text { Thickness } \\
\text { (in.) }\end{array}$ & $\begin{array}{c}\mathbf{W}_{\mathbf{f}} \\
\text { (lb.) }\end{array}$ & $\begin{array}{c}\mathbf{L}_{\mathbf{v}} \\
\text { (in. }^{\mathbf{3}} \text { ) }\end{array}$ \\
\hline $0^{0}$ fibers & 15.71 & 0.01610 & 0.109 & 2.31914 \\
\hline$+45^{0}$ fibers & 9.04 & 0.009308 & 0.063 & 1.34042 \\
\hline$-45^{0}$ fibers & 9.04 & 0.009308 & 0.063 & 1.34042 \\
\hline Mat (CSM) & 13.5 & 0.013851 & 0.09375 & 1.99468 \\
\hline Total & 47.29 & 0.048567 & 0.32875 & 6.99466 \\
\hline
\end{tabular}

Table 2.2 DDBM 4015 fabric specifications

\begin{tabular}{|c|c|c|c|c|}
\hline $\begin{array}{c}\text { Fiber } \\
\text { orientation }\end{array}$ & $\begin{array}{c}\text { Nominal Wt. } \\
\left.\text { (oz./yd. }{ }^{2}\right)\end{array}$ & $\begin{array}{c}\text { Thickness } \\
\text { (in.) }\end{array}$ & $\begin{array}{c}\mathbf{W}_{\mathbf{f}} \\
(\mathbf{l b .})\end{array}$ & $\begin{array}{c}\mathbf{L}_{\mathbf{v}} \\
\text { (in. }^{\mathbf{3}} \text { ) }\end{array}$ \\
\hline$+45^{0}$ & 11.44 & 0.011731 & 0.0794 & 1.68936 \\
\hline $90^{0}$ & 17.28 & 0.017730 & 0.12 & 2.55319 \\
\hline$-45^{0}$ & 11.44 & 0.011731 & 0.0794 & 1.68936 \\
\hline Mat (CSM) & 13.5 & 0.013844 & 0.0937 & 1.99361 \\
\hline Total & 53.66 & 0.055036 & 0.3725 & 7.92552 \\
\hline
\end{tabular}

Where, $W_{f}=$ Weight of CSM/fabric per square foot $(\mathrm{lb}.) / \mathrm{ft}^{2}$

$L_{v}=$ Volume of 1'x 1' composite laminate (in. ${ }^{3}$ ) 


\section{CHAPTER 3}

\section{FINITE ELEMENT MODEL}

\subsection{INTRODUCTION}

The development of a finite element model in the general purpose finite element program ANSYS of the low-profile multi-cellular deck is described in this chapter. One of the most important steps in a finite element model generation is the choosing of the type of element suitable for the model based on the application, type of results, etc.

\subsection{TYPE OF ELEMENT}

The common types of elements used in the modeling of composite structures are solid and shell elements. The two elements that have been considered for modeling the bridge deck in ANSYS are SHELL99 and SOLID46. The SHELL99 is an 8-node, 3-D shell element with six degrees of freedom at each node. The SHELL99 element is designed to model thin and moderately thick plate and shell structures with a side-tothickness ratio of roughly 10 or greater. The SOLID46 element is a 3-D solid, 8-noded layered element with three degrees of freedom at each node, which is used in design structures with complex shapes and smaller side-to-thickness ratios [ANSYS (2007)]. As this research focuses on the 3-D joint analysis, the SOLID46 element is preferred over the SHELL99 element in the modeling of the layered composite bridge deck. Moreover the SOLID46 element simulates the web-flange connectivity very well in Prodeck 4. 


\subsubsection{Description of SOLID46 Element}

The SOLID46 element is a 3-D solid, 8-noded layered element with three degrees of freedom at each node (UX, UY, UZ), i.e., translations in the nodal $X, Y$ and $Z$ directions, respectively. This element is designed to model thick layered shells or layered solids and allows up to 250 uniform-thickness layers per element. As shown in Fig. 3.1 the SOLID46 element is defined by eight nodes, layer thicknesses, layer material direction angles and layer orthotropic material properties. Every element has a default element or local coordinate system orientation associated with it. In the case of SOLID46 element, the default element $x$-axis is the projection of side $I-J$, side $M-N$, or their average onto to the reference plane and $z$-axis is along layer thickness direction as displayed in Fig. 3.1.

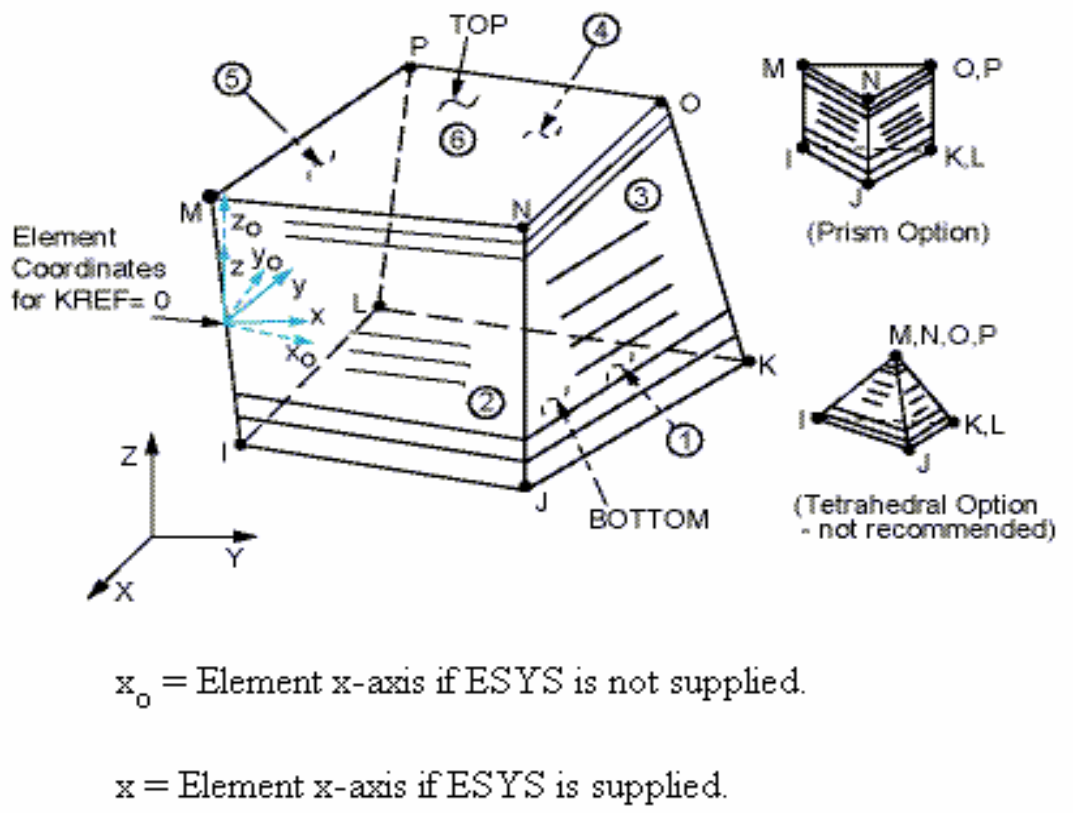

Fig. 3.1 SOLID46 geometry [ANSYS (2007)] 
The orientation of the element coordinate system can be changed for area and volume elements by making it parallel to a previously defined local system after meshing. For the SOLID46 element the input of material properties may be either in matrix form or layer form. For matrix form, the matrices must be computed outside of ANSYS. Thermal strains, most stresses and even the failure criteria are not available with matrix input [ANSYS (2007)].

Unlike isotropic materials that require only Young's modulus and Poisson's ratio to be defined, the SOLID46 element used for orthotropic material requires various material properties to be defined.

Material properties that need to be given as input for each layer are:

- $E_{1}, E_{2}$ and $E_{3}$ (Modulus of Elasticity in the $X_{1}, X_{2}$ and $X_{3}$ directions respectively).

- $\mu_{12}, \mu_{23}$ and $\mu_{13}$ (Poisson's ratio in the $X_{1} X_{2}, X_{2} X_{3}$ and $X_{3} X_{1}$ directions respectively).

- $G_{12}, G_{23}$ and $G_{13}$ (Shear modulus in the $X_{1} X_{2}, X_{2} X_{3}$ and $X_{3} X_{1}$ directions respectively).

- $\theta$ (Angle between the fiber orientation of the layer and $x$-axis of the element coordinate system in degrees).

- $t_{k}$ (Thickness of the layer in the positive $z$ direction). 


\subsection{MATERIAL PROPERTIES}

The material properties of the layer are calculated using micromechanics formulas. In general, micromechanics is defined as the study of composite materials taking into account the interaction of the constituent materials in detail. It can be used to predict stiffness and strength of the composite materials. Properties of the composite ply are controlled by the fiber volume fraction $\left(V_{f}\right)$ of the material [Barbero (1998)].

\subsubsection{Fiber Volume Fraction}

The Fiber volume fraction $\left(V_{f}\right)$ of a composite ply is defined as the ratio of volume of the fiber to the total volume of the composite. The deck that is being considered here comprises of fabrics, continuous strand mat (CSM) and rovings. "A strand is an untwisted bundle of continuous filaments (fibers) used as a unit". "A mat is formed by randomly oriented chopped filaments (chopped strand mat), short fibers, or swirled filaments (continuous strand mat, CSM) loosely held together with a very small amount of adhesive (binder)." "A roving is a collection of parallel continuous strands." [Barbero (1998)].

The Fiber volume fractions for fabrics, rovings and CSM are calculated using the formulas given below:

For continuous strand mat (CSM) and fabric

$$
V_{f}=\frac{W_{f}}{\rho_{f} L_{v}}
$$

where,

$W_{f}=$ Weight of CSM/ fabric per square foot (lb) 
$L_{v}=$ Volume of 1'x 1' ply of composite lamina (in. ${ }^{3}$ )

$\rho_{f}=$ Density of CSM or fabric (lb/ in. $\left.{ }^{3}\right)$

For Rovings

$$
V_{f}=\frac{n \pi D^{2}}{4 b t}
$$

where,

$n=$ Number of bundles

$b=$ Width of lamina (in.)

$t=$ Thickness of composite layer (in.)

$D=$ Diameter of fiber $=\sqrt{\frac{1}{\rho_{f} Y 9 \pi}}$

$\rho_{f}=$ Density of fiber $\left(\mathrm{lb} / \mathrm{in}^{3}{ }^{3}\right)$

$Y=$ Yield $(\mathrm{yd} / \mathrm{lb})$

After finding the values of $V_{f}$ for the fabric, CSM and roving by using the above formulas, the properties of lamina are calculated as shown in the following section.

\subsubsection{Lamina Properties}

Some of the properties such as modulus of elasticity $(E)$, shear modulus $(G)$, and Poisson's ratio $(v)$ of the E-glass fiber and vinyl ester matrix are provided by the manufacturer. These values are further required for the calculation of lamina properties. The properties provided by the manufacturer are as follows:

Modulus of elasticity of fiber $\left(E_{f}\right)=10.5 \times 10^{6} \mathrm{psi}$

Modulus of elasticity of matrix $\left(E_{m}\right)=4.9 \times 10^{5} \mathrm{psi}$ 
Shear modulus of fiber $\left(G_{f}\right)=4.30 \times 10^{6} \mathrm{psi}$

Shear modulus of matrix $\left(G_{m}\right)=1.8 \times 10^{5} \mathrm{psi}$

From the above properties Poisson's ratio can be calculated as

$$
\begin{array}{ll}
\text { Poisson's ratio of fiber: } & v_{f}=\frac{E_{f}}{2 G_{f}}-1 \\
\text { Poisson's ratio of matrix: } & v_{m}=\frac{E_{m}}{2 G_{m}}-1
\end{array}
$$

The results obtained are $v_{f}=0.22$ and $v_{m}=0.38$.

\section{Computation of lamina properties}

\section{For fabric and rovings}

- Longitudinal Modulus:

The longitudinal modulus $\left(E_{1}\right)$ or modulus of elasticity in the fiber direction can be obtained by the rule of mixtures (ROM) formula. The important assumption in this formula is that the strains in the direction of the fibers are the same in the matrix and fiber, which signifies that the fiber and matrix bond is perfect. The ROM formula for $E_{1}$ is

$$
E_{1}=E_{f} V_{f}+E_{m}\left(1-V_{f}\right)
$$

- Transverse Modulus:

The transverse modulus $\left(E_{2}\right)$ is the modulus in the direction transverse to the fibers. The main assumption in this formulation is that the stress is the same in the fiber and the matrix. This assumption is required to maintain equilibrium in the transverse direction. The resulting formula for $E_{2}$ is 


$$
E_{2}=\frac{E_{f} E_{m}}{E_{f}\left(1-V_{f}\right)+E_{m} V_{f}}
$$

The above equation is known as the inverse ROM. It is generally said that $E_{2}$ is a matrix-dominated property. The inverse ROM equation does not predict $E_{2}$ accurately and so it is mostly used for qualitative evaluation of different candidate materials but not for design calculations.

The semi empirical Halpin-Tsai formula [Barbero (1998)] gives a better prediction.

$$
E_{2}=E_{m}\left[\frac{1+\zeta \eta V_{f}}{1-\eta V_{f}}\right]
$$

where,

$$
\eta=\frac{\left(E_{f} / E_{m}\right)-1}{\left(E_{f} / E_{m}\right)+\zeta}
$$

And $\zeta$ is an empirical parameter obtained by curve fitting.

- In plane Poisson's Ratio:

In general Poisson's ratio is defined as the negative ratio of the resulting transverse strain to the applied strain.

$$
v_{i j}=-\frac{\varepsilon_{j}}{\varepsilon_{i}}
$$

The ROM equation for the in plane Poisson ratio derived from the mechanics of materials approach is given by

$$
v_{12}=v_{f} V_{f}+v_{m}\left(1-V_{f}\right)
$$

Then the minor Poisson's ratio $\left(v_{21}\right)$ is obtained from the formula 


$$
v_{21}=\frac{v_{12} E_{2}}{E_{1}}
$$

- In plane Shear Modulus:

The in plane shear modulus $\left(G_{12}\right)$ is also predicted by the inverse ROM equation:

$$
G_{12}=\frac{G_{f} G_{m}}{G_{f} V_{m}+V_{f} G_{m}}
$$

Even in this case, the inverse ROM gives a simple but inaccurate equation for the prediction of the in plane shear modulus.

- Interlaminar Shear Modulus:

The interlaminar shear modulus $\left(G_{23}\right)$ can be calculated with the semiempirical stress-partitioning parameter (SPP) technique:

$$
G_{23}=G_{m} \frac{V_{f}+\eta_{23}\left(1-V_{f}\right)}{\eta_{23}\left(1-V_{f}\right)+V_{f} G_{m} / G_{f}}
$$

where $\eta_{23}$ is given by

$$
\eta_{23}=\frac{3-4 v_{m}+G_{m} / G_{f}}{4\left(1-v_{m}\right)}
$$

\section{For Continuous Strand Mat}

Continuous strand mat (CSM) is a fiber system that contains randomly placed continuous rovings held together by a binder. The CSM is used to obtain bidirectional properties on pultruded composites where unidirectional rovings constitute the main reinforcement. The elastic properties of CSM can be predicted assuming that they are random composites. A layer of composite with randomly oriented fibers can be idealized as a laminate with large number of thin unidirectional layers, each with a different 
orientation from $0^{0}$ to $180^{\circ}$. The properties of the random composite are the average properties of this fictitious laminate.

The elastic modulus for $\operatorname{CSM}\left(E_{c s m}\right)$ is given by

$$
E_{c s m}=\frac{3}{8} E_{1}+\frac{5}{8} E_{2}
$$

The shear modulus for CSM $\left(G_{c s m}\right)$ is given by

$$
G_{c s m}=\frac{1}{8} E_{1}+\frac{1}{4} E_{2}
$$

Poisson's ratio for CSM $\left(v_{c s m}\right)$ is given by

$$
v_{c s m}=\frac{E_{c s m}}{2 G_{c s m}}-1
$$

Where $E_{1}$ and $E_{2}$ are the longitudinal and transverse moduli of a fictitious unidirectional layer having the same fiber volume fraction as that of the CSM layer. One of the important things to be noted is that continuous strand mat is assumed to behave in an isotropic manner and so only one modulus value is required.

\subsubsection{Material Specifications of the Laminas used in Prodeck 4}

The Prodeck 4 consists of three layers namely CDBM 3415, DDBM 4015 and 56 Yield Rovings (4 roving per inch).

Both CDBM 3415 and DDBM 4015 layers are made of a set of 4 sub-layers each with different fiber configurations and orientations. This set of sub-layers has Mat included in it. The material properties for each layer are calculated using the micromechanics equations mentioned in the previous sections. These properties obtained are given as input to the ANSYS software for developing the finite element model of 
Prodeck 4. The CADEC software [Barbero (1998)] is used to calculate some of these material properties. The properties of the lamina for Prodeck 4 that are calculated are shown in Tables 3.1 and 3.2.

Table 3.1 Layer properties of fibers and roving

\begin{tabular}{|c|c|c|c|c|c|c|c|}
\hline Fiber type & $V_{f}$ & $E_{\mathbf{1}}(\mathbf{m s i})$ & $E_{\mathbf{2}}(\mathbf{m s i})$ & $\boldsymbol{v}_{\mathbf{1 2}}$ & $\boldsymbol{v}_{\mathbf{2 3}}$ & $\boldsymbol{G}_{\mathbf{1 2}}$ (msi) & $\boldsymbol{G}_{\mathbf{2 3}}$ (msi) \\
\hline Fibers/Roving & 0.5 & 5.49 & 1.54 & 0.37 & 0.58 & 0.482 & 0.484 \\
\hline
\end{tabular}

Table 3.2 Layer properties of mat

\begin{tabular}{|c|c|c|c|c|}
\hline Fiber type & $\boldsymbol{V}_{\boldsymbol{f}}$ & $\boldsymbol{E}_{c s m}(\mathbf{m s i})$ & $\boldsymbol{v}_{c s m}$ & $\boldsymbol{G}_{c s m}(\mathbf{m s i})$ \\
\hline Mat (CSM) & 0.50 & 3.07 & 0.40 & 1.09 \\
\hline
\end{tabular}

\subsection{FINITE ELEMENT MODEL}

Once the material properties are calculated, a finite element model of Prodeck 4 is generated. First, a solid model of Prodeck 4 is generated by creating key points at required locations in the global co-ordinate system and then defining volumes by selecting proper key points. The volumes thus formed are map meshed and the orientations of the layers are checked, reorientation is carried out if required.

Figure 3.2 displays a solid model of the twin-panel Prodeck 4 that consists of 48 volumes per panel. Local coordinates are defined for all the volumes to enable proper orientation of the elements after meshing. 


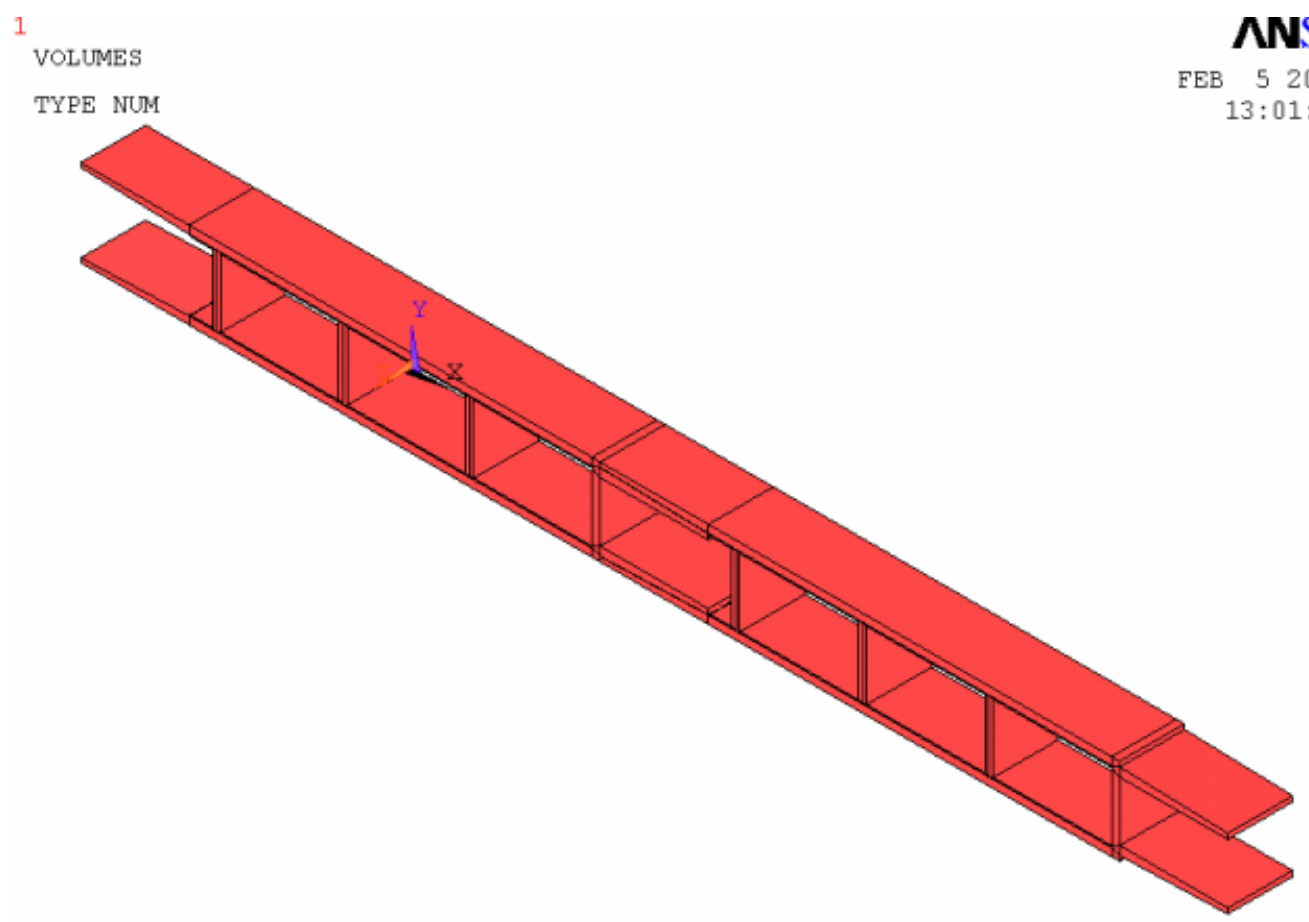

Fig. 3.2 Solid model of Prodeck 4

Once a solid model of Prodeck 4 is generated, it is map-meshed. Figure 3.3 shows the mapped mesh of Prodeck 4. Elements in some of the volumes generated their own coordinate systems and so changes are manually made in the coordinate systems orientations in order to align with the fiber directions. 
1 ELEMENT S
NNSYS

FEB 52007

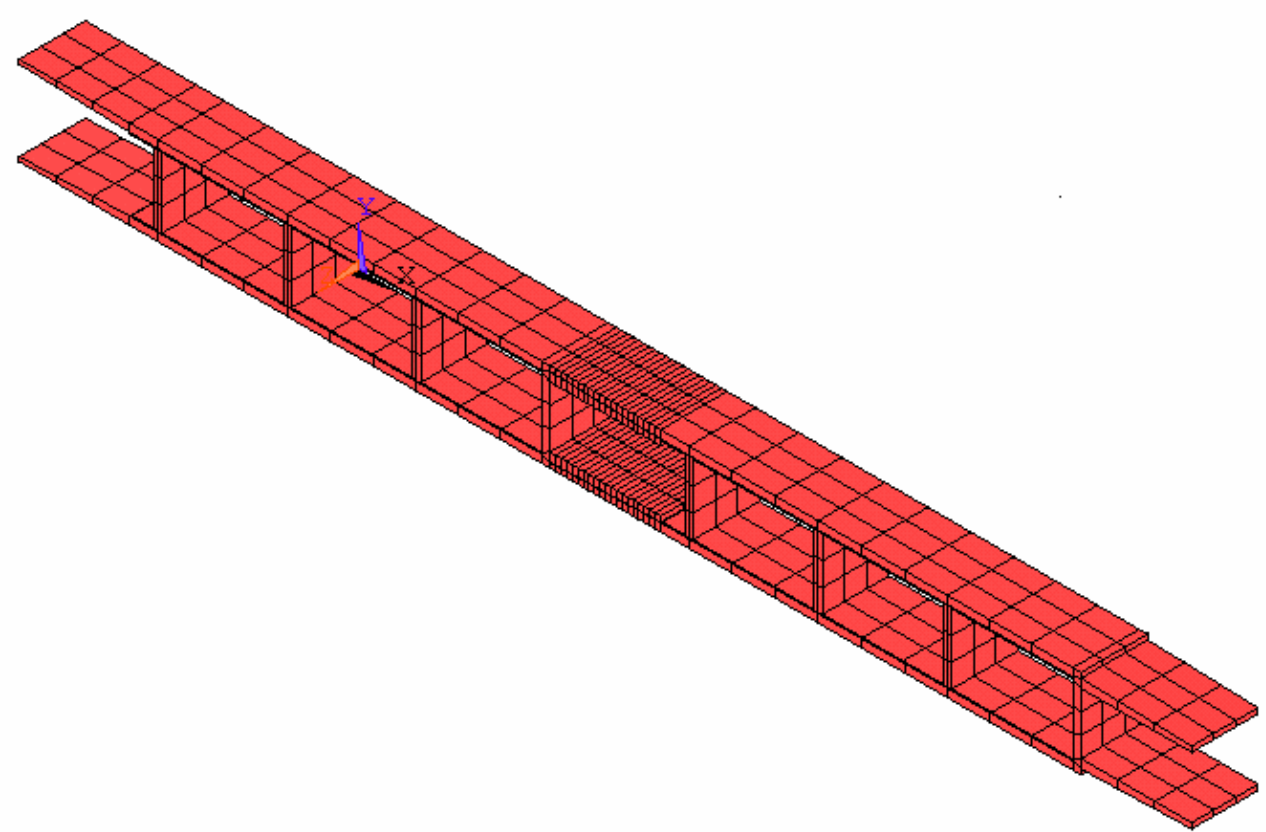

Fig. 3.3 Meshed model of a twin-panel glued Prodeck 4

Figure 3.4 shows the total number of layers, their orientations, and material number associated with each layer for a randomly selected element. The element orientations are with respect to the locally defined coordinate systems for all the elements. 


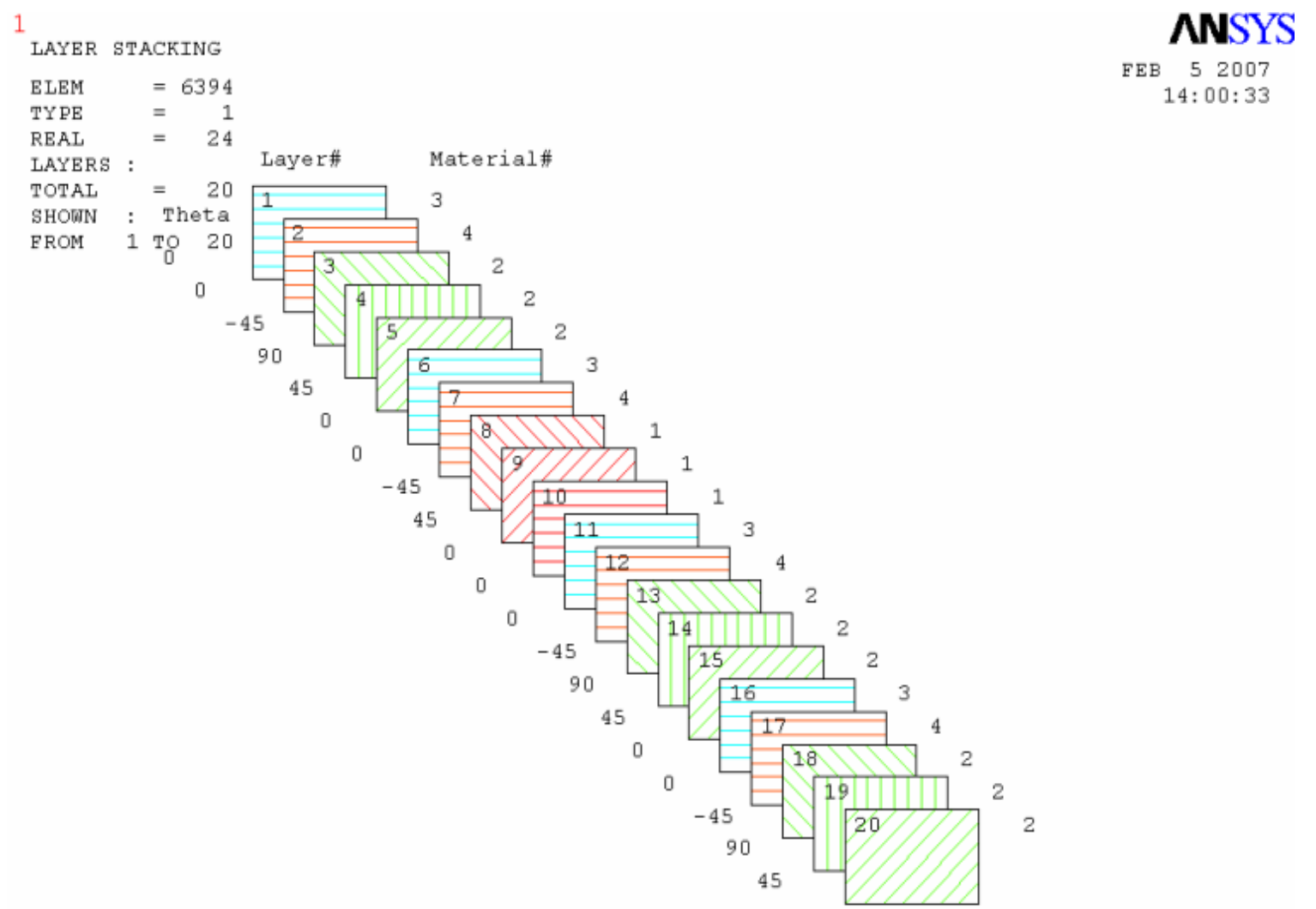

Fig. 3.4 Fiber orientations of individual layers of an element in Prodeck 4

\subsection{BOUNDARY CONDITIONS}

In order to perform tests under compressive loads, the left end of the deck is completely fixed, and in the finite element model all the DOF's at this end of the deck are set to zero (Fig. 3.5). In order to model the deck under bending loads, the specimens are simply supported by setting the DOF along the $U x, U y$ and $U z$ of all the nodes on the line at one end of the deck to zero and allowing translation along the $U x$ at the other end. 


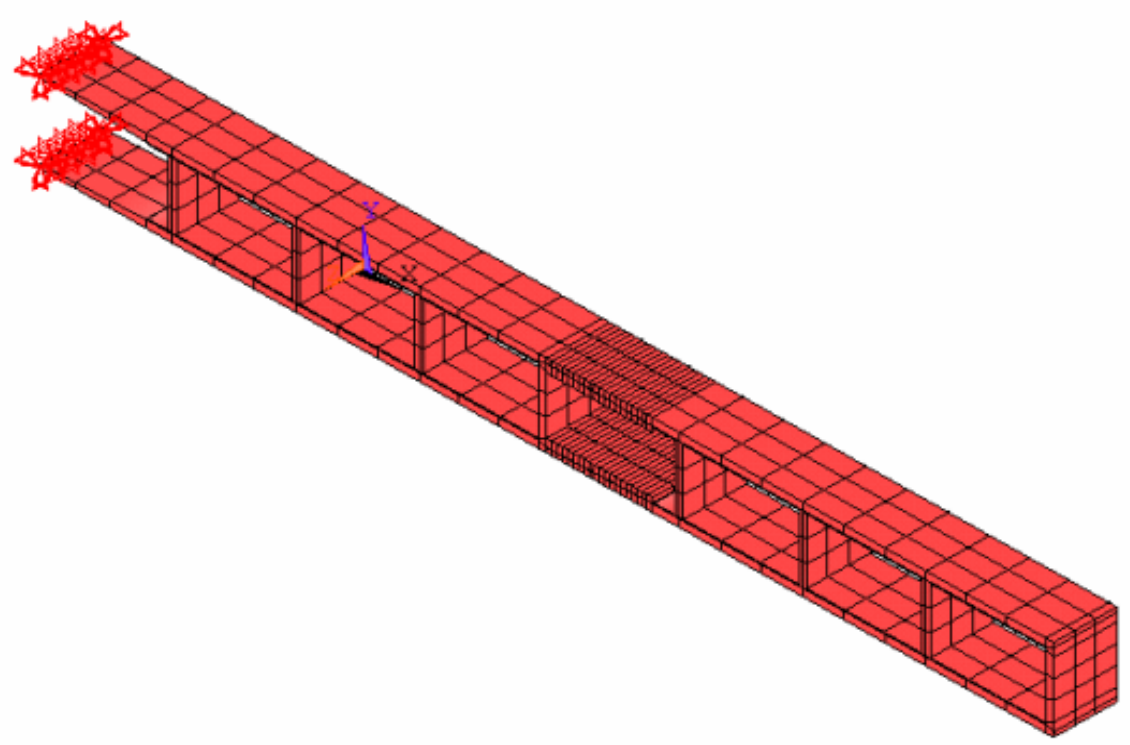

Fig. 3.5 Pictorial representation of boundary conditions applied on Prodeck 4 under axial compression.

\subsection{APPLIED LOADS}

\subsubsection{Compressive Load}

A surface load over an area of 3"x 3" is applied on the web at the right end of the Prodeck 4. In the experiment testing load is applied to the upper end using a hydraulic jack setting. In finite element model this is obtained by applying equivalent pressure over the middle area of the flange at the free end. The surface load applied is as shown in the Fig. 3.6. The flange extensions at the free end are cut off in the finite element as the load is applied on the web at the free end of the deck. 


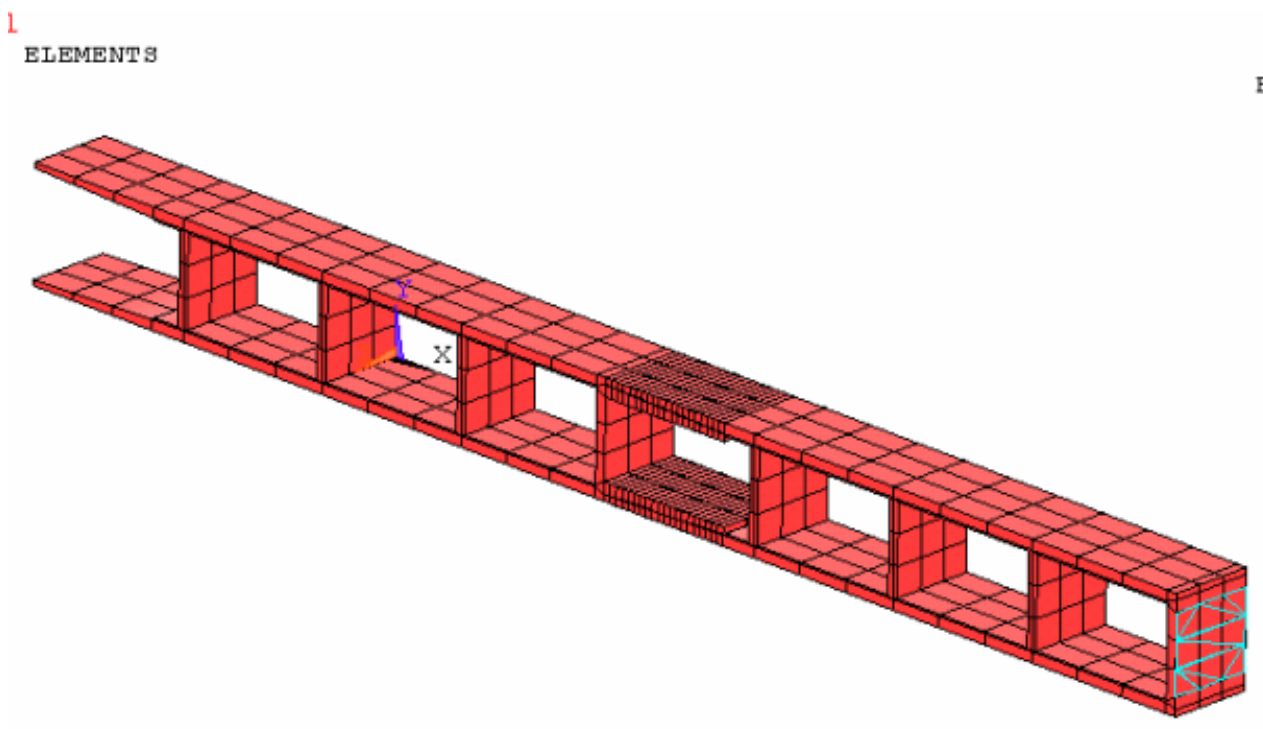

NNSYS

FEB 52007

$13: 26: 17$

Fig. 3.6 Pictorial representation of 3"x 3" surface load applied on Prodeck 4

\subsubsection{Bending Loads}

In addition to testing the Prodeck 4 joint system under axial compression, Ganga Rao et al. (2004) have also performed four-point bend tests. The simulation of this type of test in the current finite element model is shown in Fig. 3.7. 


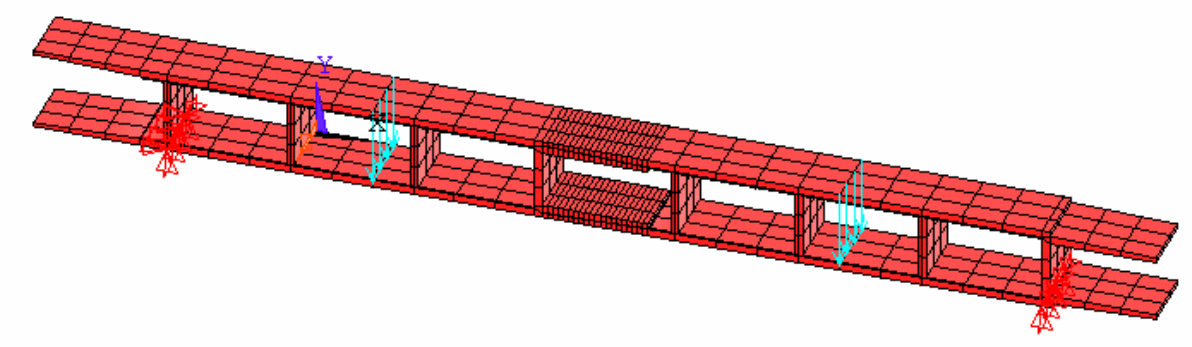

Fig. 3.7 Four-point bending analysis on an adhesively-bonded twin-panel Prodeck 4.

\subsection{ADHESIVE MODELING}

In the experimental [Ganga Rao et al. (2004)] setup Pliogrip 6600 has been used as the adhesive for connecting the two Prodeck 4 modules. The properties of cured Pliogrip 6600 adhesive as provided by the manufacturer are as follows:

Young's Modulus $=56,270$ Psi

Poisson Ratio $=0.40$

Compressive Modulus@ $23^{\circ} \mathrm{C}=13,581$ Psi 
The Finite element model uses the SLOSH190 element to model the adhesive between the decks. The SLOSH190 element is designed to model very thin to moderately thick three-dimensional objects. This element is a combination of Solid and Shell elements. It is used to model very thin objects in a three-dimensional sense, thus making for an excellent choice as the element used to model the adhesive. The element possesses the continuum solid element topology and features 8-node connectivity with three degrees of freedom at each node: translations in the nodal $x, y$, and $z$ directions. Thus, connecting SOLSH190 with other continuum elements requires no extra effort. A pictorial representation of the SLOSH190 element is shown in Fig. 3.8. [ANSYS (2007)]

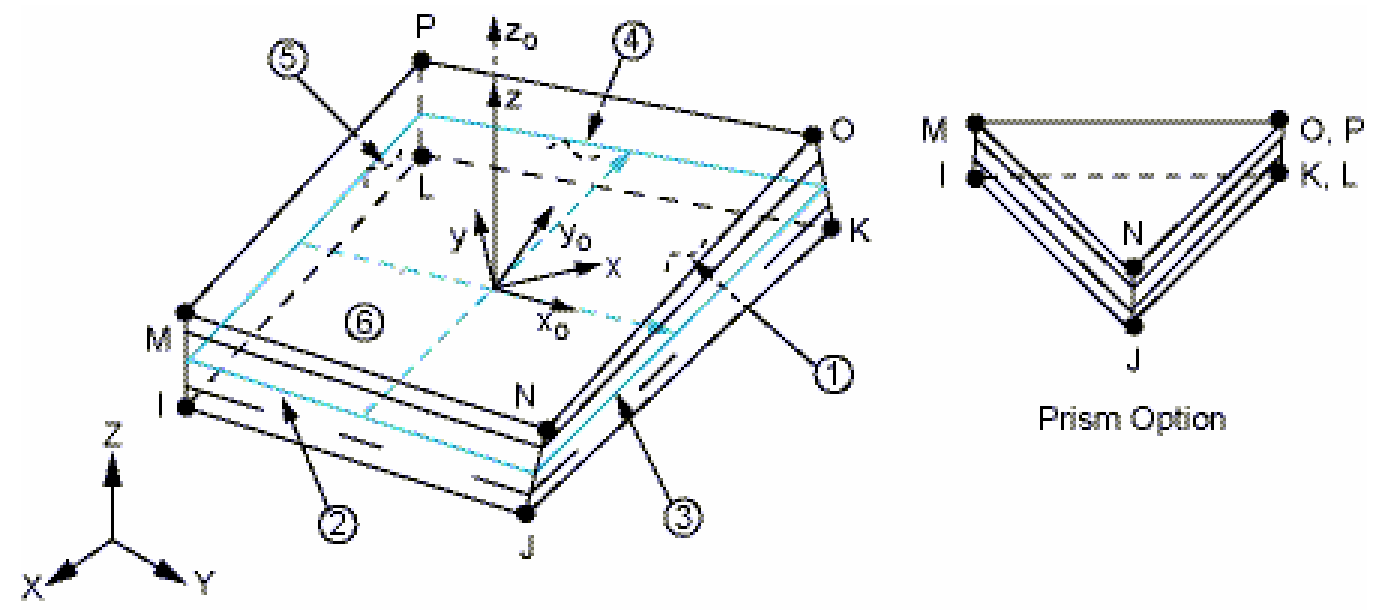

Fig. 3.8 SOLSH190 geometry [ANSYS (2007)]

The Prodeck 4 modeled using the adhesive is shown in Fig. 3.3. The joint section is the critical segment of the deck and hence finer elements are used to mesh the volumes at the joints. Detailed study on the joint segment will be provided in Chapter 4. 


\subsection{RIVET MODELING}

The mechanical connections in the experimental setup by Ganga Rao et al. (2004) has employed Grade 5 A340 rivet to connect the two Prodeck 4 modules. The properties of the rivet as provided by the manufacturer are as follows:

Young's Modulus $=29,000 \mathrm{ksi}$

Poisson Ratio $=0.280$

The SOLID45 element is a 3-D solid, 8-noded element with three degrees of freedom at each node $(U X, U Y, U Z)$, i.e., translations in the nodal $X, Y$ and $Z$ directions, respectively, as shown in Fig. 3.9.

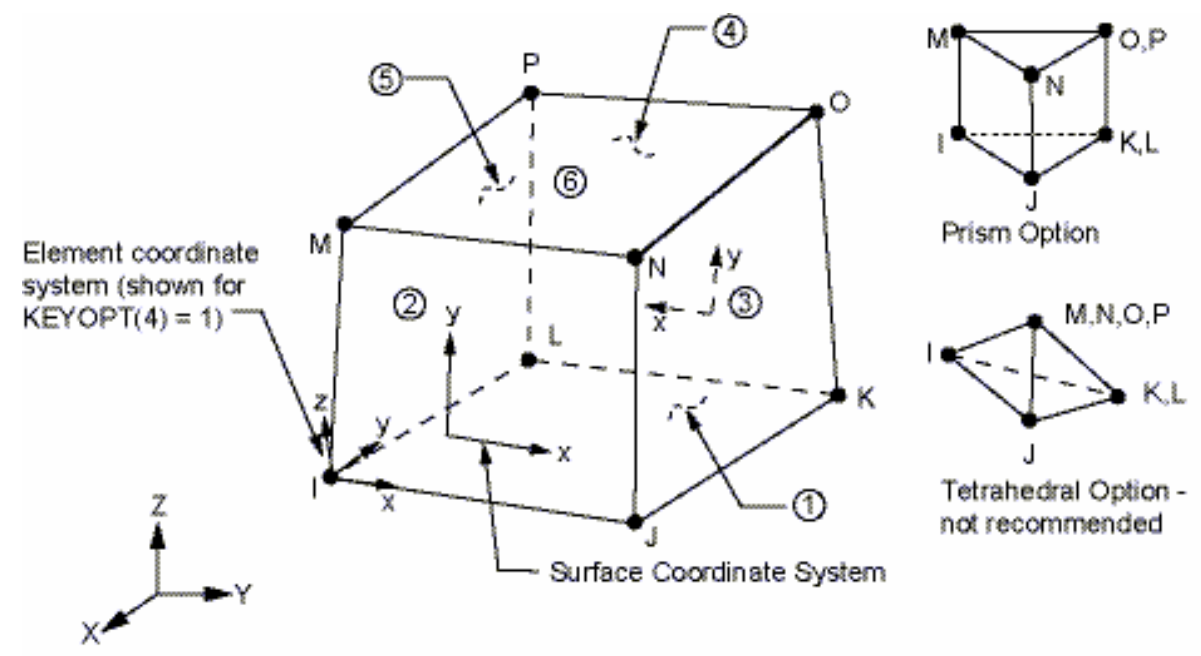

Fig. 3.9 SOLID45 geometry [ANSYS (2007)]

The rivet modeled using SOLID45 is shown in Fig. 3.10. Detailed study on the riveted joint will be discussed in Chapter 5 . 


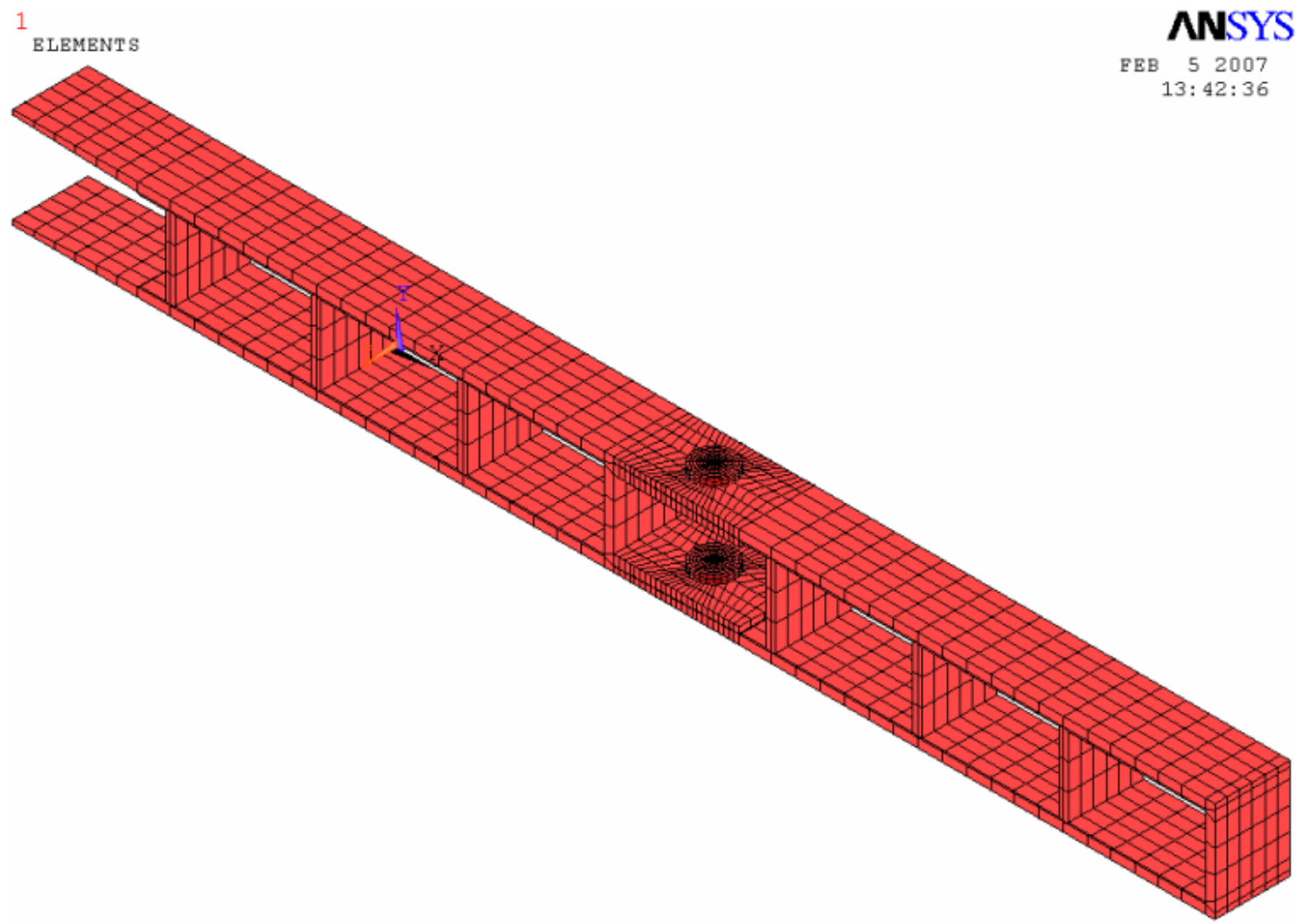

Fig. 3.10 Meshed model of a riveted Prodeck 4 connection 


\section{CHAPTER 4}

\section{ANALYSIS OF ADHESIVELY BONDED FRP}

\section{PANELS}

\subsection{INTRODUCTION}

This chapter deals with the development of a finite element model of the adhesively-bonded low-profile FRP bridge deck panels. Once the finite element model is made, it is subjected to compressive and bending loads to obtain the strain profile across the joint. The results thus obtained are then compared with that obtained in experiments conducted by previous researchers.

\subsection{FINITE ELEMENT MODEL}

First a solid model of the FRP panel is generated in ANSYS by creating key points and then defining volumes by selecting key points. The volumes thus formed are map meshed and then the orientations of the layers are checked as mentioned earlier in Section 3.4 .

Figure 4.1 displays a solid model of the adhesively bonded FRP twin-panel connection with a cross section dimension of 23 " $x 4$ ". The solid model when map meshed using Soild-46 element results in a total of 768 elements consisting of 1864 nodes. The orientations of the coordinate systems of all the elements are checked to see if they are aligned in the fiber direction and changes in the orientations are manually made if necessary. 
Figures 4.2 and 4.3 show the map-meshed model of the twin FRP panels and orientations of element coordinate systems, respectively. The element orientation is with respect to the locally defined coordinate system for the elements.

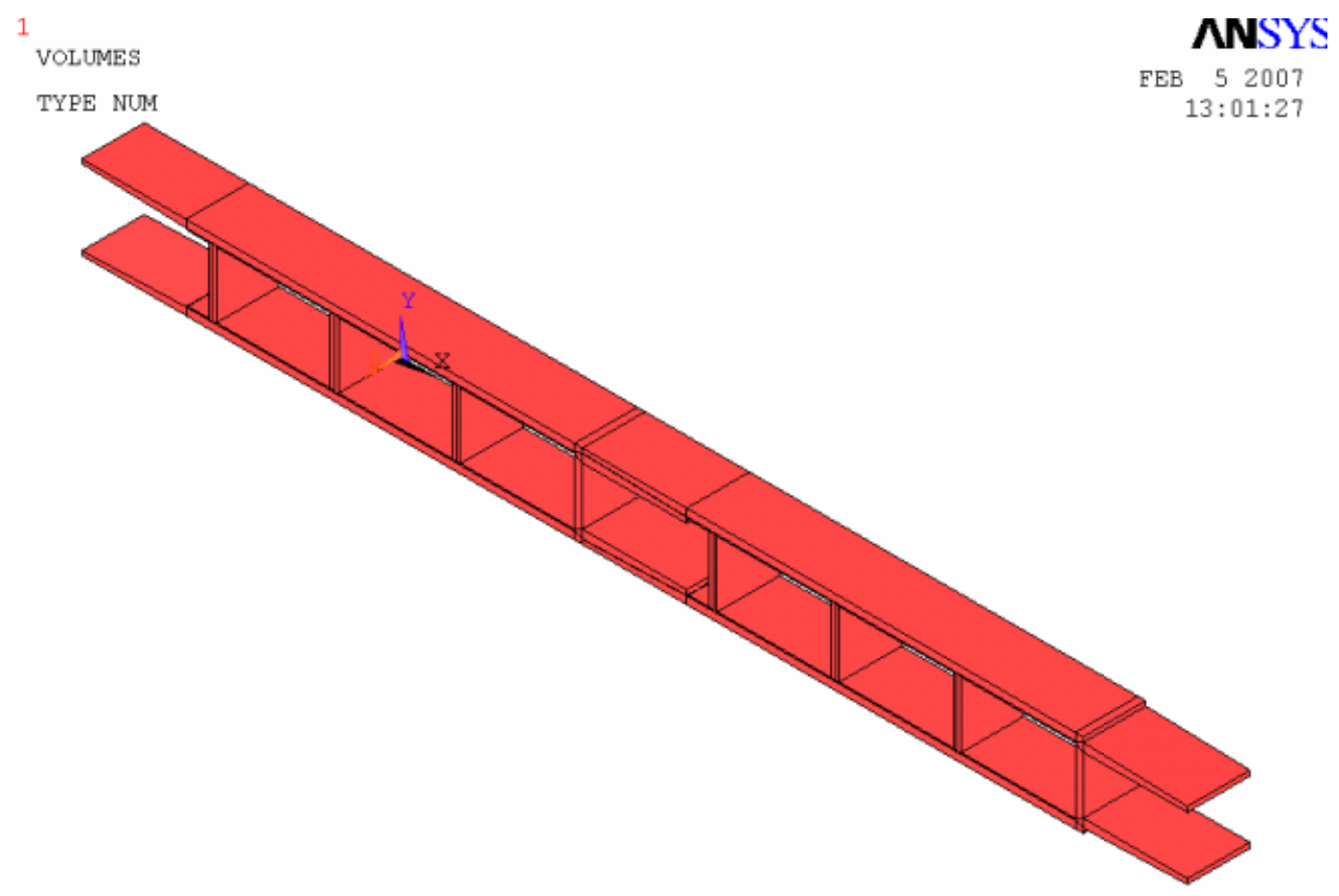

Fig. 4.1 Solid model of an adhesively bonded FRP twin-panel connection 
1

ELEMENT
NNSYS

FEB 52007

$13: 21: 04$

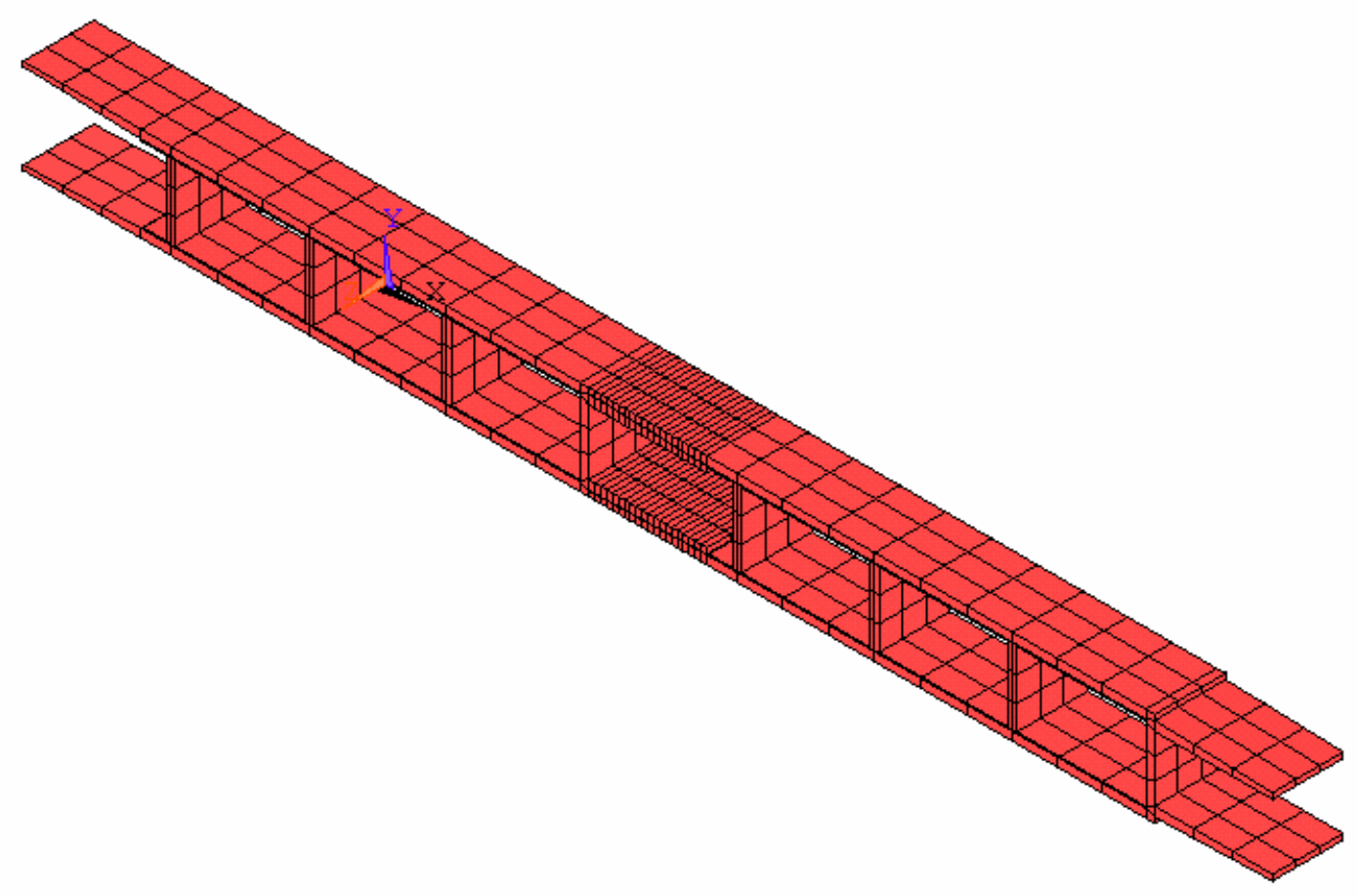

Fig. 4.2 Map meshed model of an adhesively bonded FRP twin-panel connection

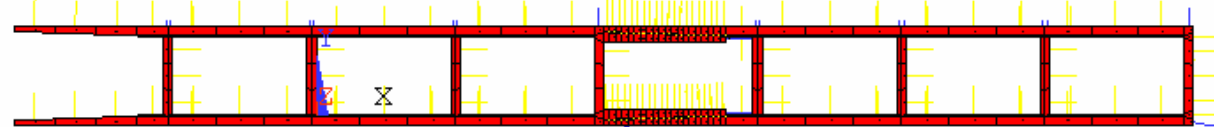

Fig. 4.3 Orientations of element coordinate systems in FRP Panel connection 
The adhesive used to connect the two panels is modeled using the SOLSH-190 element. The adhesive is modeled as a thin volume and then map meshed resulting in 120 elements. The glue properties correspond to the specifications of Pliogrip 6600. A detailed report on Pliogrip 6600 and SOLSH-190 can be found in Chapter 3. Figure 4.4 shows a closer look of the joint section of the connection with the adhesive modeled in between the flange extensions of the panels.

1

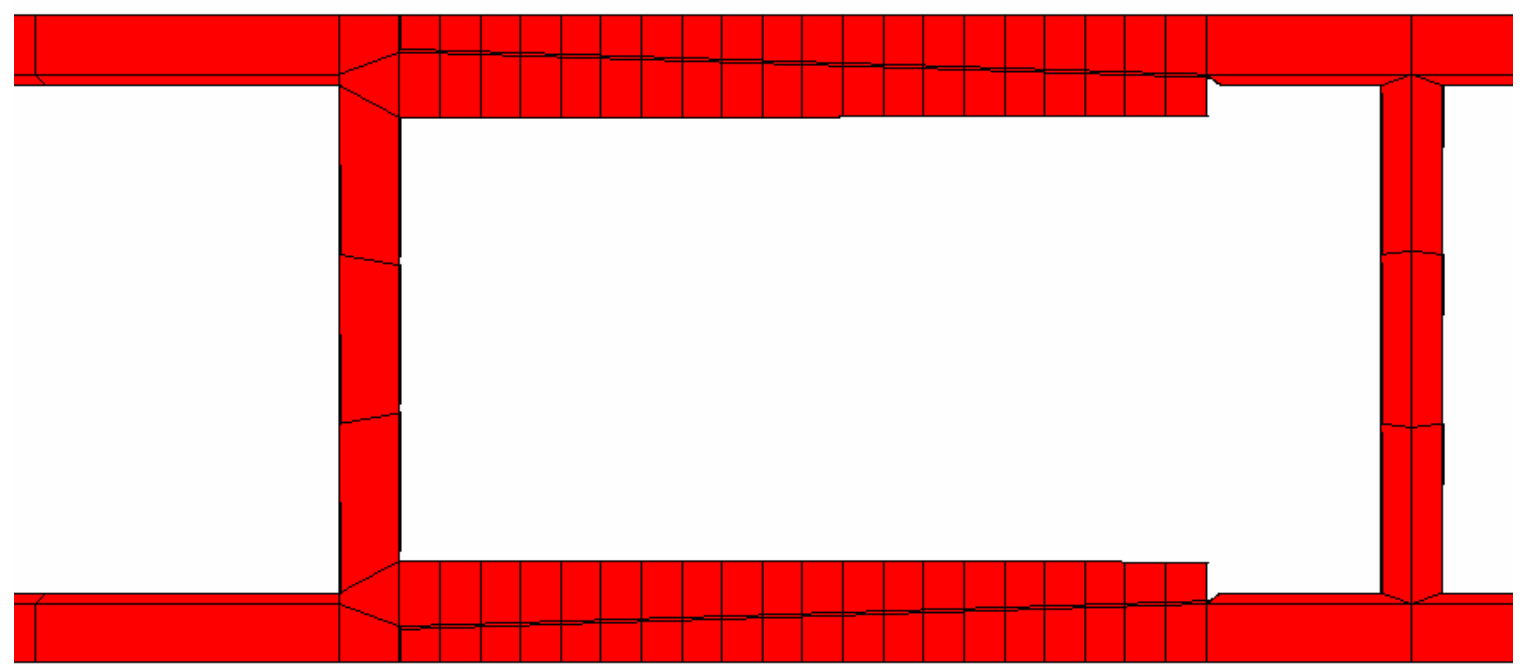

Fig 4.4 Joint section of the FRP twin-panel connection 


\subsection{BOUNDARY CONDITIONS FOR COMPRESSIVE LOADING}

The boundary conditions applied to the twin-panel are subject to an axial compressive load shown in Fig. 4.5. The structure is fixed at one end by setting the degree of freedom in $X, Y$ and $Z$ to zero. The flange extensions at the free end of the twinpanel bridge deck do not contribute to the analysis and thus are neglected.

1

ELEMENTS

\section{NNSYS}

PEB 52007 $13: 23: 33$

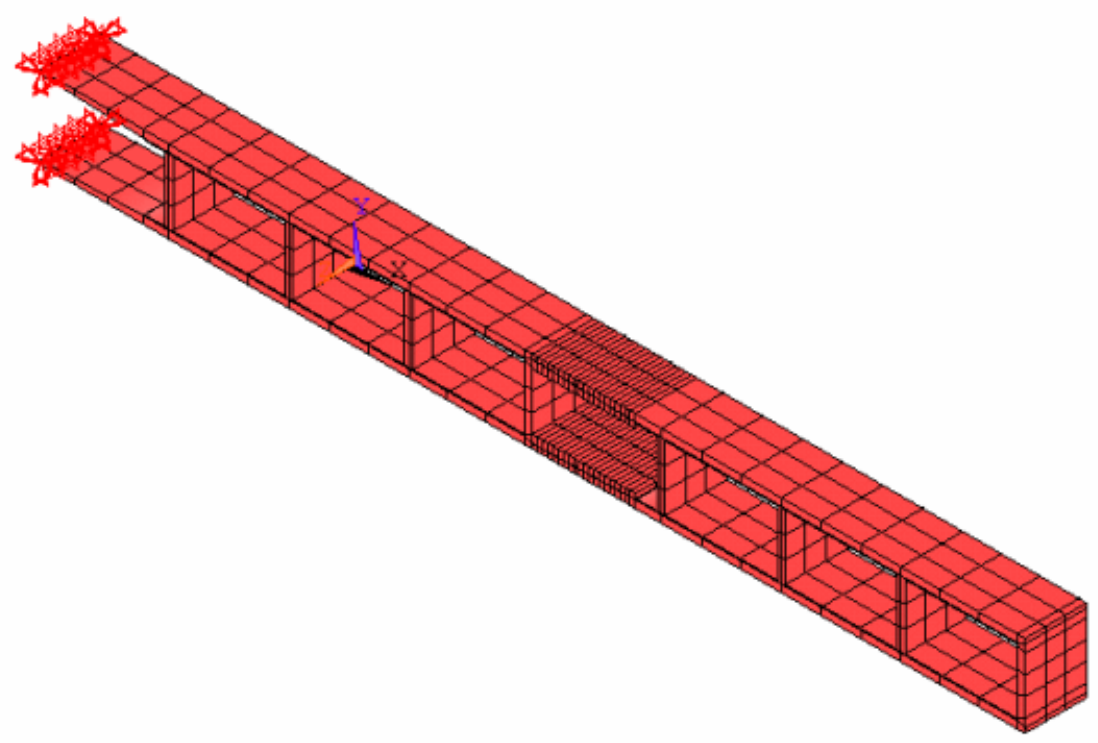

Fig. 4.5 Boundary conditions applied to the FRP twin-panel under compression 


\subsection{APPLIED LOADS}

A surface load over an area of 3"x 3" is applied in the form of uniform pressure on the web at the right end to simulate the effect of compressive loading. Ganga Rao et al. (2004) applied a compressive load on the web at the right end of the FRP twin-panel.

ELEMENTS

NNSYS

FEB 52007

$13: 26: 17$

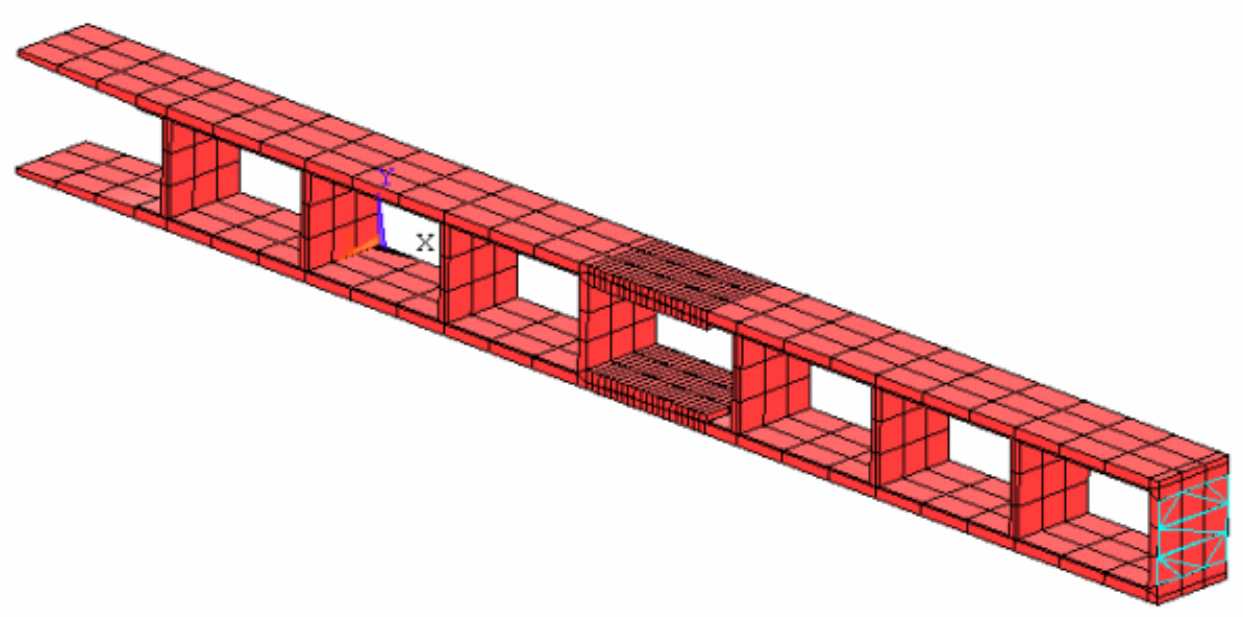

Fig. 4.6 Uniform pressure applied on the adhesively-bonded FRP twin-panel 


\subsection{RESULTS - COMPRESSIVE LOADING CASE}

\subsubsection{Analysis of Stain Profile Across the Joint}

A static analysis is performed on the finite element model of the FRP twin-panel connection that is generated. The model is subjected to compressive loading and strain values across the joints are monitored. The values of the resultant applied compressive load $(P)$ correspond to that of the experimental ones selected by Ganga Rao et al. (2004) and are namely 104, 281474 and $563 \mathrm{lb}$. The contour plot of the longitudinal strain across the joint at the resultant compressive of $104 \mathrm{lb}$ is shown in Fig. 4.7. 1

NODAL SOLUTION

NNSYS

$\operatorname{STE} P=1$

SUB $=1$

TIME $=1$

EPTOX (AVG)

RSYS $=0$

DMX $=.002243$

SMN $=-.100 \mathrm{E}-03$

$\operatorname{SMX}=.546 \mathrm{E}-04$

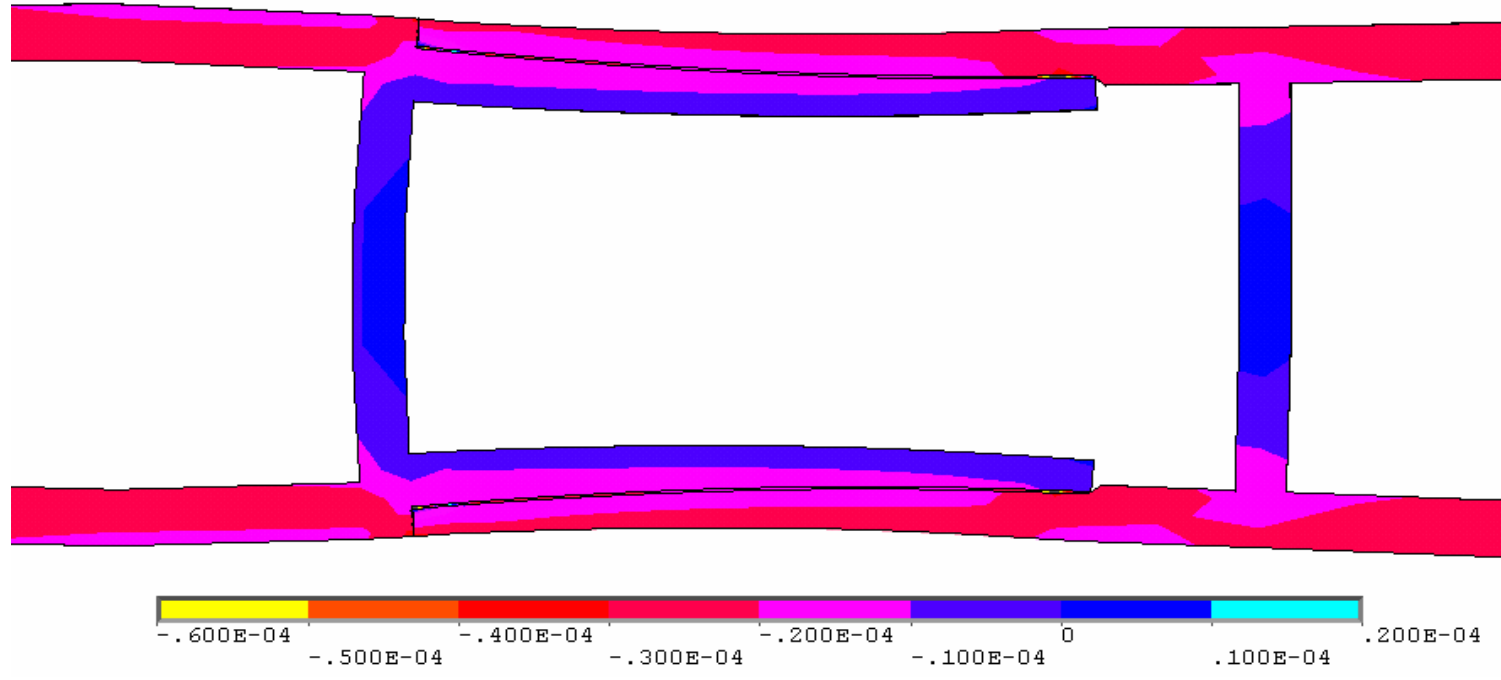

Fig. 4.7 Contour plot of longitudinal strain in the joint region for a compressive load of $104 \mathrm{lb}$ 

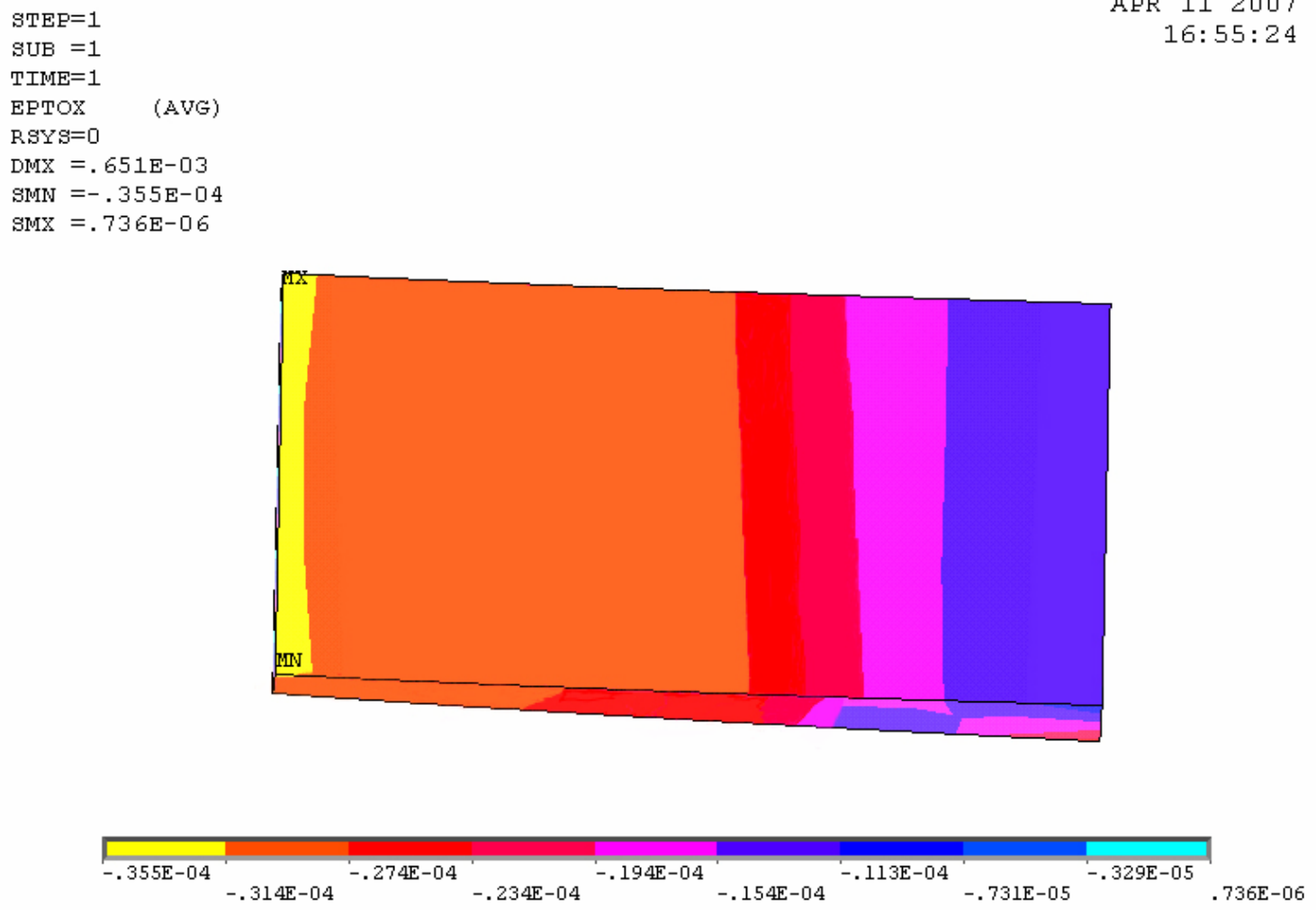

Fig. 4.8 Strain profile across the top of the Joint under a load of $104 \mathrm{lb}$

Figure 4.8 represents the longitudinal strain variation across the joint. The figure shows the top surface of the joint where the strain gauges had been placed while performing the actual experiment by Ganga Rao et al. (2004). 
Table 4.1 Longitudinal strain values across the joint for different applied loads

\begin{tabular}{|c|c|c|c|c|}
\hline \multicolumn{5}{|c|}{ Analytical data } \\
\hline $\begin{array}{l}\text { Distance from the } \\
\text { start of the joint } \\
\text { (in.) }\end{array}$ & $P=-104 \mathrm{lb}$ & $P=-281 \mathrm{lb}$ & $P=-474 \mathrm{lb}$ & $P=-563 \mathrm{lb}$ \\
\hline 0 & $-33.1 E-6$ & $-85.2 E-6$ & $-125.2 E-6$ & $-153.4 \mathrm{E}-6$ \\
\hline 0.5 & $-32.8 E-6$ & $-84.6 E-6$ & $-124.1 E-6$ & $-152.5 E-6$ \\
\hline 1.5 & $-31.4 \mathrm{E}-6$ & $-83.8 E-6$ & $-122.6 \mathrm{E}-6$ & -150.7E-6 \\
\hline 2.5 & $-30.1 E-6$ & $-80.3 E-6$ & -119.3E-6 & $-147.4 \mathrm{E}-6$ \\
\hline 3.5 & -26.4E-6 & $-65.5 E-6$ & $-100.4 E-6$ & $-123.4 \mathrm{E}-6$ \\
\hline 5 & $-15.3 E-6$ & $-45.6 \mathrm{E}-6$ & $-69.4 \mathrm{E}-6$ & -79.6E-6 \\
\hline \multicolumn{5}{|c|}{ Experimental Results [Ganga Rao et al. (2004)] } \\
\hline $\begin{array}{l}\text { Distance from the } \\
\text { start of the joint } \\
\text { (in.) }\end{array}$ & $P=-104 \mathrm{lb}$ & $P=-281 \mathrm{lb}$ & $P=-474 \mathrm{lb}$ & $P=-563 \mathrm{lb}$ \\
\hline 0.5 & $-39.5 E-6$ & $-91.0 \mathrm{E}-6$ & $-130.0 E-6$ & -158.0E-6 \\
\hline 2.5 & $-39.8 E-6$ & $-88.0 \mathrm{E}-6$ & $-128.0 E-6$ & $-154.0 \mathrm{E}-6$ \\
\hline 5 & $-21.5 E-6$ & $-50.0 \mathrm{E}-6$ & $-76.0 \mathrm{E}-6$ & $-85.0 \mathrm{E}-6$ \\
\hline
\end{tabular}

The same results are represented graphically in Fig. 4.9. The solid lines represent analytical results while the dotted lines represent the experimental results. The longitudinal strain values on the top surface of the joint for different load values are presented in Table 4.1. The corresponding experimental strain values from Ganga Rao et al. (2004) are also included in this table. 


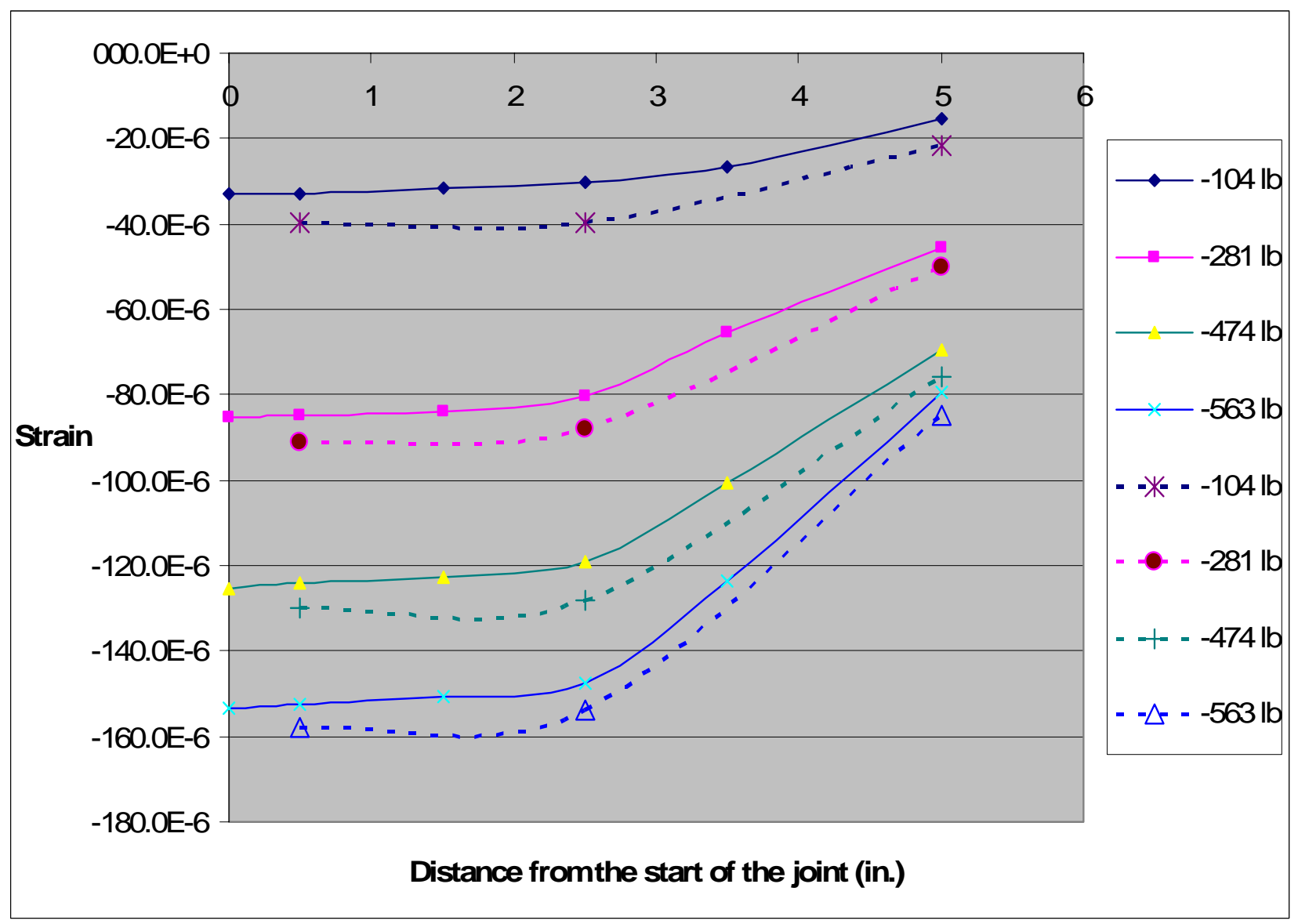

Fig. 4.9 Strain profile across the length of the glued joint

The distribution of the longitudinal strain from the current analysis follows the same trend as that of the experimental one for the four loads considered. In all the cases, the agreement between the analytical and the experimental results is very good at the three locations of the joint. 


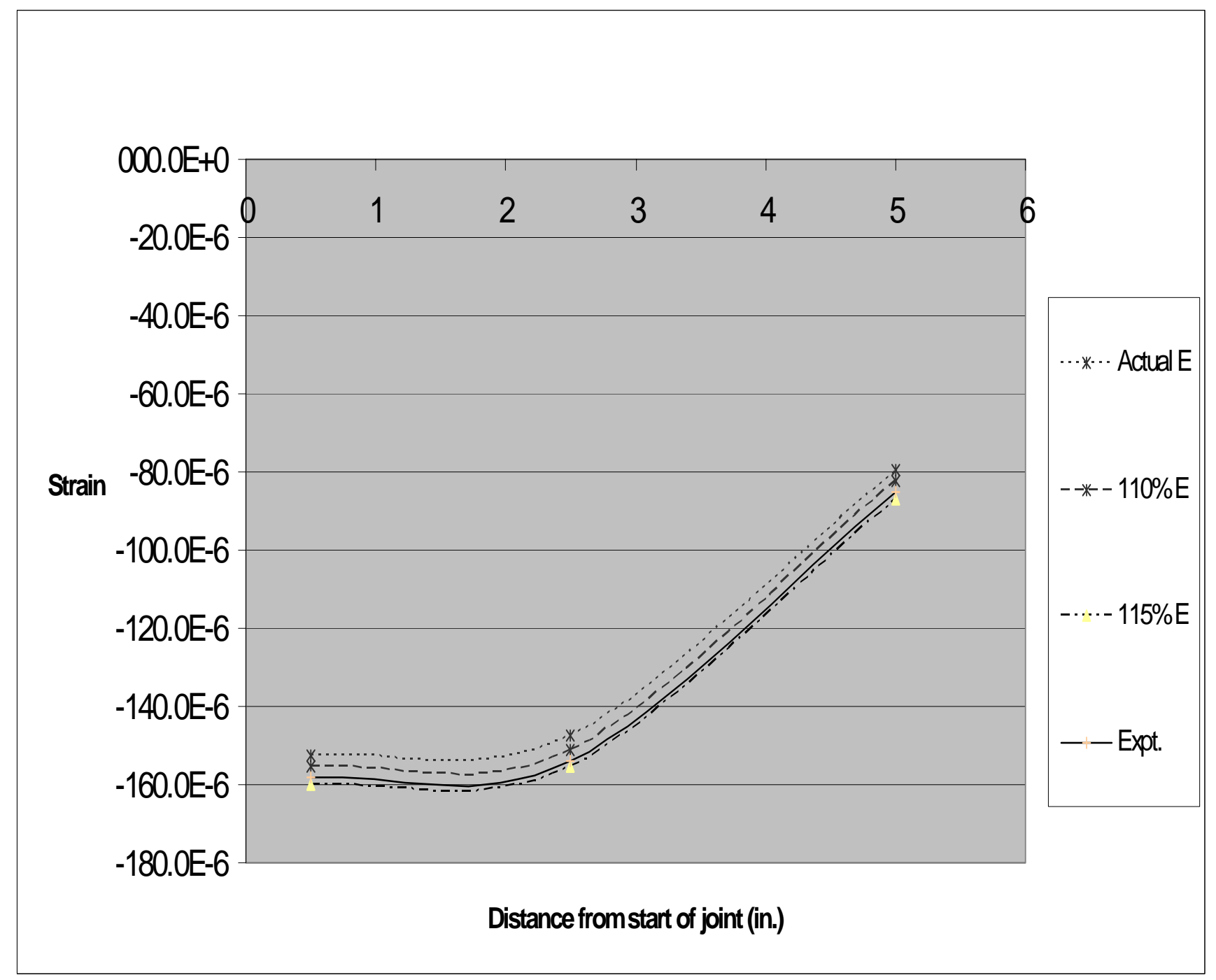

Fig. 4.10 Strain profile across the length of the glued joint at different adhesive properties under a compressive load of $563 \mathrm{lb}$

\subsubsection{Analysis with varying Young's Modulus}

Several investigators [e.g., Jager et al (2003)] have reported that adhesives when used as a thin layer exhibit an apparent increase in Young's modulus compared to the values reported by manufactures based on testing the adhesives independently. This apparent increase could be as high at $20 \%$. To test this phenomenon in our joint analysis of bridge decks, the material stiffness is increased artificially and the results are 
compared with the experimental results of Ganga Rao et al. (2004). Figure 4.10 shows the strain distribution on the top surface of the bridge-deck joint for three values of the adhesive Young's modulus $(E)$, namely the actual value, $110 \% E$, and $115 \% E$ for a compressive load of $563 \mathrm{lb}$. The corresponding experimental results from Ganga Rao et al. (2004) are also included in the figure. It is seen that the results for different $E$ values follow the same trend as that of the experiment ones but the graph for $115 \% E$ is aligned more closely with that of the experimental curve. Thus this test with artificially increased material stiffness confirms the findings of other experimental investigations such as Jager et al. (2003) that there is an apparent increase in the material stiffness.

\subsection{COUPON-LEVEL ADHESIVE LAP-JOINT ANALYSIS}

\subsubsection{Introduction}

A coupon-level joint analysis is performed to further understand the nature of the glued joint. First a solid model of the coupon-level is generated by creating key points and then defining volumes by selecting key points. The same layer stacking sequence used for modeling the Prodeck 4 flanges is used to model the coupon-level joint. Thus the same layer material properties which have been used in the finite element model of the FRP twin-panel are used in this case. The volumes thus formed are map meshed and then the orientations of the layers are checked as mentioned earlier in Section 3.4.

The adhesive between the two adherends is modeled as a thin layer using SOLSH-190 elements. The glue properties correspond to the specifications of Pliogrip 6600. A detailed report on Pliogrip 6600 and the SOLSH-190 element is provided in 
Chapter 3. The nodes between the adhesive and the adherends are merged in a similar way as done in the glued twin-panel analysis.

Figure 4.11 shows the solid model of the adhesively-bonded coupon-level lap joint. The solid model consists of 6 volumes which when map meshed using Soild-46 results in a total of 122 elements consisting of 1864 nodes. The orientations of the coordinate systems of all the elements are checked to see if they are aligned in the fiber direction and changes in the orientations are manually made if necessary. The left end of the bottom plate is fixed while a uniform compressive stress is applied to the right end of the top plate. Figure 4.12 shows the boundary conditions and applied load on the couponlevel lap joint.

1 1 Volumes NNSYS TYPE NUM MAR $\begin{array}{r}7 \quad 2007 \\ 13: 24: 26\end{array}$

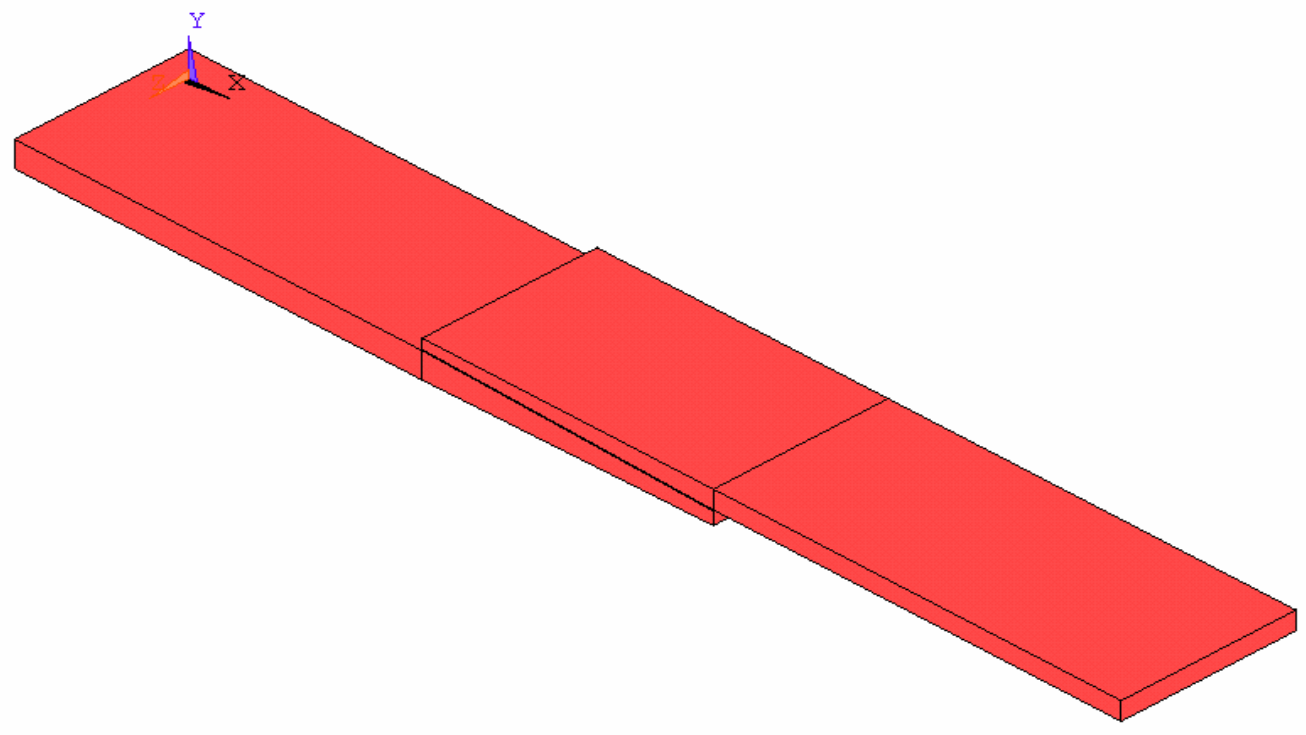


Fig 4.11 Adhesively-bonded coupon-level single lap joint

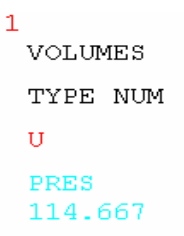

NNSYS

MAR 142007 $16: 57: 43$

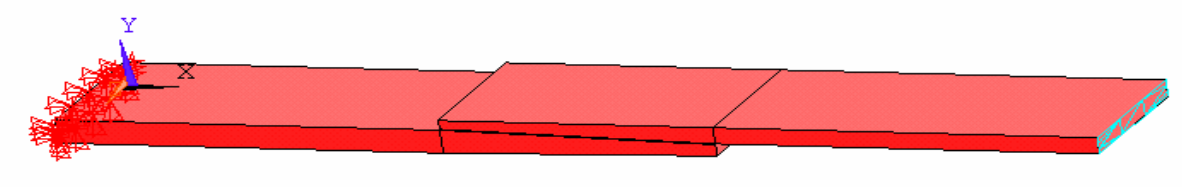

Fig. 4.12 Pictorial representation of uniform pressure and boundary conditions applied on the adhesively-bonded coupon-level joint

\subsubsection{Analysis of Stain Profile across the Coupon-Level Joint}

A static analysis is performed on the finite element model of the coupon joint that is generated. The model is subjected to compressive loading and strain values across the joint are monitored. The values of the resultant applied compressive load $(P)$ are 104, 281, 474 and $563 \mathrm{lb}$. The contour plot of the longitudinal strain variation on the top surface across the coupon at the resultant applied compressive load of $104 \mathrm{lb}$ is shown in Fig. 4.13. Figure 4.14 represents the longitudinal strain variation across the joint for a load of $281 \mathrm{lb}$. 
SUB $=1$

TIME $=1$

EPTOX

(AVG)

RSYS $=0$

$\mathrm{DMX}=.03668$

SMN $=-.229 \mathrm{E}-03$

$\mathrm{SMX}=.142 \mathrm{E}-03$
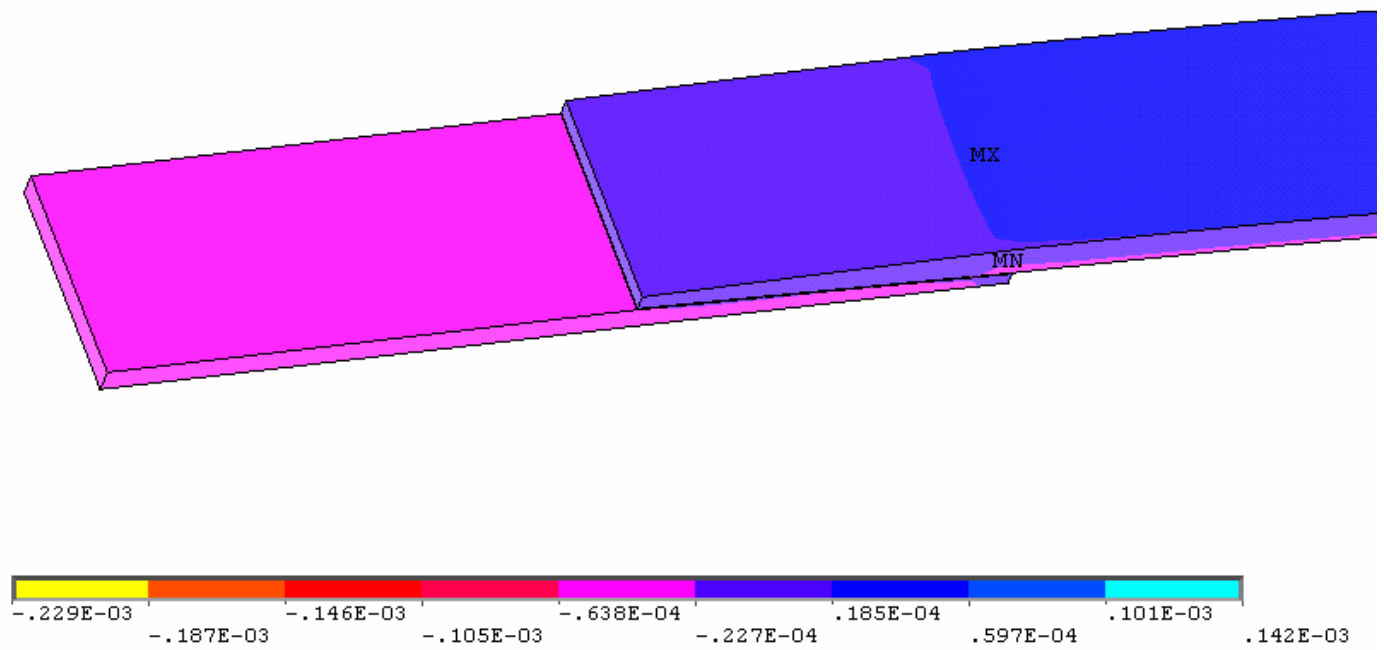

Fig. 4.13 Contour plot of longitudinal strain in the joint region for a compressive load of $104 \mathrm{lb}$ 
TIME $=1$

EPTOX (AVG)

RSYS $=0$

$\mathrm{DMX}=.023947$

SMN $=-.929 \mathrm{E}-04$

SMX $=-.806 \mathrm{E}-05$
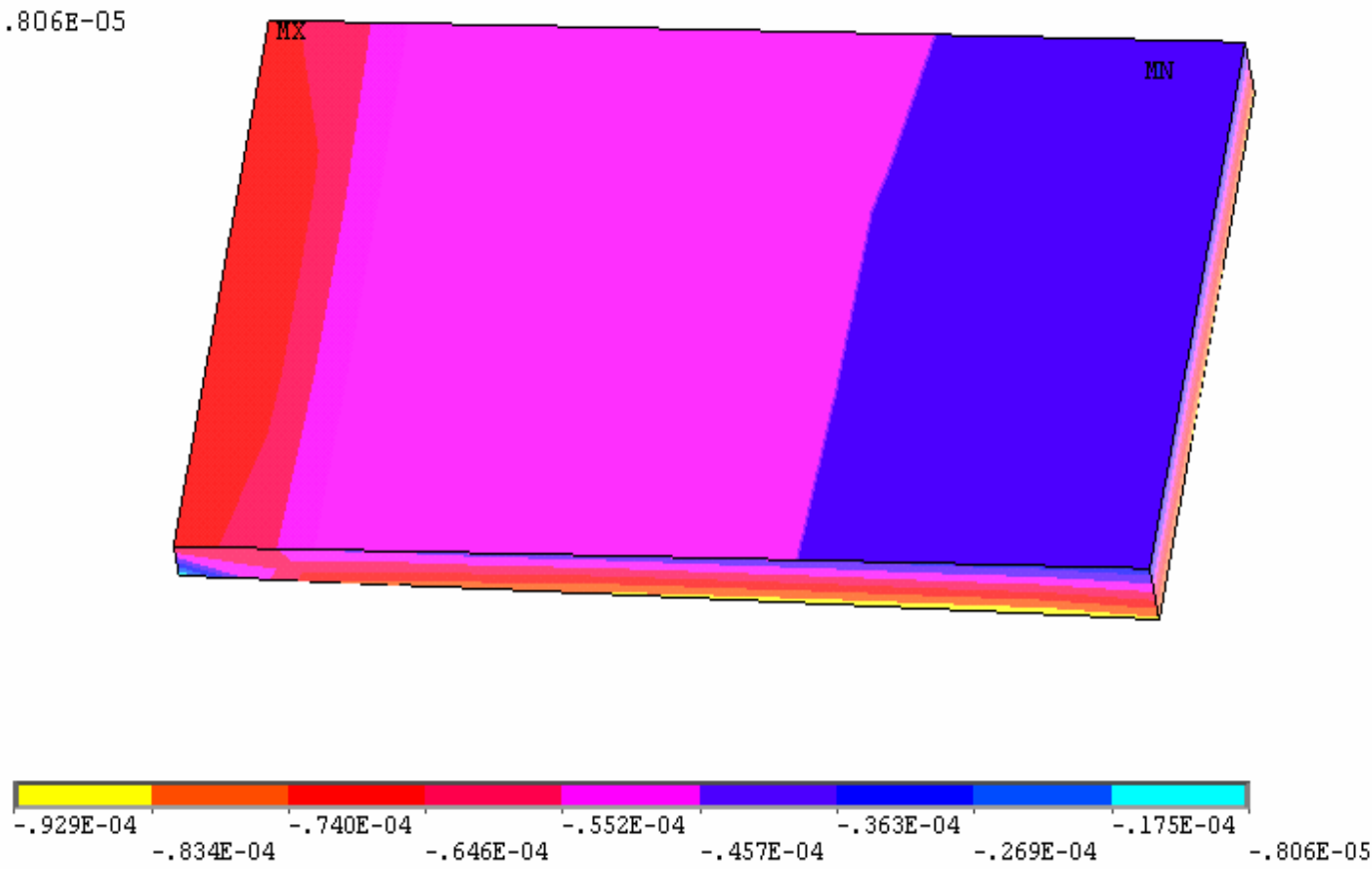

Fig. 4.14 Strain profile across the top of the Joint under a load of $281 \mathrm{lb}$ 
Table 4.2 Longitudinal strain values across the glued coupon joint for different applied loads

\begin{tabular}{|c|c|c|c|c|}
\hline \multicolumn{5}{|c|}{ Analytical data } \\
\hline $\begin{array}{c}\text { Distance from the } \\
\text { start of the joint } \\
\text { (in.) }\end{array}$ & $P=-104 \mathrm{lb}$ & $P=-281 \mathrm{lb}$ & $P=-474 \mathrm{lb}$ & $P=-563 \mathrm{lb}$ \\
\hline 0 & $-30.2 \mathrm{E}-6$ & $-72.3 \mathrm{E}-6$ & $-114.0 \mathrm{E}-6$ & $-140.2 \mathrm{E}-6$ \\
\hline 0.5 & $-28.9 \mathrm{E}-6$ & $-68.4 \mathrm{E}-6$ & $-110.3 \mathrm{E}-6$ & $-135.5 \mathrm{E}-6$ \\
\hline 1.5 & $-26.3 \mathrm{E}-6$ & $-60.0 \mathrm{E}-6$ & $-101.3 \mathrm{E}-6$ & $-121.2 \mathrm{E}-6$ \\
\hline 2.5 & $-22.3 \mathrm{E}-6$ & $-52.0 \mathrm{E}-6$ & $-89.6 \mathrm{E}-6$ & $-110.6 \mathrm{E}-6$ \\
\hline 3.5 & $-19.4 \mathrm{E}-6$ & $-44.3 \mathrm{E}-6$ & $-79.5 \mathrm{E}-6$ & $-95.4 \mathrm{E}-6$ \\
\hline 5 & $-15.1 \mathrm{E}-6$ & $-31.4 \mathrm{E}-6$ & $-60.3 \mathrm{E}-6$ & $-70.6 \mathrm{E}-6$ \\
\hline
\end{tabular}

Longitudinal strain values on the top surface of the joint for different loads are presented in Table 4.2. The same results are represented graphically in Fig. 4.15. 


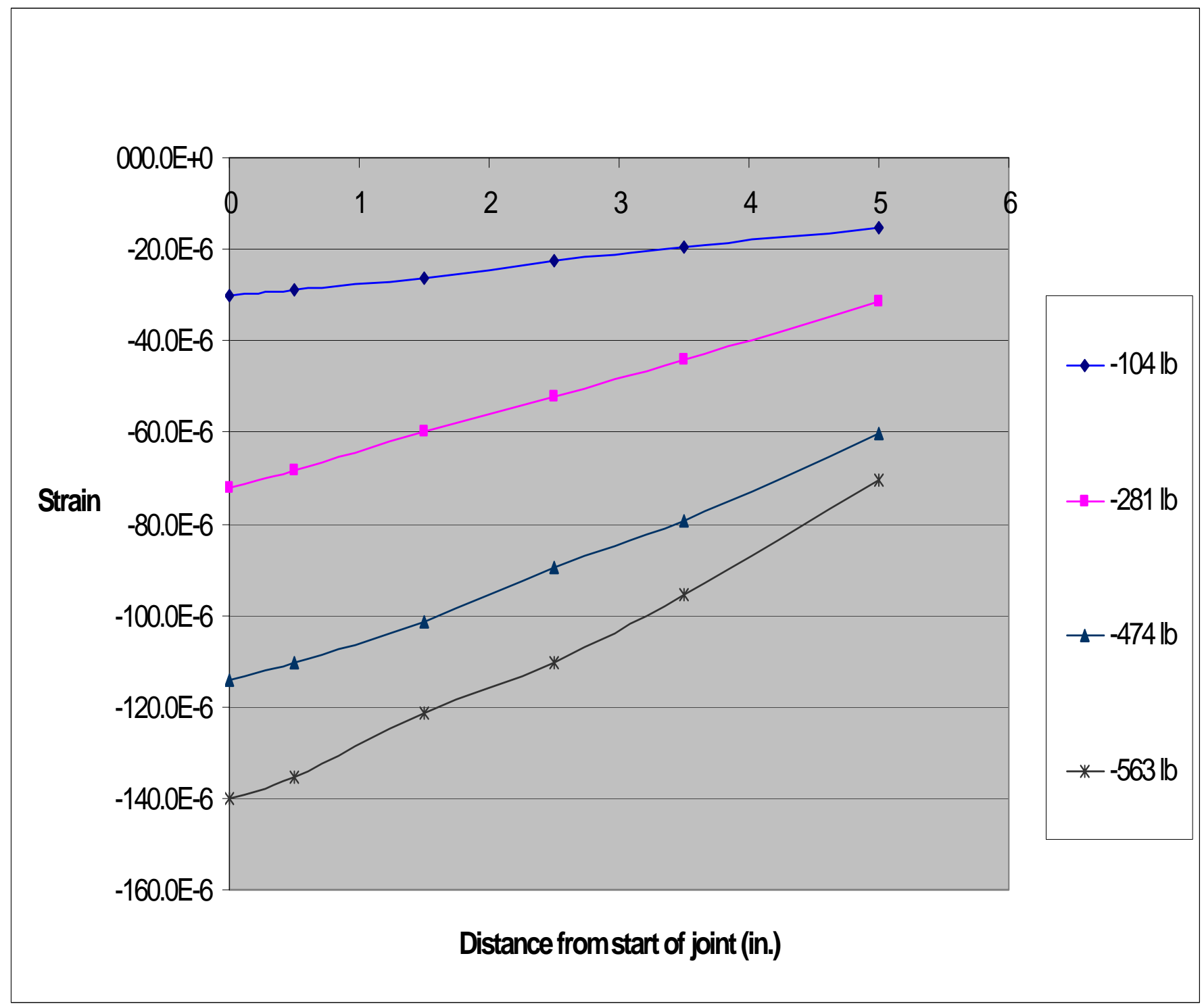

Fig. 4.15 Strain profile across the length of the coupon-level glued joint

The distribution of the longitudinal strain from the coupon-level joint analysis loaded under compressive loading follows a linear variation for the loads considered. There is considerable difference in the strain trend when compared to the strain variation of the deck level analysis. 


\subsection{SHEAR STRESS VARIATION IN THE ADHESIVE}

Shear stress in the adhesive is a common failure mode in lap joints. To understand the nature of the shear stress distribution at the joint, the in plane shear stress in the joint region is examined for the case of the adhesively-connected twin-panel bridge deck subjected to a compressive load of 5631b. A contour plot of the shear stress in the top and bottom adhesives of the twin-panel deck is shown in Fig. 4.16. The shear stress in both the top and bottom adhesives of the joint show high gradients at the ends of the joint with almost uniform distribution in the middle.

1

NODAL SOLUTION

NNSYS

$\operatorname{STEP}=1$

SUB $=1$

TIME $=1$

SXY

RSYS $=0$

$\mathrm{DMX}=.002637$

$\mathrm{SMN}=-53.787$

SMX $=58.765$
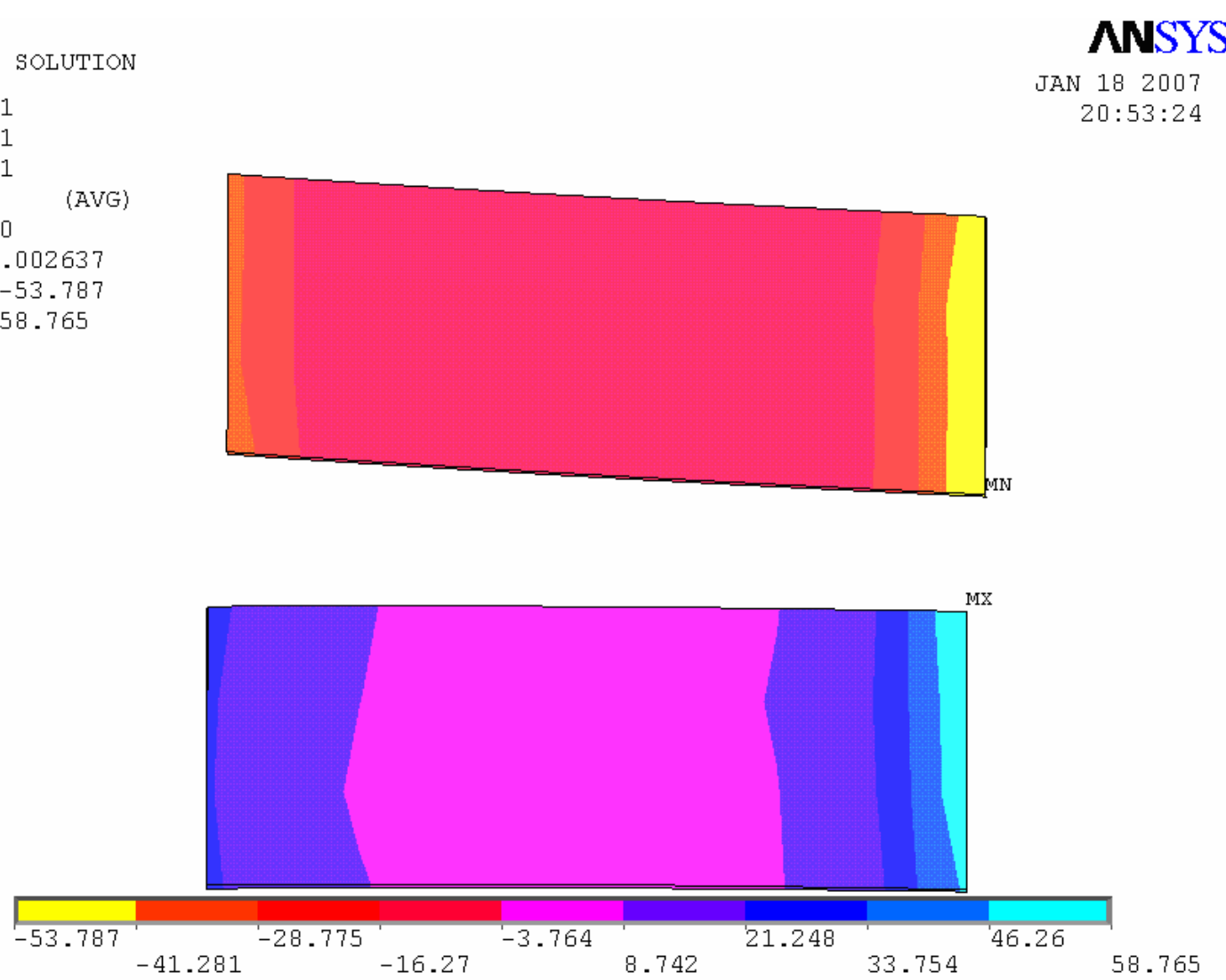

Fig. 4.16 Shear stress variation in the adhesive 
The shear stress in the adhesive is depicted in the form of an ANSYS generated graph in Fig. 4.17. In this graph, the $\mathrm{X}$-axis represents the distance, in inches, from the start of the joint, and the Y-axis represents the shear stress, in psi. This shear stress variation in the adhesive is similar to the ones in the laps - high gradients at the end an uniform distribution in the middle. The maximum value of the shear stress in the adhesive is about 60 psi. Recalling that the shear strength of the Pliogrip 6600 adhesive is $1225 \mathrm{psi}$, the factor of safety is about 20 w.r.t. the applied load of $563 \mathrm{lb}$. The two adherends are of unequal thickness in the present model and the shear stress variation in the adhesive agrees very well with that characterized by Mosallam (1994).
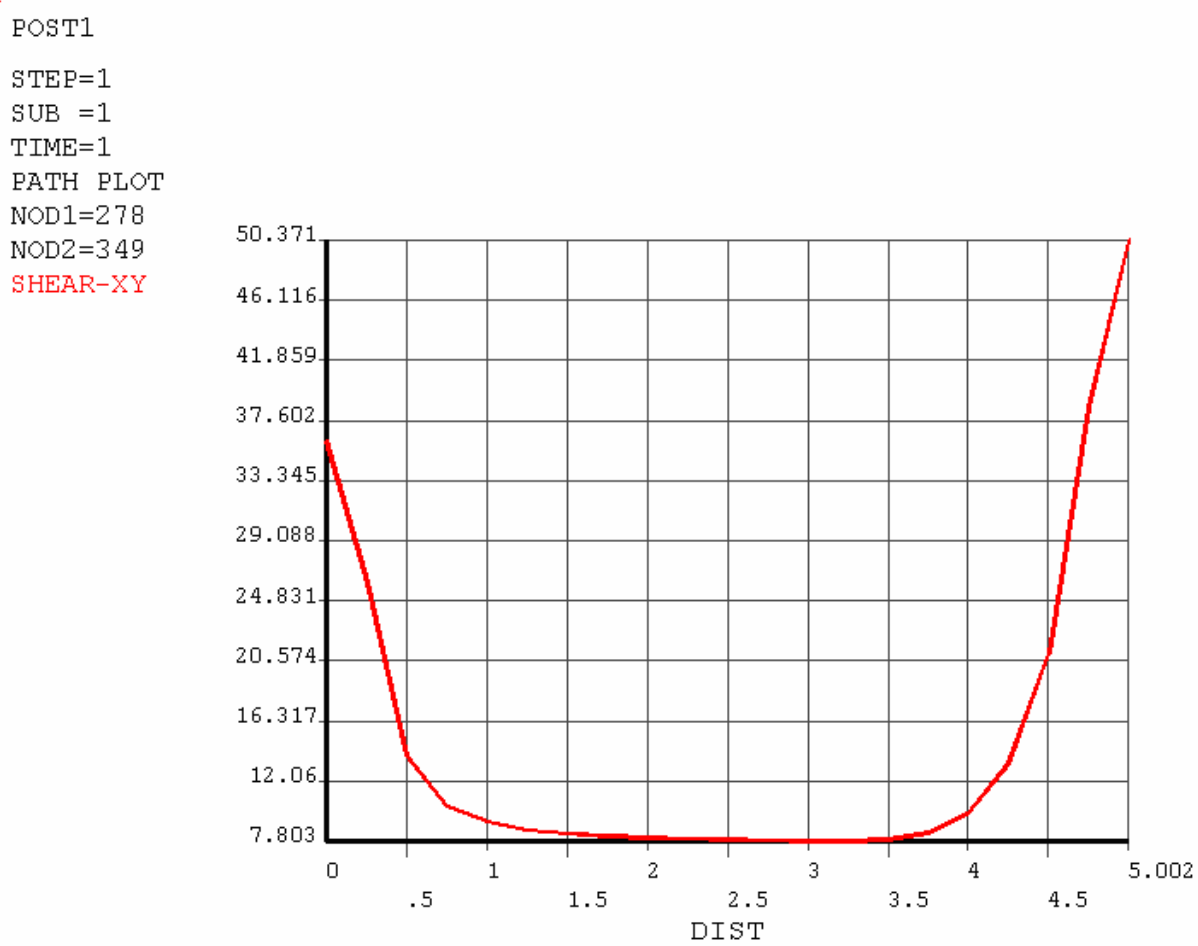

Fig. 4.17 Graphical representation of shear stress variation across the adhesive 


\subsection{BENDING ANALYSIS}

Next, the adhesively-connected twin-panel deck is subjected to a four-point bending analysis. This allows for the monitoring of the load transfer in compression as well as tension. The corresponding finite element model along with the boundary conditions and applied load is shown in Fig. 4.19. In the four-point model, the distance between the outer points (supports) is $41.544 \mathrm{in}$. and the distance between the inner points (loads) is 20.772 in.. A downward load of $74 \mathrm{lb}$ is applied at each of the inner points.

1

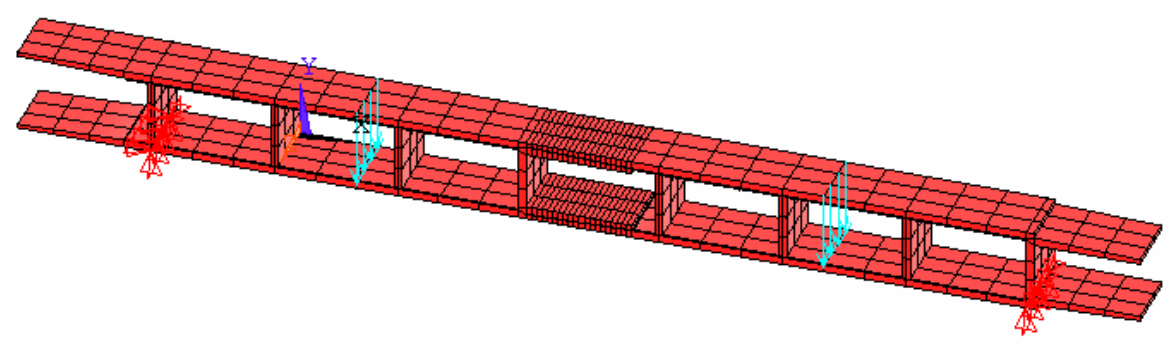

Fig. 4.18 Four point bending analysis on an adhesively-bonded twin Prodeck 4 panel. 
This model simulates the experimental investigation of the four-point bend test conducted by Ganga Rao et al. (2004). In their experiment, they have monitored tensile strains by placing strain gages on the bottom flange in the joint region. $\perp$

NODAL SOLUTION

NNSYS

STEP $=1$

SUB $=1$

TIME $=1$

EPTOX

RSYS $=0$

$\mathrm{DMX}=.043855$

SMN $=-.442 \mathrm{E}-03$

SMX $=.364 \mathrm{E}-03$
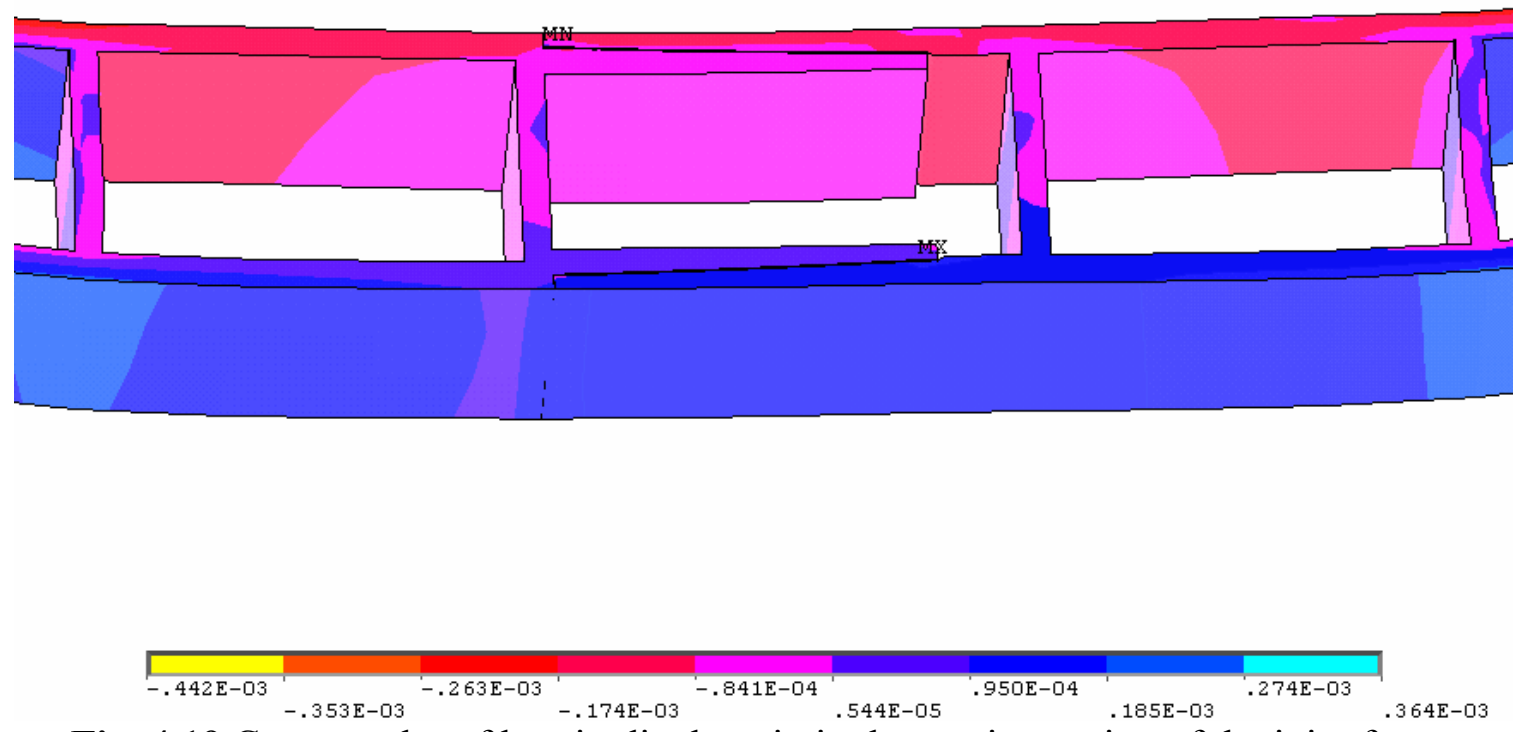

Fig. 4.19 Contour plot of longitudinal strain in the tension region of the joint for an

$$
\text { equivalent load of } 148 \mathrm{lb}
$$

The contour plot of the longitudinal strain in the joint region is depicted in Fig. 4.19. The longitudinal strain at selected locations on the bottom flange at the joint region is presented in Table 4.3. The experimental results (at strain gage locations) from Ganga Rao et al. (2004) are also included in this table. The two sets of results in graphical form are shown in Fig. 4.20. While the present strain profile (based on the finite element analysis) agrees very well with that of the experimental one as far as the trend is 
concerned, there is about a $15 \%$ difference in the magnitude. This difference is attributed to the apparent increase in Young's modulus of adhesives when employed as a thin film.

Table 4.3 Longitudinal strain values across the joint under tension for applied load

\begin{tabular}{|c|c|c|}
\hline Distance (in.) & $\begin{array}{c}\text { Analytical Strain at } \\
P=148 \text { Ib }\end{array}$ & $\begin{array}{c}\text { Experimental Strains } \\
\text { [Ganga Rao et al. (2004)] } \\
P=148 \text { lb }\end{array}$ \\
\hline 0 & $1.00 \mathrm{E}-04$ & N/A \\
\hline 0.5 & $106.3 \mathrm{E}-6$ & $122.0 \mathrm{E}-6$ \\
\hline 1.5 & $121.2 \mathrm{E}-6$ & $\mathrm{~N} / \mathrm{A}$ \\
\hline 2.5 & $131.0 \mathrm{E}-6$ & $143.0 \mathrm{E}-6$ \\
\hline 3.5 & $139.8 \mathrm{E}-6$ & $\mathrm{~N} / \mathrm{A}$ \\
\hline 5 & $146.0 \mathrm{E}-6$ & $158.0 \mathrm{E}-6$ \\
\hline
\end{tabular}

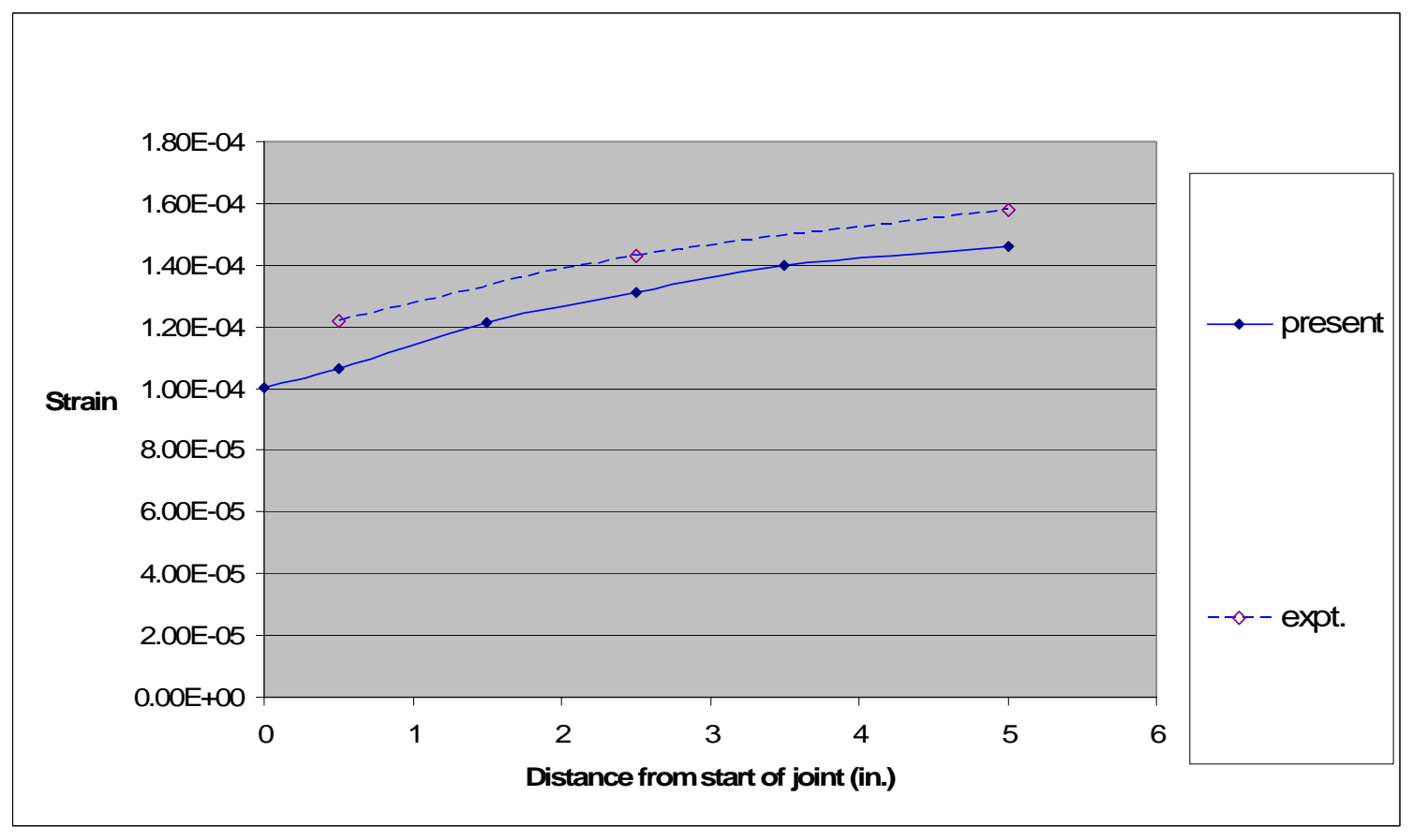

Fig. 4.20 Strain profile on the bottom flange of the bridge-panel under 4-point bend test. 
The longitudinal compressive strain on the top flange in the joint region is seen in Fig. 4.21. Comparing Figs. 4.20 and 4.21, the strain profile in tension is different from that in compression, both in magnitude and shape.

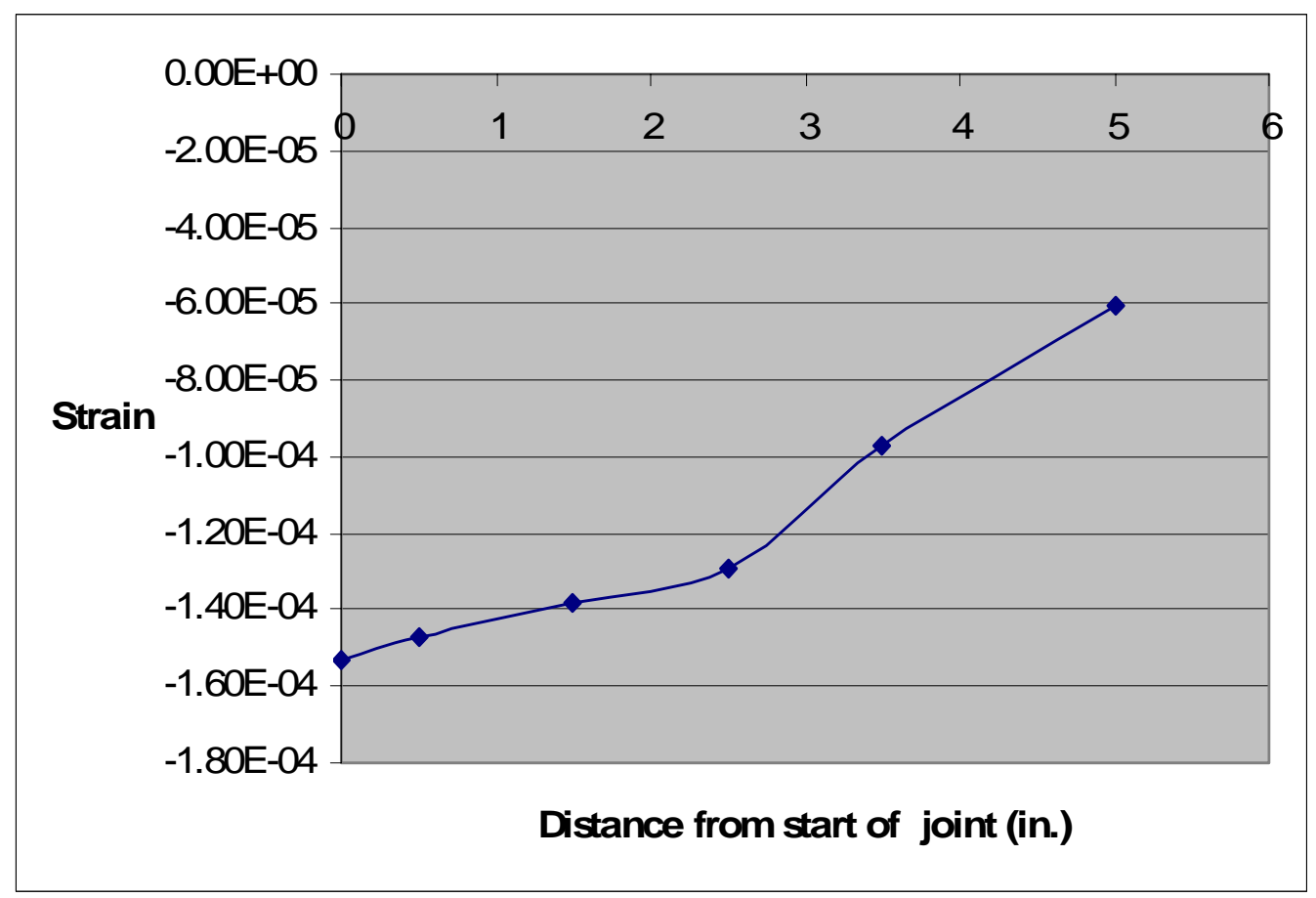

Fig. 4.21 Strain profile on the top flange of the bridge-panel joint under 4-point bend test. 


\section{CHAPTER 5}

\section{ANALYSIS OF MECHANICALLY CONNECTED}

\section{FRP PANELS}

\subsection{INTRODUCTION}

This chapter deals with the development of a finite element model of the mechanically-bonded, low-profile, FRP, bridge-deck panels. Rivets are used as the mechanical fasteners. Once the finite element model is done, it is subjected to a compressive test to obtain the strain profile across the joint section. The results thus obtained are then compared with that obtained in experiments conducted by previous researchers.

\subsection{FINITE ELEMENT MODEL}

First a solid model of the FRP panel is generated in ANSYS in a similar way as done in Chapter 4 for the adhesive joint. In this model there is no adhesive used and a hole is drilled in the center of the top and bottom overlapping panel sections. Bolts are modeled and map meshed at the drilled locations. The remaining volumes are map meshed and then the orientations of the layers checked as mentioned earlier in Section 3.4. The nodes on the outer surface of the rivets are merged with the nodes on the inner surface of the drilled sections. This design consideration allows for the load transfer from one panel to the other panel through the bolt and maintains continuity in the model.

Figure 5.1 shows a solid model of the mechanically bonded FRP twin-panel connection, which consists of 76 volumes that are combined. The orientations of the 
coordinate systems of all the elements are checked to see if they are aligned in the fiber direction and changes in the orientations are manually made, if necessary.

Figure 5.2 shows the map-meshed model of the mechanically bonded FRP panels. The element orientations are with respect to the locally defined coordinate systems for all the elements which are illustrated in Fig. 5.3. VOLUMES NNSYS TYPE NUM MAR 192007 $19: 53: 41$

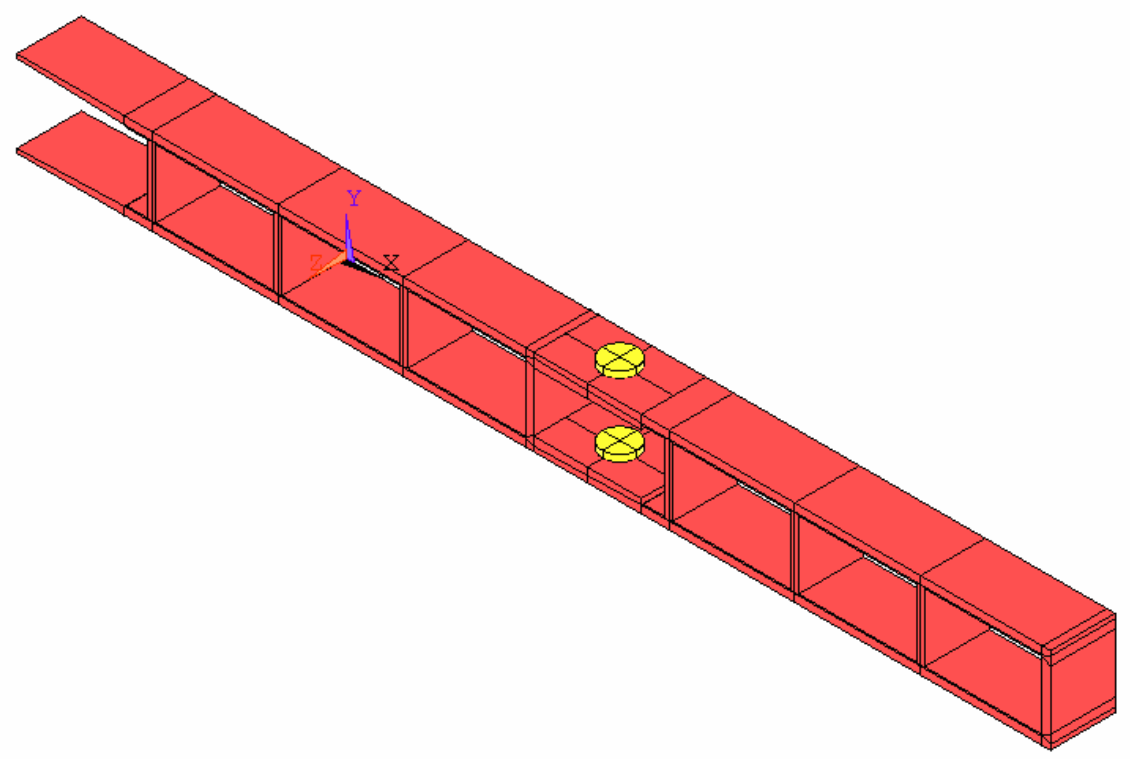

Fig. 5.1 Solid model of a mechanically bonded FRP twin-panel 


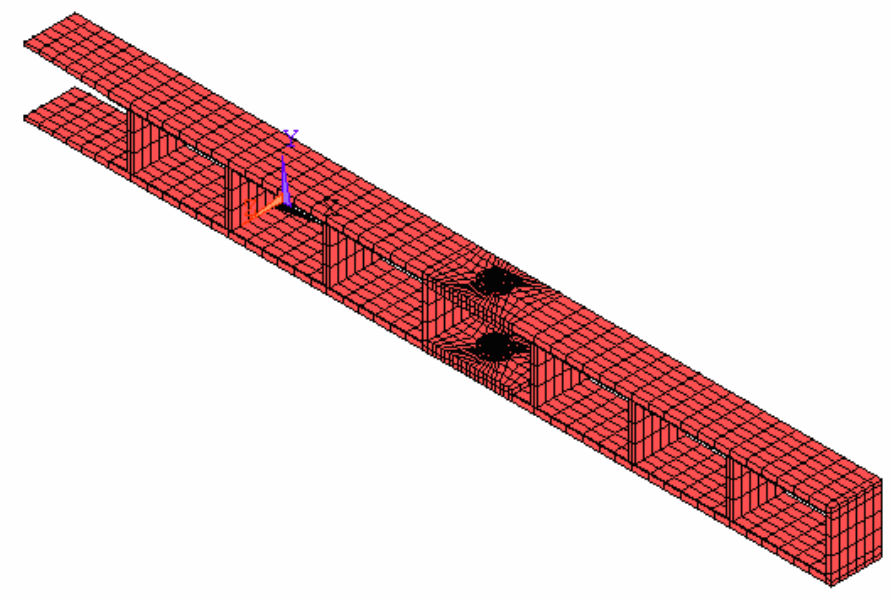

Fig. 5.2 Map-meshed model of a mechanically bonded FRP twin-panel

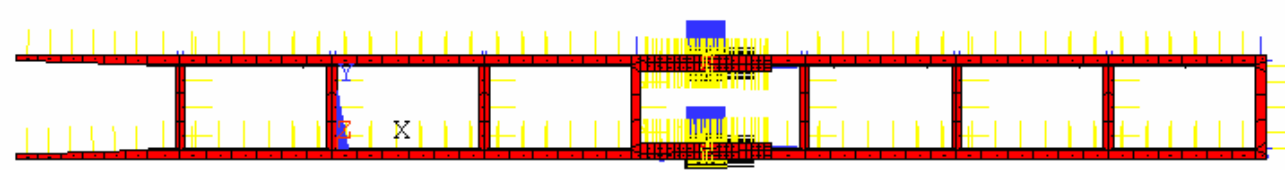

Fig. 5.3 Orientations of element coordinate systems in FRP twin-panel 
The rivets used to connect the two panels are modeled using the SOLID-45 element in ANSYS. The rivet properties correspond to the specification of Grade 5 A-340 carbon steel rivets. Figure 5.4 shows a closer look of the connection with the rivets modeled between the panels.

1 ELEMENTS NNSYS MAR 192007 $19: 54: 51$

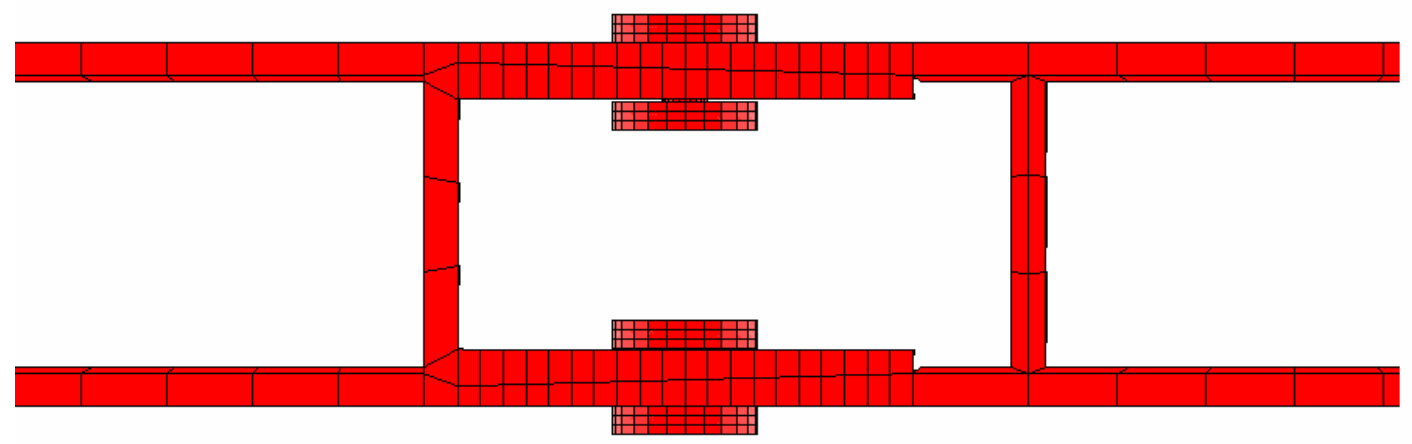

Fig. 5.4 Joint section of the riveted FRP twin-panel 


\subsection{BOUNDARY CONDITIONS AND APPLIED LOADS}

The boundary conditions applied to the FRP beam model are as shown in Fig. 5.5. The structure is fixed at one end by setting the degree of freedom in $X, Y$ and $Z$ directions to zero. A surface load over an area of 3"x 3 " is applied in the form of a uniform pressure at the web at the right end to simulate the effect of compressive loading.

1 VOLUMES

TYPE NUM
NNSYS

MAR 192007

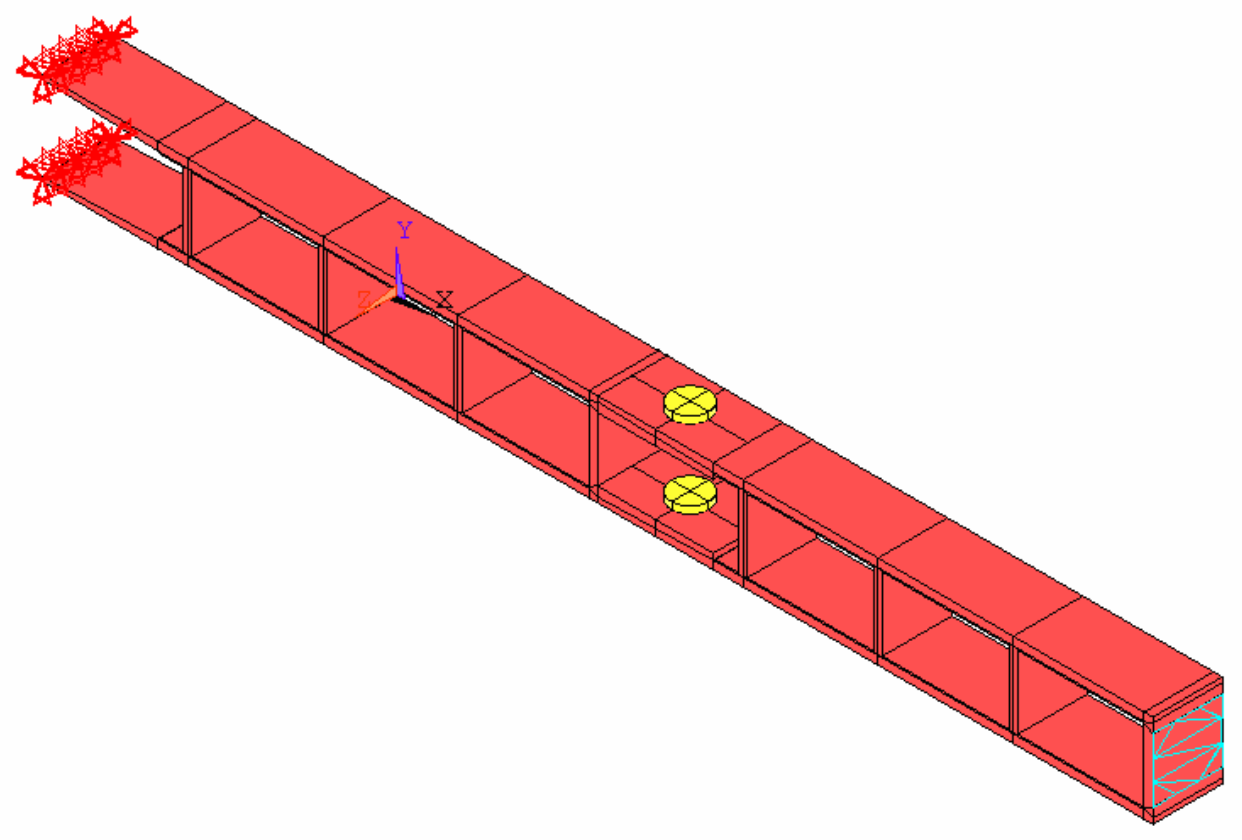

Fig. 5.5 Pictorial representation of boundary conditions and applied load on riveted FRP twin-panel 


\subsection{RESULTS}

\subsubsection{Analysis of Strain Profile Across the Joint}

A static analysis is performed on the finite element model of the FRP twin-panel that is generated. The model is subjected to compressive loading and strain values across the joint are monitored. The values of the resultant applied compressive load $(P)$ correspond to that of the experimental ones selected by Ganga Rao et al. (2004) and are, namely, 148, 400, 563 and $622 \mathrm{lb}$. The contour plot of the longitudinal strain variation across the joint section at the resultant compressive load of $400 \mathrm{lb}$ is shown in the Fig. 5.6 .

1 ELEMENT SOLUTION

NNSYS

$\operatorname{STEP}=1$

SUB $=1$

TIME $=1$

EPTOX (NOAVG)

RSYS $=0$

$\mathrm{DMX}=.010369$

SMN $=-.719 \mathrm{E}-03$

SMX $=.408 \mathrm{E}-03$
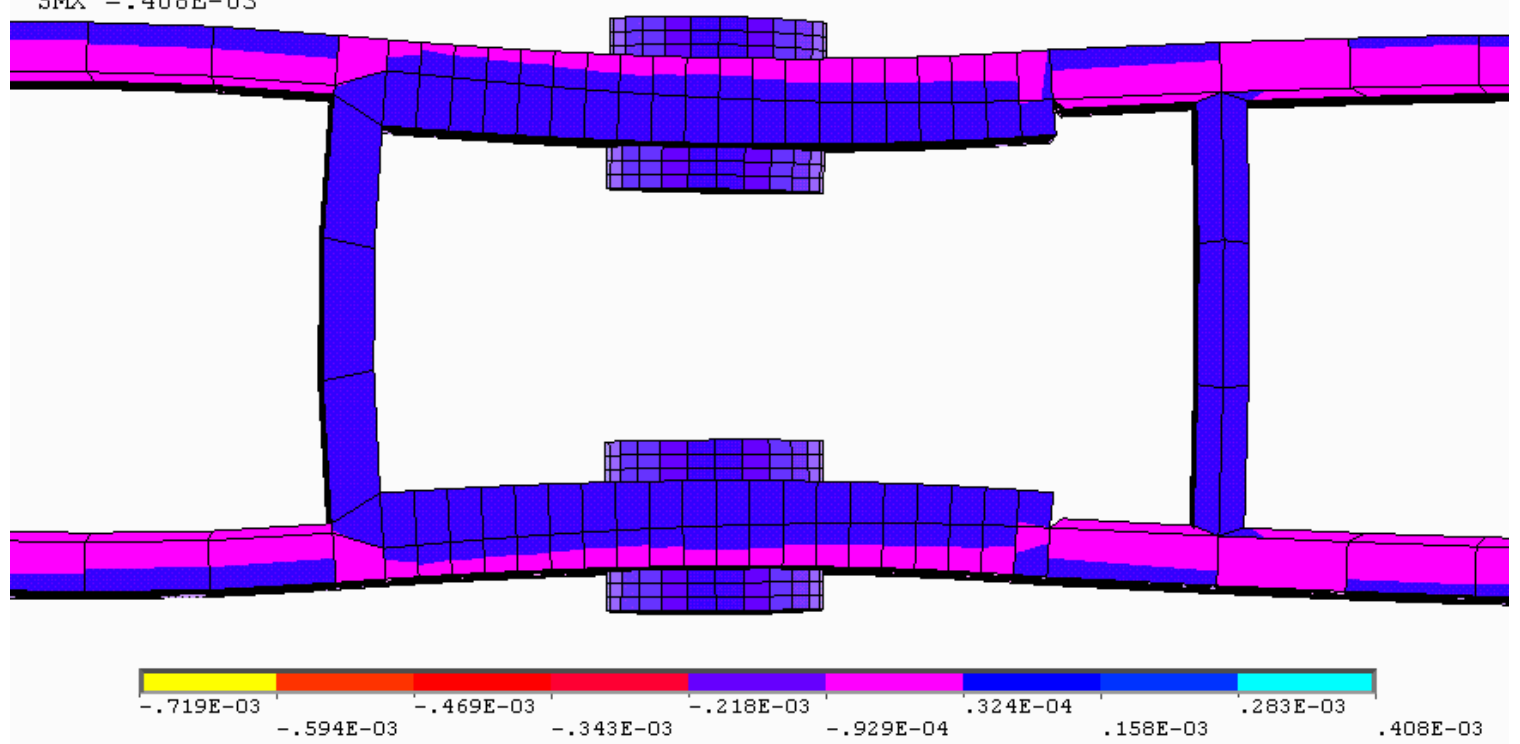

Fig. 5.6 Contour plot of longitudinal strain in the joint region for a compressive load of

$400 \mathrm{lb}$ 
1

NODAL SOLUTION

NNSYS

STEP=1

SUB $=1$

TIME $=1$

EPTOX (AVG)

RSYS $=0$

$\mathrm{DMX}=.024012$

SMN $=-.966 \mathrm{E}-04$

$\operatorname{SMX}=.191 \mathrm{E}-04$
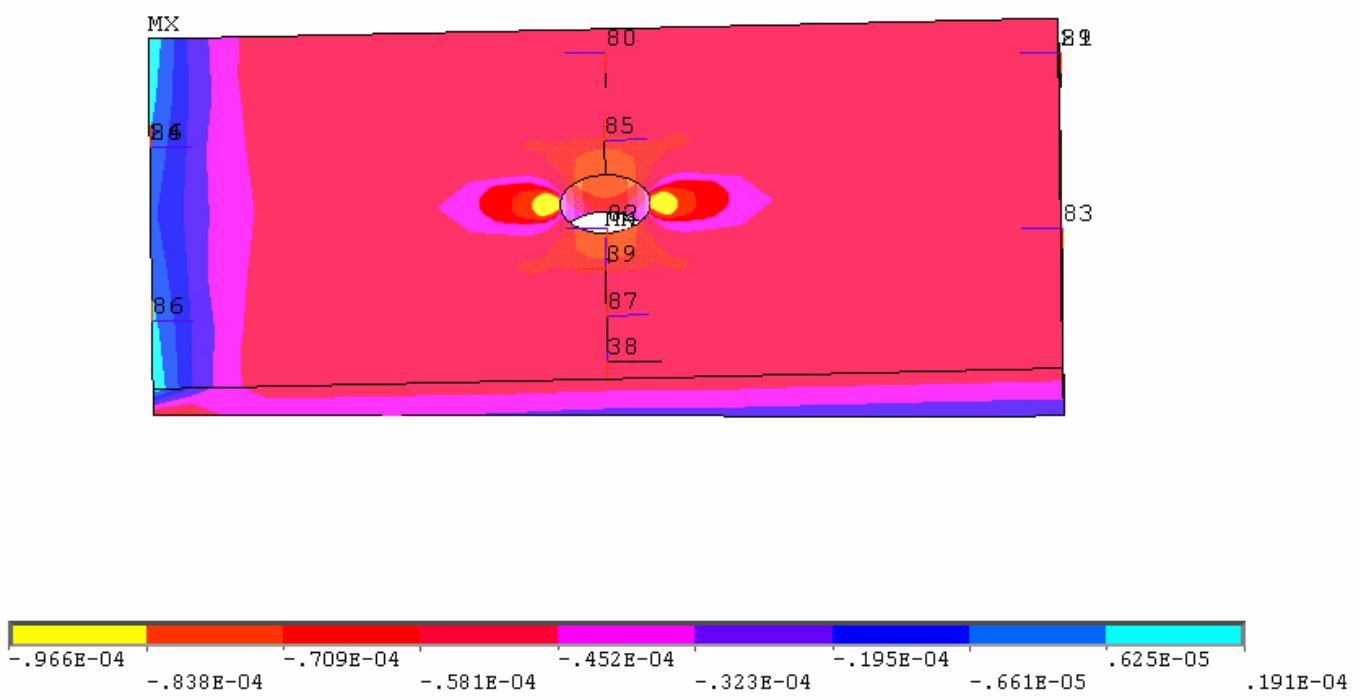

Fig. 5.7 Strain profile across the top of the joint under a load of $400 \mathrm{lb}$

Figure 5.7 shows the longitudinal strain variation across the joint under a compressive load of $400 \mathrm{lb}$. The figure shows the top end of the joint where the strain gauges have been placed while performing the actual experiment by Ganga Rao et al. (2004). The strain at the middle of the joint has been measured around the diameter of the hole at the middle of the joint. 
Table 5.1 Longitudinal strain values across the riveted joint for different applied loads

\begin{tabular}{|c|c|c|c|c|}
\hline \multicolumn{5}{|c|}{ Analytical strains at } \\
\hline $\begin{array}{l}\text { Distance from the } \\
\text { start of the joint (in.) }\end{array}$ & $P=-148 \mathrm{lb}$ & $P=-400 \mathrm{lb}$ & $P=-563 \mathrm{lb}$ & $P=-622 \mathrm{lb}$ \\
\hline 0 & $-8.5 E-6$ & 20.2E-6 & $38.4 \mathrm{E}-6$ & 47.4E-6 \\
\hline 0.5 & $-9.7 E-6$ & $6.2 \mathrm{E}-6$ & 18.6E-6 & 24.5E-6 \\
\hline 2 & $-12.5 E-6$ & $-58.4 \mathrm{E}-6$ & $-74.0 \mathrm{E}-6$ & $-95.0 \mathrm{E}-6$ \\
\hline 3.2 & $-14.3 E-6$ & $-95.0 \mathrm{E}-6$ & $-144.6 E-6$ & $-168.1 E-6$ \\
\hline 4 & $-15.4 \mathrm{E}-6$ & $-74.5 \mathrm{E}-6$ & $-129.0 \mathrm{E}-6$ & $-153.1 E-6$ \\
\hline 5 & $-16.8 \mathrm{E}-6$ & $-49.0 \mathrm{E}-6$ & $-104.5 E-6$ & $-117.1 \mathrm{E}-6$ \\
\hline \multicolumn{5}{|c|}{ Experimental Results [Ganga Rao et al. (2004)] } \\
\hline $\begin{array}{l}\text { Distance from the } \\
\text { start of the joint (in.) }\end{array}$ & $P=-148 \mathrm{lb}$ & $P=-400 \mathrm{lb}$ & $P=-563 \mathrm{lb}$ & $P=-622 \mathrm{lb}$ \\
\hline 0.5 & $-8.0 \mathrm{E}-6$ & $5.0 \mathrm{E}-6$ & $20.0 \mathrm{E}-6$ & $30.0 \mathrm{E}-6$ \\
\hline 3.2 & $-9.0 \mathrm{E}-6$ & $-100.0 \mathrm{E}-6$ & $-155.0 \mathrm{E}-6$ & $-177.0 \mathrm{E}-6$ \\
\hline 5 & $-9.5 \mathrm{E}-6$ & $-53.0 \mathrm{E}-6$ & $-110.0 \mathrm{E}-6$ & $-122.0 \mathrm{E}-6$ \\
\hline
\end{tabular}

The strain results are represented graphically in Fig. 5.8. The solid line represents the data corresponding to the present results obtained numerically and the dotted lines represent the data corresponding to the results obtained experimentally by Ganga Rao et al. (2004). Same results are present in Table 5.1. 


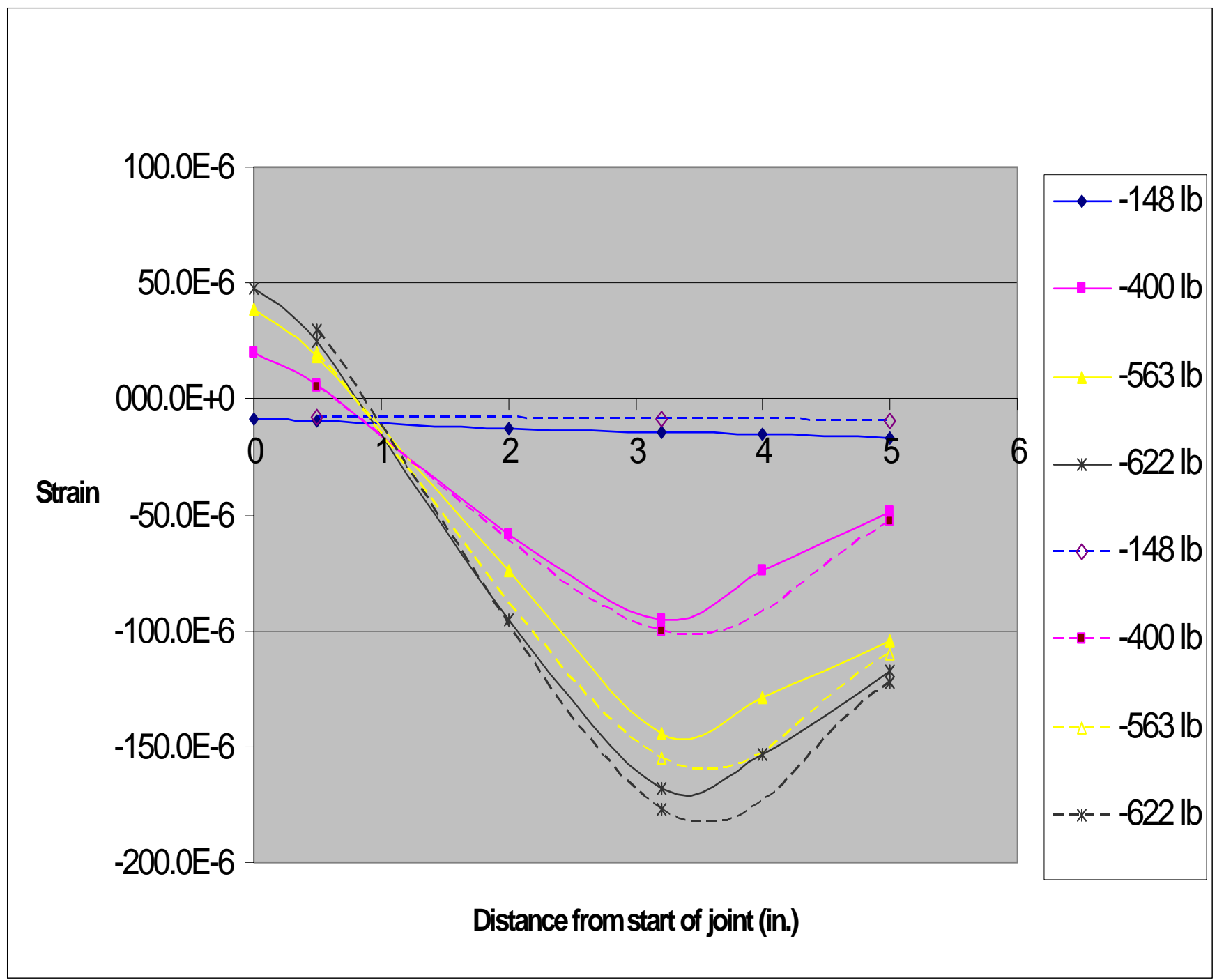

Fig. 5.8 Strain Profile across the length of the riveted joint

The distribution of the longitudinal strain from the current analysis follows the same trend as that of the experimental one for the four loads considered. In all the cases the agreement between the analytical and experimental results is very good at the all the three locations where experimental data is available. The strain variation observed for the load of $148 \mathrm{lb}$ is linear. The variation becomes non-linear as the applied load increases. 
The high strain values at the middle could be explained due to the presence of the hole which is a region of high stress concentration.

\subsection{COUPON-LEVEL MECHANICALLY CONNECTED LAP JOINT ANALYSIS}

\subsubsection{Introduction}

Coupon-level joint analysis is performed to further understand the nature of the riveted joint. First a solid model of the Coupon-level is generated by creating key points and then defining volumes by selecting key points. The same layer stacking sequence used in the Prodeck 4 flanges are used for the coupon-level joints. Thus the same layer material properties which are used to model the FRP deck panel are used in this finite

element model. The volumes thus formed are map meshed and then the orientations of the layers are checked as mentioned earlier in Section 3.4.

The rivet between the two adherends is modeled as mentioned in section 5.2 using SOLID-45 elements. The rivet properties correspond to the specification of Grade 5 A-340 carbon steel rivets. A detailed report on the SOLID-45 element and carbon steel rivets is provided in Chapter 3. The nodes on the surface of the rivet diameter and the inner surface of the hole on the adherends are merged to give continuity of the model and ensure load transfer through the rivet to the other adherend. 
Figure 5.9 shows a solid model of the mechanically-connected coupon-level joint. The orientations of the coordinate systems of all the elements are checked to see if they are aligned in the fiber direction and changes in the orientations are manually made if necessary. The boundary conditions and load applied to the model is seen in Fig.5.10.

1 volumes

TYPE NUM
NNSYS

MAR 202007

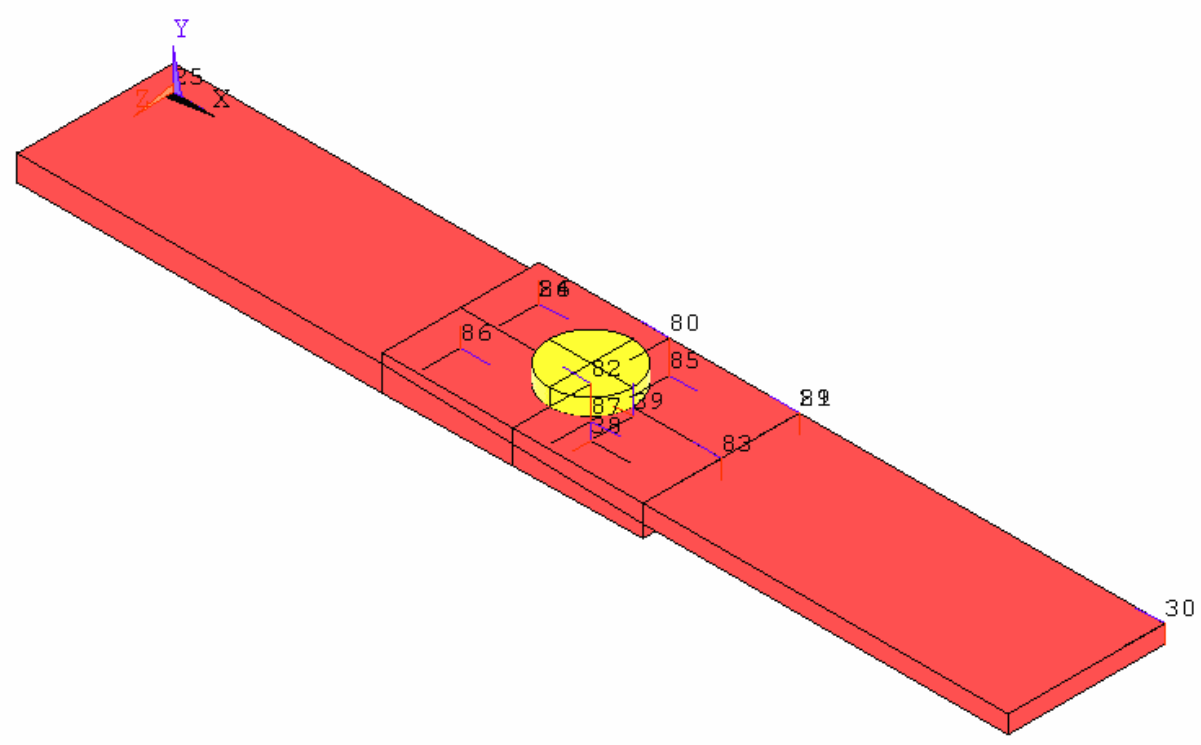

Fig. 5.9 Mechanically connected coupon-level single lap joint 


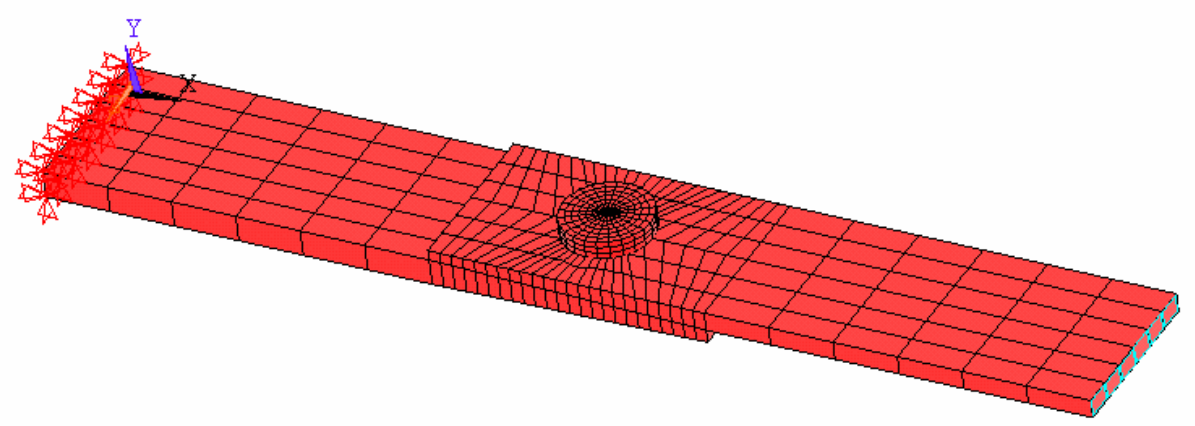

Fig. 5.10 Pictorial representation of uniform pressure and boundary conditions applied on the mechanically connected coupon-level joint

\subsubsection{Analysis of Stain Profile across the Coupon-Level Joint}

A static analysis is performed on the finite element model of the Coupon-level joint that is generated. The model is subjected to compressive loading and strain values across the joint are monitored. The values of the resultant applied compressive load $(P)$ are 148, 400, 563 and $622 \mathrm{lb}$. The contour plot of the longitudinal strain variation across the joint section at the resultant compressive load of $400 \mathrm{lb}$ is shown in Fig. 5.11. 
TIME $=1$

EPTOX

RSYS $=0$

$\mathrm{DMX}=.046882$

SMN $=-.106 \mathrm{E}-03$

SMX $=.808 \mathrm{E}-04$

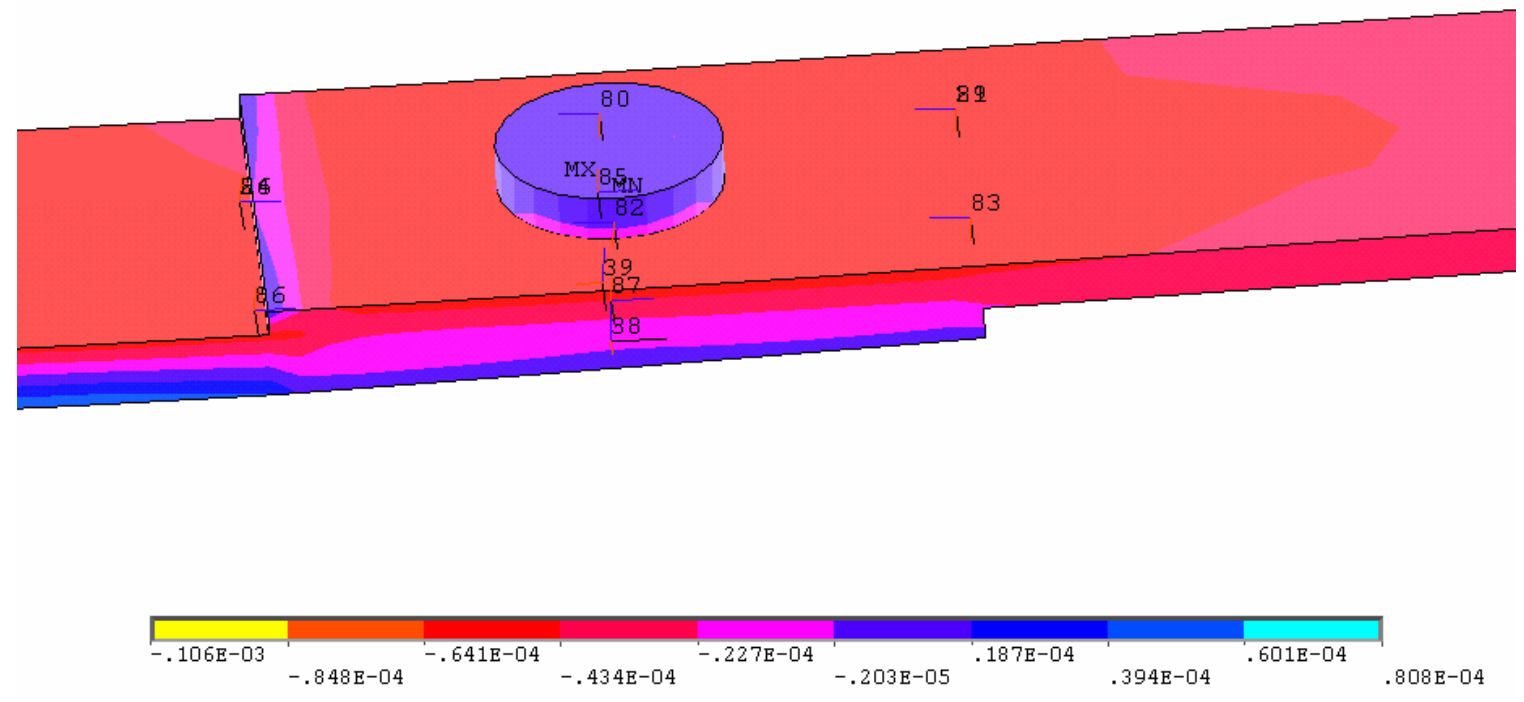

Fig. 5.11 Contour plot of longitudinal strain in the joint region of the riveted coupon joint under a compressive load of $400 \mathrm{lb}$ 

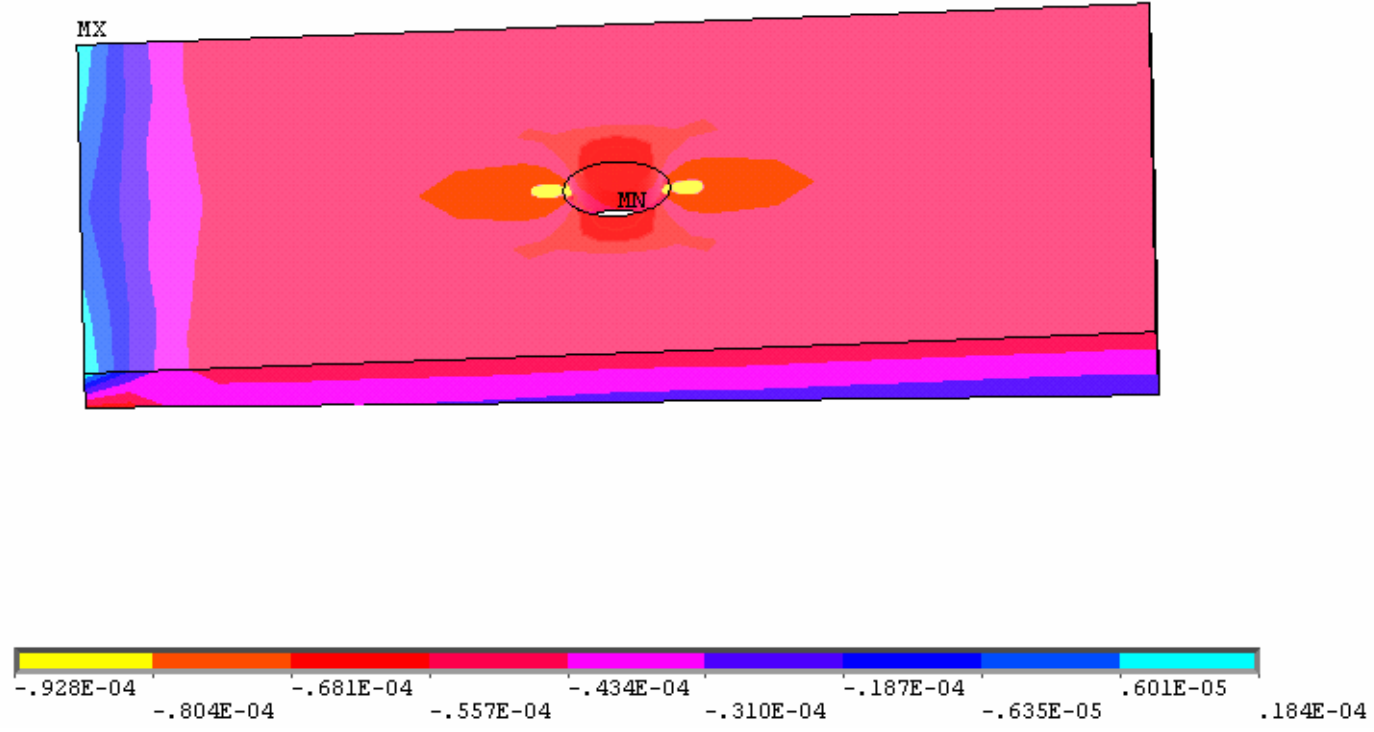

Fig. 5.12 Strain profile across the top of the joint under a load of $400 \mathrm{lb}$

Figure 5.12 represents the longitudinal strain variation at the joint segment. The picture shows the top end of the joint where the strain gauges have been placed while performing the actual experiment by Ganga Rao et al. (2004). 
Table 5.2 Longitudinal strain values across the riveted coupon joint for different applied loads

\begin{tabular}{|c|c|c|c|c|}
\hline \multicolumn{5}{|c|}{ Analytical strains at } \\
\hline $\begin{array}{c}\text { Distance from the } \\
\text { start of the joint } \\
\text { (in.) }\end{array}$ & $P=-148 \mathrm{lb}$ & $P=-400 \mathrm{lb}$ & $P=-563 \mathrm{lb}$ & $P=-622 \mathrm{lb}$ \\
\hline 0 & $-10.1 \mathrm{E}-6$ & $21.8 \mathrm{E}-6$ & $32.1 \mathrm{E}-6$ & $39.5 \mathrm{E}-6$ \\
\hline 0.5 & $-12.2 \mathrm{E}-6$ & $11.2 \mathrm{E}-6$ & $13.5 \mathrm{E}-6$ & $19.2 \mathrm{E}-6$ \\
\hline 2 & $-13.7 \mathrm{E}-6$ & $-59.6 \mathrm{E}-6$ & $-77.2 \mathrm{E}-6$ & $-97.8 \mathrm{E}-6$ \\
\hline 3.2 & $-15.3 \mathrm{E}-6$ & $-91.0 \mathrm{E}-6$ & $-148.6 \mathrm{E}-6$ & $-165.1 \mathrm{E}-6$ \\
\hline 5 & $-18.0 \mathrm{E}-6$ & $-49.0 \mathrm{E}-6$ & $-103.0 \mathrm{E}-6$ & $-112.1 \mathrm{E}-6$ \\
\hline & & $-70.2 \mathrm{E}-6$ & $-129.4 \mathrm{E}-6$ & $-146.5 \mathrm{E}-6$ \\
\hline & & & & \\
\hline & & & & \\
\hline
\end{tabular}




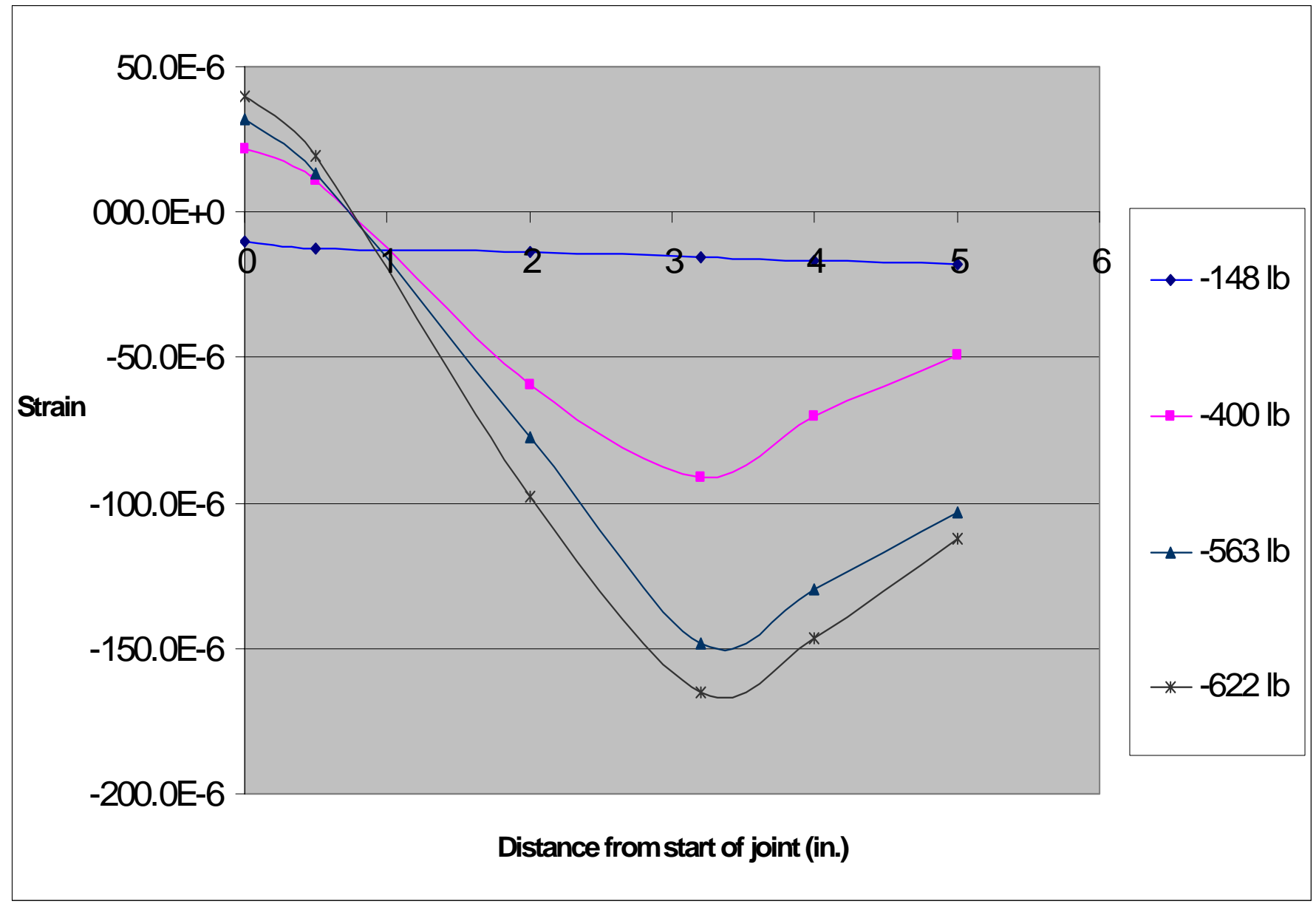

Fig. 5.13 Strain profile across the length of the coupon-level riveted joint

The distribution of the longitudinal strain from the coupon-level joint analysis loaded under compressive loading follows a similar trend as that of the experimental one for the loads considered. The strain variation observed for a compressive load of $148 \mathrm{lb}$ is linear which is expected at lower load levels. The variation becomes nonlinear as the applied load increases as expected. The strain value at the center of the joint is more due to the stress concentration at the hole, but these values are similar to the deck level strain results. The longitudinal strain values on the top surface of the joint for different loads are presented in Table 5.2. The same results are presented graphically in Fig. 5.13. 


\subsection{ANALYSIS OF MECHANICALLY AND ADHESIVELY- CONNECTED TWIN FRP PANELS}

\subsubsection{Introduction}

This section deals with the development of a finite element model of the mechanically and adhesively-connected low-profile FRP bridge deck panels. Once the finite element model is done, it is subjected to a compressive load to obtain the strain profile across the joint section. The results thus obtained are then compared with that obtained in experiments conducted by previous researchers.

\subsubsection{Finite Element Model}

A solid model of the FRP panel is generated in a way similar to that of mechanically bonded joint with a thin layer of adhesive added between the adherends. This model is a combination of the adhesive and the mechanical joint modeled earlier in this thesis. First the two FRP panels are modeled with the layer of adhesive joining them. The adhesive is modeled as thin volume and map meshed using SOLSH 190 elements as described in Chapter 4. Then a hole is made in the center of the top and bottom overlapping panel sections. The composite panels are modeled using SOLID 46 elements where the individual layers with corresponding properties are input into the model. Rivets are modeled and map meshed at the drilled locations using SOLID 45 elements. The volumes on the panels are map meshed and then the orientations of the layers are checked as mentioned earlier in Section 3.4. The nodes on the lower surface of the right panel and the upper surface of the adhesive and the lower surface of the adhesive and the top 
surface of the left panel are merged. The nodes on the outer surface of the rivets are merged with the nodes on the inner surface of the drilled sections. This design consideration allows for the load transfer from one panel to the other panel through the rivet and the adhesive and maintains continuity of the model.

Figure 5.14 displays a solid model of the mechanically and adhesively-connected FRP twin-panel, which consists of 84 volumes combined together. The orientations of the coordinate systems of all the elements are checked to see if they are aligned in the fiber direction and changes in the orientations are manually made if necessary by checking the element orientations with respect to the locally defined coordinate systems for all the elements.

$\perp$

VOLUMES

TYPE NUM

NNSYS

MAR 192007 $19: 53: 41$

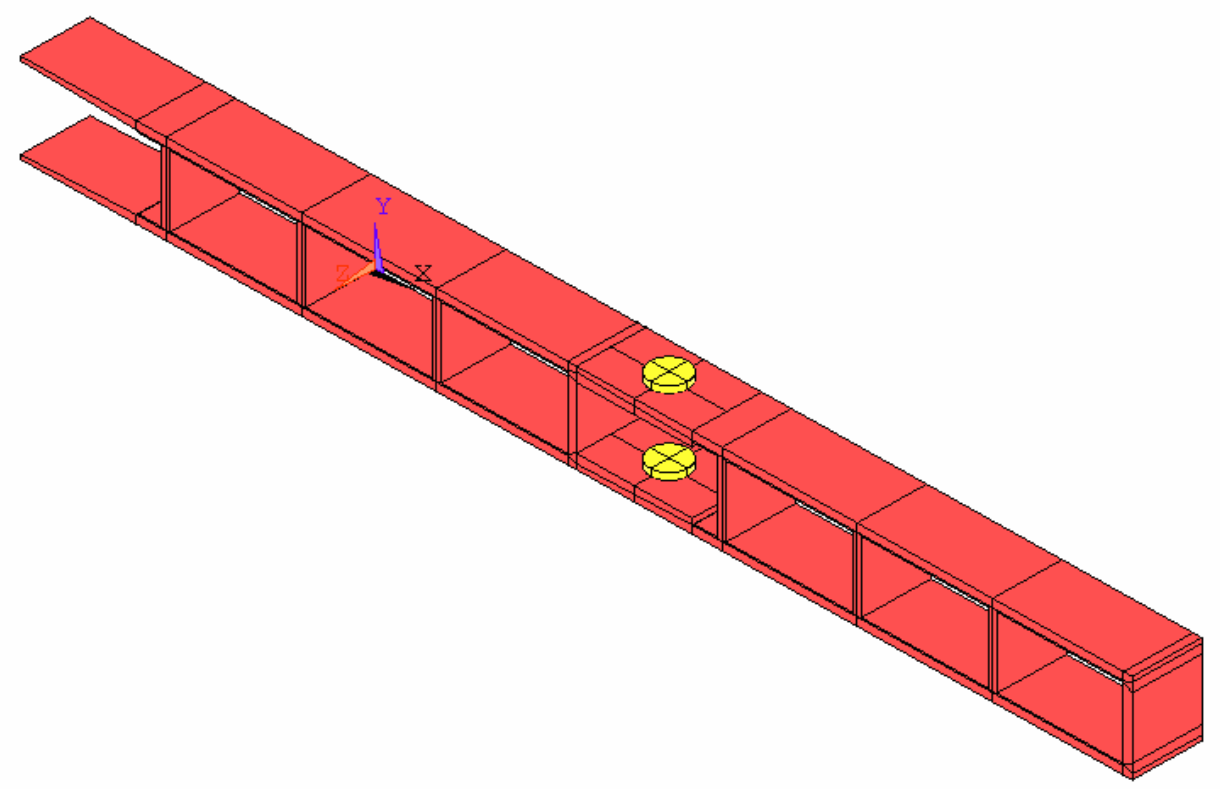

Fig. 5.14 Solid model of a mechanically and adhesively-bonded FRP twin-panel connection 
Figure 5.15 shows the map meshed model of the mechanically and adhesively connected FRP panels just across the joint section. The adhesive used to connect the two panels are modeled using SOLSH-190 elements. The adhesive is modeled as a thin volume and then map meshed resulting in 120 elements. The glue properties correspond to the specifications of Pliogrip 6600. The rivets used to connect the two panels are modeled using SOLID-45 elements. The rivet properties correspond to the specifications of Grade 5 A-340 carbon steel rivets. Figure 5.15 shows a closer look of the mechanically riveted and adhesively bonded section of the FRP twin-panel.

1 ELEMENTS

NNSYS

MAR 222007

$16: 46: 16$

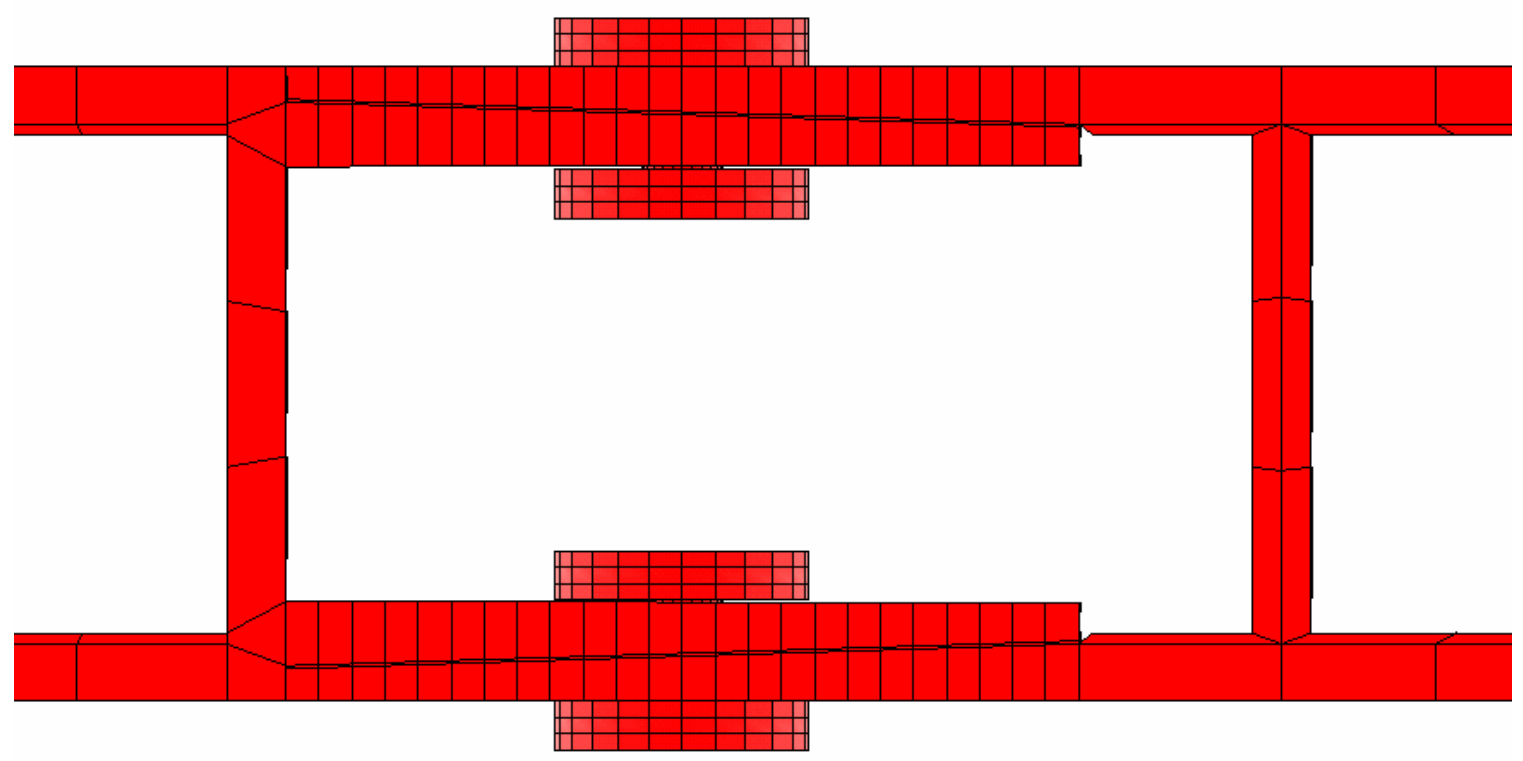

Fig. 5.15 Joint section of the riveted and adhesively bonded FRP twin-panel 


\subsubsection{Boundary Conditions and Applied Loads}

The boundary conditions applied to the FRP beam model are as shown in Fig. 5.16. The beam is fixed at one end by setting the degree of freedom in the $X, Y$ and $Z$ directions to be zero. A surface load over an area of 3"x 3 " is applied in the form of a uniform pressure on the web at the right end to simulate the effect of compressive loading.

1 VOLUME S

TYPE NUM
NNSYS

MAR 192007

$19: 53: 41$

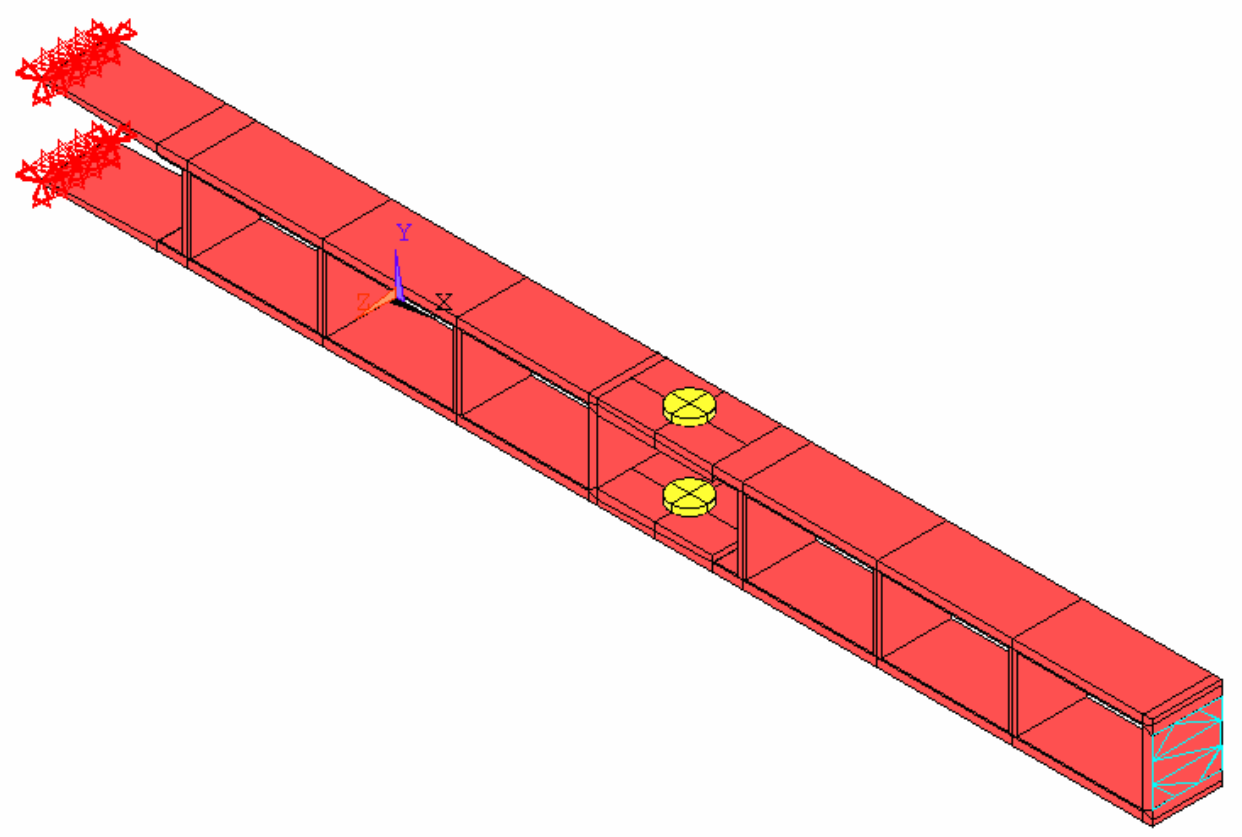

Fig. 5.16 Pictorial representation of boundary conditions and applied load on riveted and adhesively bonded FRP twin-panel 


\subsection{RESULTS}

\subsubsection{Analysis of Stain Profile across the Joint}

A static analysis is performed on the finite element model of the FRP twin-panel that is generated. The model is subjected to compressive loading and the strain values across the joint are monitored. The values of the resultant compressive load $(P)$ correspond to that of the experimental ones selected by Ganga Rao et al. (2004), and are, namely 178, 237 and $326 \mathrm{lb}$. The contour plot of the longitudinal strain variation across the joint section at the resultant compressive load of $178 \mathrm{lb}$ is shown in the Fig 5.17. 1

NODAL SOLUTION

NNSYS

$\mathrm{STEP}=1$

SUB $=1$

TIME $=1$

EPTOX (AVG)

RSYS $=0$

$\mathrm{DMX}=.004301$

SMN $=-.253 \mathrm{E}-03$

$\mathrm{SMX}=.177 \mathrm{E}-03$
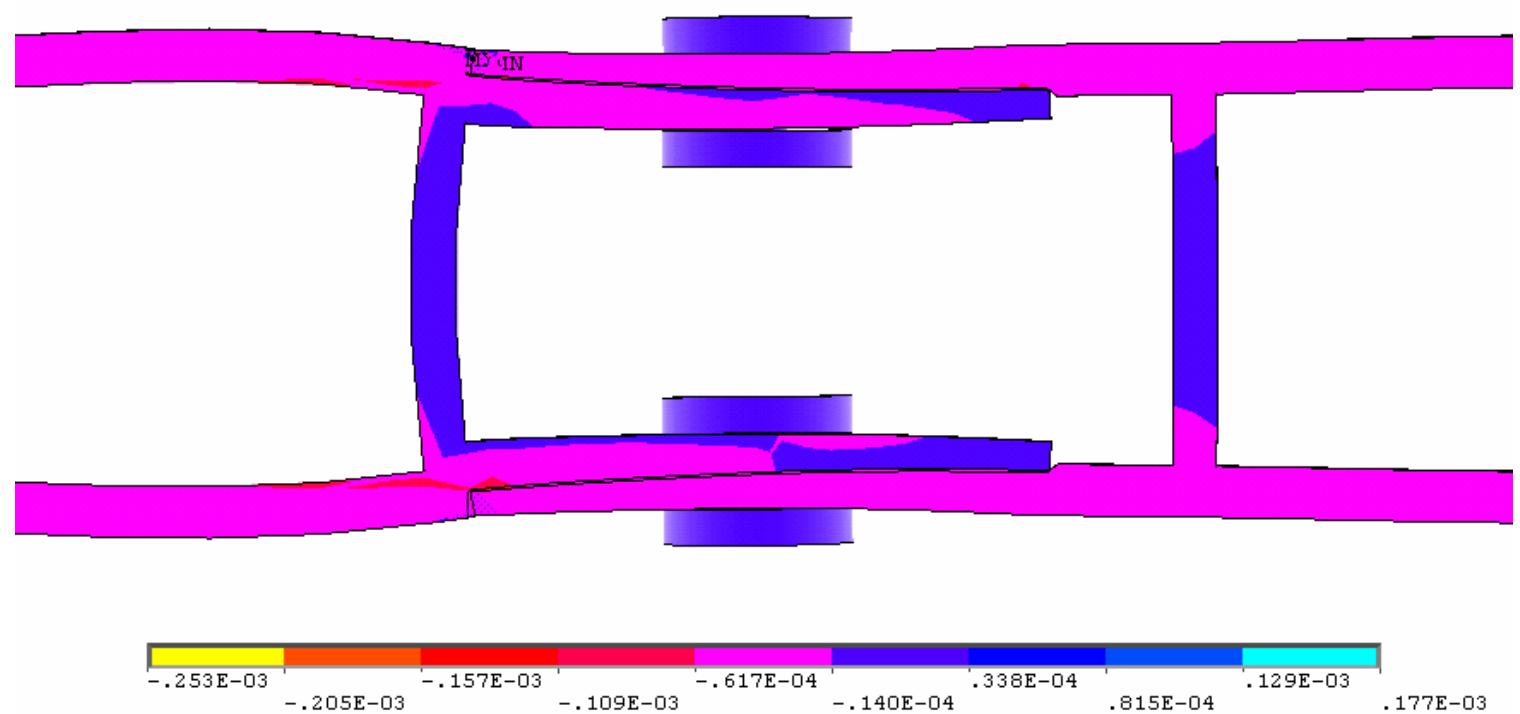

Fig. 5.17 Contour plot of longitudinal strain in the joint region for a compressive load of $178 \mathrm{lb}$ 


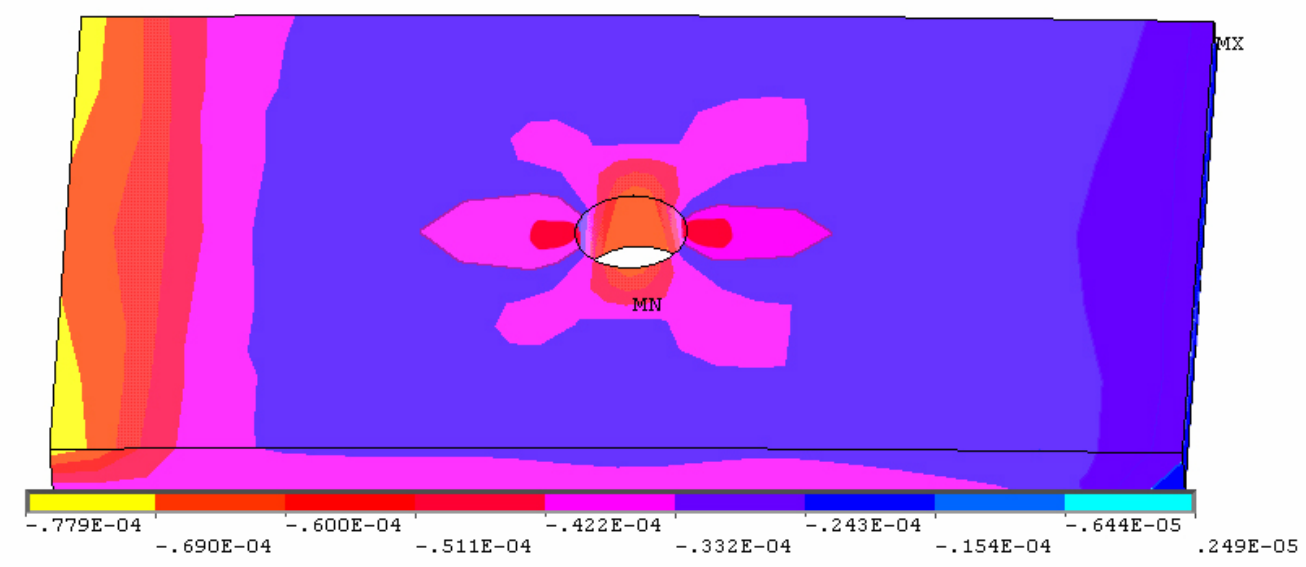

Fig. 5.18 Strain profile across the top of the joint under a load of $178 \mathrm{lb}$

Figure 5.18 represents the longitudinal strain variation across the joint under a compressive load of $178 \mathrm{lb}$. The figure shows the top surface of the joint where the strain gauges had been placed while performing the actual experiment by Ganga Rao et al. (2004). The strain at the middle of the joint has been measured around the diameter of the hole. 
Table 5.3 Longitudinal strain values across the riveted and adhesively-connected joint for different applied loads

\begin{tabular}{|c|c|c|c|}
\hline \multicolumn{4}{|c|}{ Analytical strains at } \\
\hline $\begin{array}{l}\text { Distance from the start of } \\
\text { the joint (in.) }\end{array}$ & $P=-178 \mathrm{lb}$ & $P=-237 \mathrm{lb}$ & $P=-326 \mathrm{lb}$ \\
\hline 0 & $-64.3 E-6$ & $-78.4 \mathrm{E}-6$ & $-120.3 E-6$ \\
\hline 0.5 & $-61.1 E-6$ & $-75.5 E-6$ & $-114.3 E-6$ \\
\hline 2 & $-53.4 \mathrm{E}-6$ & $-67.5 \mathrm{E}-6$ & $-97.1 \mathrm{E}-6$ \\
\hline 3.2 & $-45.2 E-6$ & $-58.9 E-6$ & $-83.1 E-6$ \\
\hline 4 & $-38.2 E-6$ & $-49.6 \mathrm{E}-6$ & $-67.4 \mathrm{E}-6$ \\
\hline 5 & $-29.6 \mathrm{E}-6$ & $-38.0 \mathrm{E}-6$ & $-49.2 E-6$ \\
\hline \multicolumn{4}{|c|}{ Experimental Results [Ganga Rao et al. (2004)] } \\
\hline $\begin{array}{l}\text { Distance from the start of } \\
\text { the joint (in.) }\end{array}$ & $P=-178 \mathrm{lb}$ & $P=-237 \mathrm{lb}$ & $P=-326 \mathrm{lb}$ \\
\hline 0.5 & $-65.0 \mathrm{E}-6$ & $-81.0 \mathrm{E}-6$ & $-118.0 \mathrm{E}-6$ \\
\hline 3.2 & $-51.0 \mathrm{E}-6$ & $-64.0 \mathrm{E}-6$ & $-91.0 \mathrm{E}-6$ \\
\hline 5 & $-35.0 \mathrm{E}-6$ & $-42.0 \mathrm{E}-6$ & $-58.0 \mathrm{E}-6$ \\
\hline
\end{tabular}

The strain results are represented graphically in Fig. 5.19. The solid lines represent analytical results while the dotted lines represent the experimental results. The longitudinal strain values on the top surface of the joint for different load values are presented in Table 5.3. The corresponding experimental strain values (at the strain gage locations) from Ganga Rao et al. (2004) are also included in this table. 


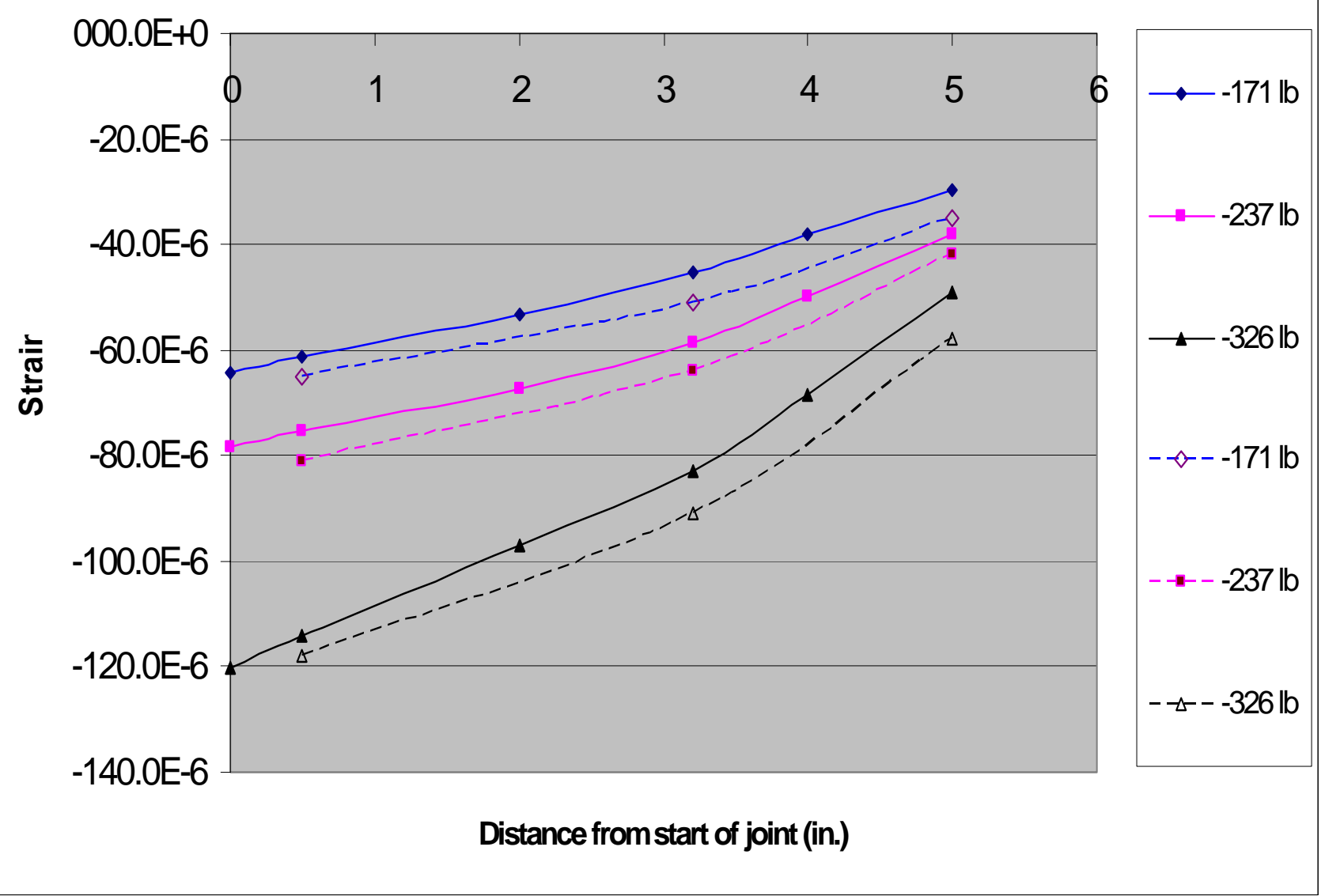

Fig. 5.19 Strain profile across the length of the riveted and glued FRP panels

The distribution of the longitudinal strain from the current analysis follows the same trend as that of the experimental one for the three loads considered. In all the cases, the agreement between the analytical and experimental results is very good. The longitudinal strains are maximum (in magnitude) at the start (left end) of the joint and gradually decrease in magnitude toward the right end. This suggests that the bulk of the load transfer takes place at the start of the joint. 


\subsection{COUPON-LEVEL MECHANICALLY AND ADHESIVELY BONDED JOINT ANALYSIS}

\subsubsection{Introduction}

A coupon-level joint analysis is performed to further understand the nature of the glued and riveted joint. First a solid model of the coupon-level is generated by creating key points and then defining volumes by selecting key points. The same layer stacking sequence used to model the Prodeck 4 flanges is used to model the coupon-level joints. Thus the same layer material properties which are used in the finite element model of the FRP twin-panel are used in this case. The volumes thus formed are map meshed and then the orientations of the layers are checked as mentioned earlier in Section 3.4.

The adhesive used to connect the two panels is modeled using SOLSH-190 element. The adhesive is modeled as a thin volume and then map meshed using SOLSH190. The glue properties correspond to the specifications of Pliogrip 6600. Rivet between the two adherends is modeled using SOLID-45 elements. The rivet properties correspond to the specifications of Grade 5 A-340 carbon steel rivets. The nodes on the lower face of the top adherend and the upper surface of the adhesive and the lower surface of the adhesive and the top surface of the lower adherend are merged. The nodes on the surface of the rivet diameter and the inner surface of the hole on the adherends are merged to give continuity of the model and ensure load transfer through the rivet to the other adherend. 
Figure 5.20 shows a solid model of the mechanically riveted and adhesivelyconnected coupon-level joint. The orientations of the coordinate systems of all the elements are checked to see if they are aligned in the fiber direction and changes in the orientations are manually made if necessary. The boundary conditions and load applied to the model is seen in Fig. 5.21.

1

VOLUMES

NNSYS

TYPE NUM

MAR 262007

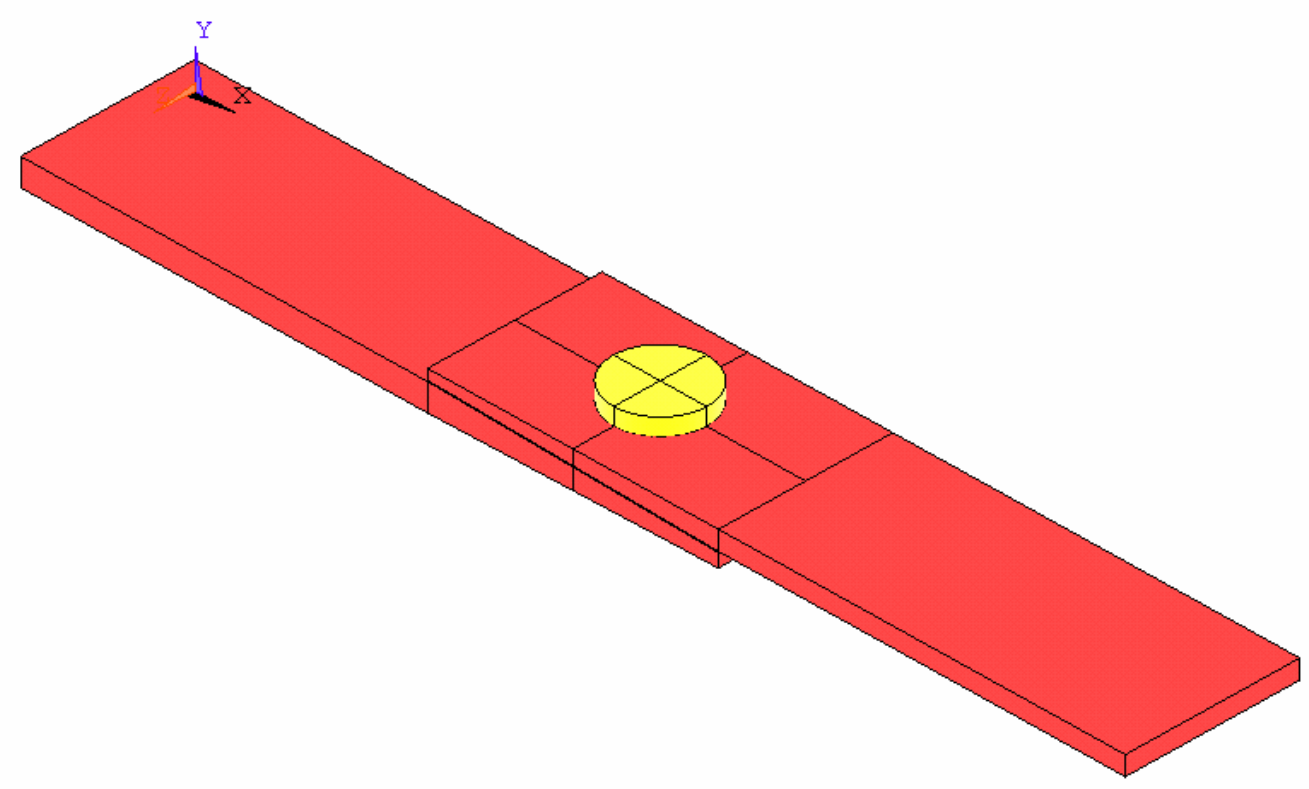

Fig. 5.20 Mechanically riveted and adhesively connected coupon-level single lap joint 


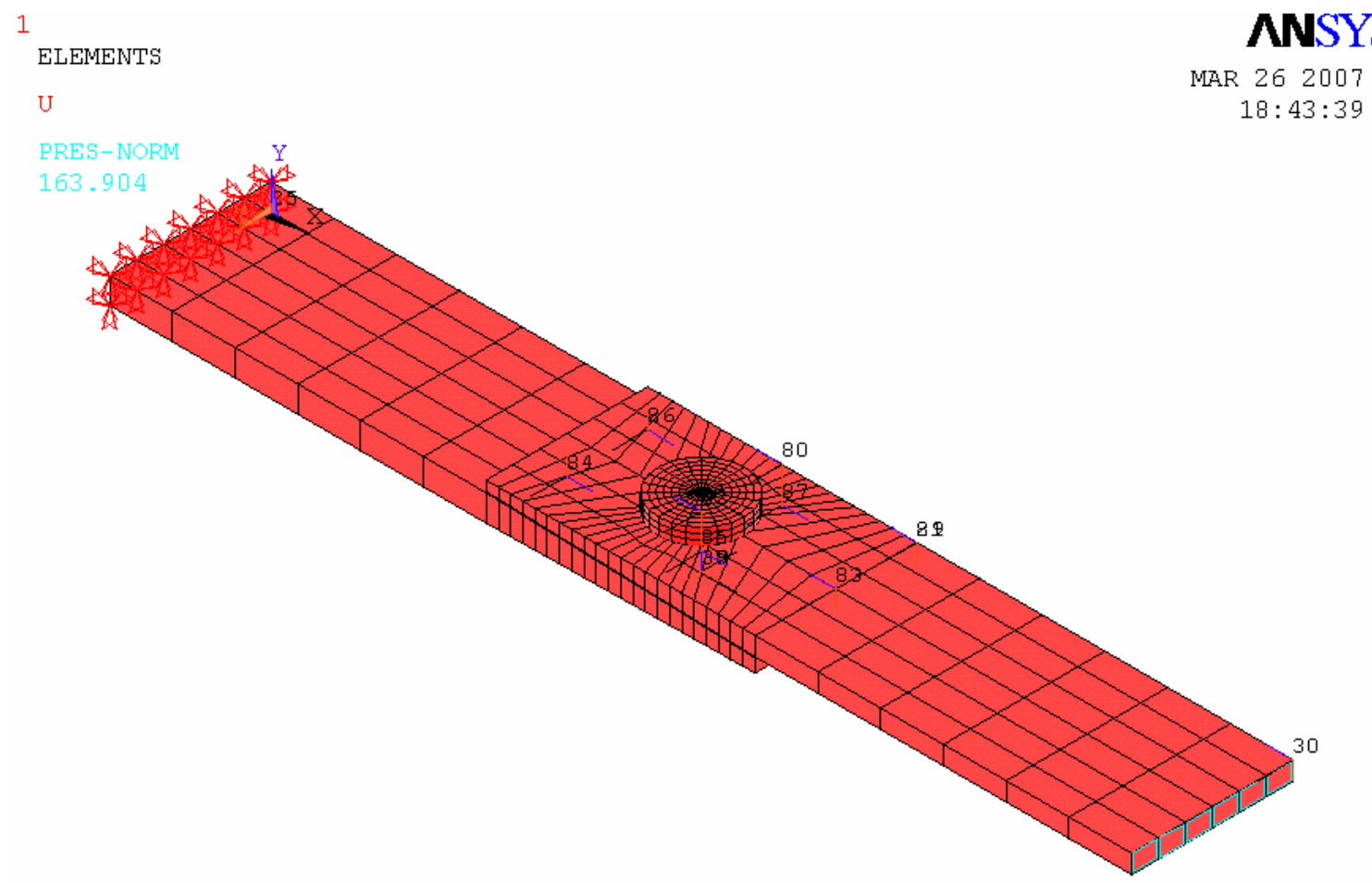

Fig. 5.21 Pictorial representation of uniform pressure and boundary conditions applied on the mechanically riveted and adhesively bonded coupon-level joint

\subsubsection{Analysis of Strain Profile across the Coupon-Level Joint}

A static analysis is performed on the finite element model of the Coupon joint that is generated. The model is subjected to compressive loading and strain values across the joint are monitored. The values of the resultant applied compressive load $(P)$ are 178, 237 and $326 \mathrm{lb}$. The contour plot of the longitudinal strain variation across the coupon at the resultant applied compressive load of $178 \mathrm{lb}$ is shown in the Fig. 5.22. 

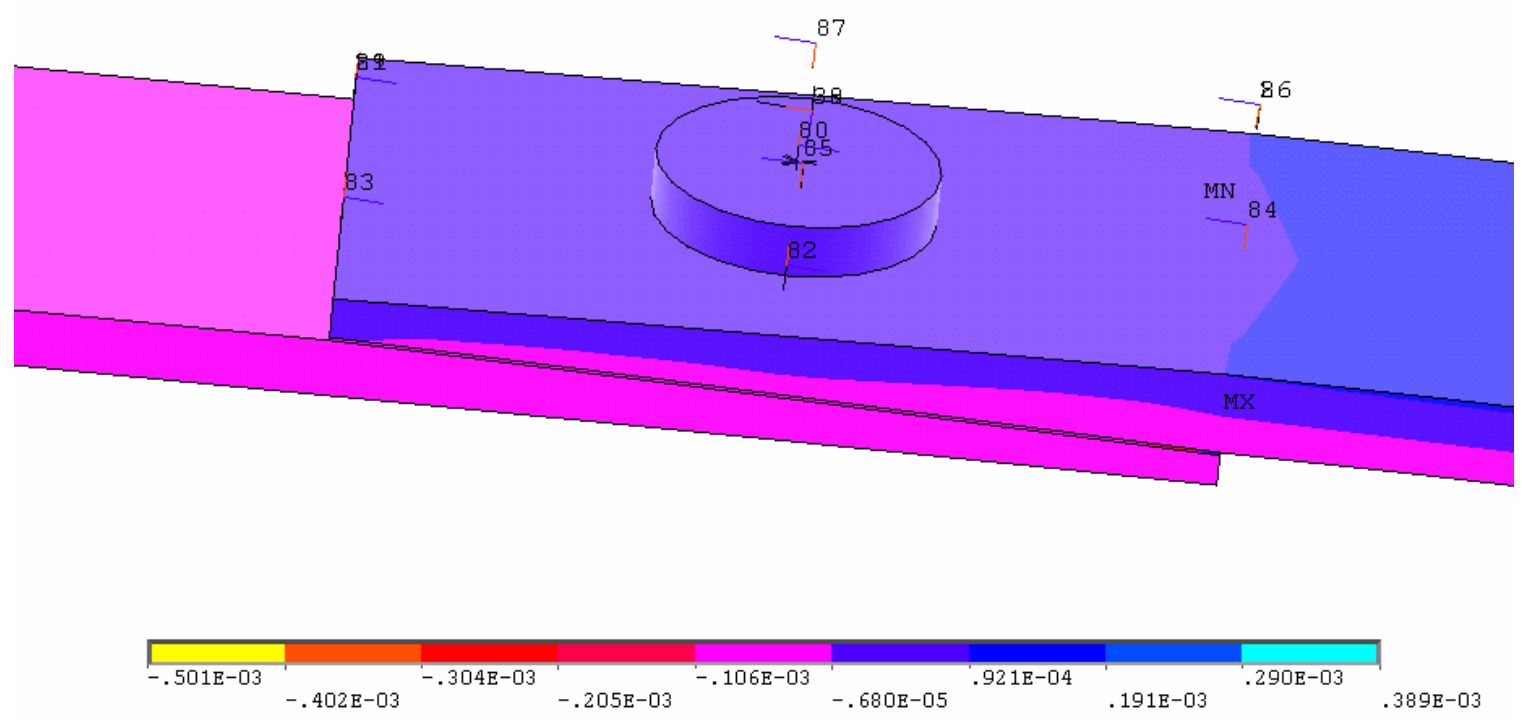

Fig. 5.22 Contour plot of the longitudinal strain in the joint region of the riveted and glued coupon joint for a compressive load of $178 \mathrm{lb}$ 
Table 5.4 Longitudinal Strain values across the coupon-level joint for different applied loads

\begin{tabular}{|c|c|c|c|}
\hline \multicolumn{4}{|c|}{ Analytical strains at } \\
\hline $\begin{array}{c}\text { Distance from the start } \\
\text { of the joint (in.) }\end{array}$ & $P=-148 \mathrm{lb}$ & $P=-400 \mathrm{lb}$ & $P=-563 \mathrm{lb}$ \\
\hline 0 & $-62.1 \mathrm{E}-6$ & $-79.3 \mathrm{E}-6$ & $-118.2 \mathrm{E}-6$ \\
\hline 0.5 & $-59.9 \mathrm{E}-6$ & $-75.5 \mathrm{E}-6$ & $-113.3 \mathrm{E}-6$ \\
\hline 2 & $-54.0 \mathrm{E}-6$ & $-68.0 \mathrm{E}-6$ & $-100.4 \mathrm{E}-6$ \\
\hline 3.2 & $-47.2 \mathrm{E}-6$ & $-61.9 \mathrm{E}-6$ & $-87.1 \mathrm{E}-6$ \\
\hline 4 & $-38.0 \mathrm{E}-6$ & $-50.3 \mathrm{E}-6$ & $-68.0 \mathrm{E}-6$ \\
\hline 5 & $-29.6 \mathrm{E}-6$ & $-38.0 \mathrm{E}-6$ & $-49.2 \mathrm{E}-6$ \\
\hline
\end{tabular}




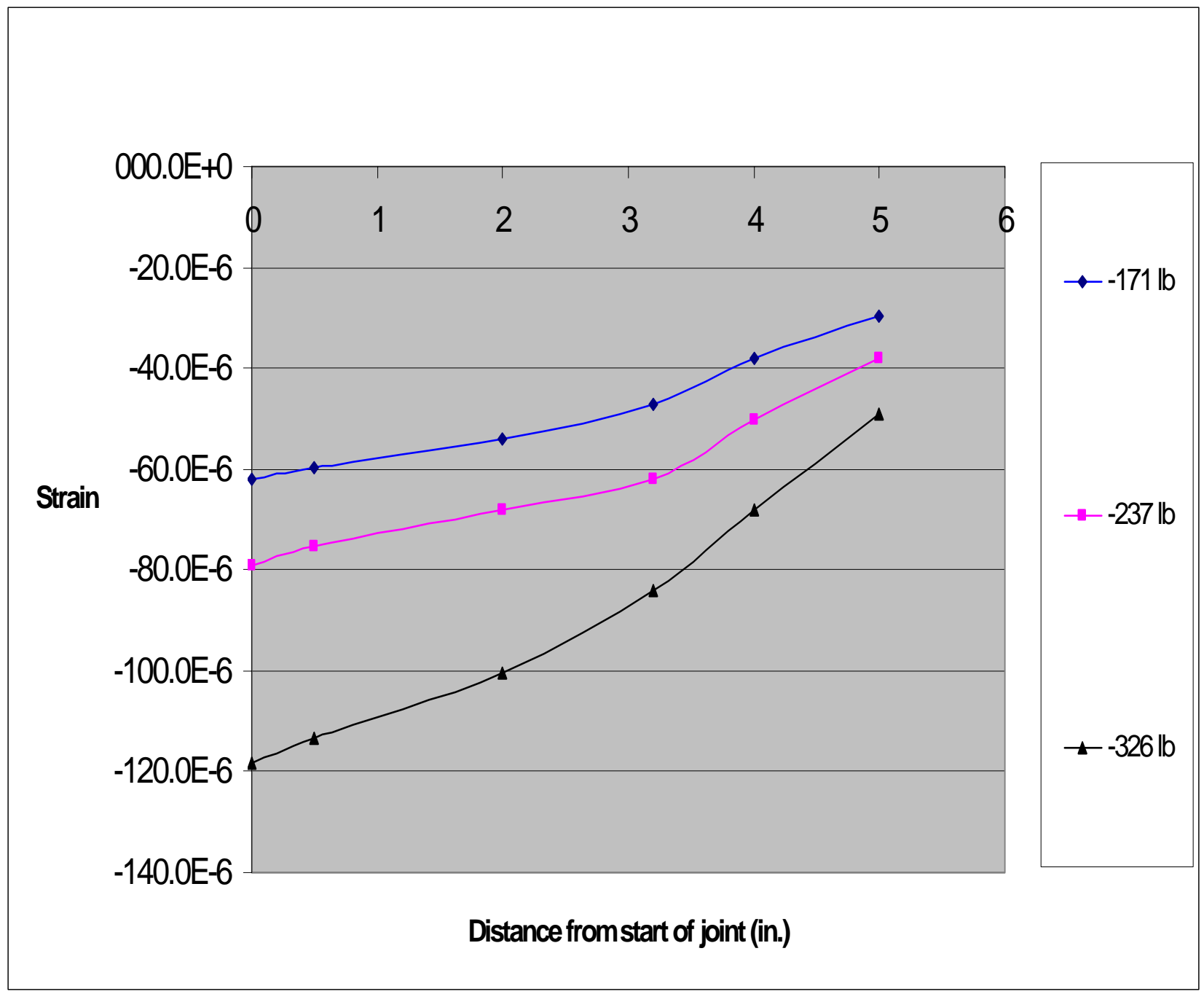

Fig. 5.23 Strain profile across the length of the riveted and glued coupon joint

The distribution of the longitudinal strain from the coupon-level joint analysis loaded under compressive loading follows a similar trend as that of the analytical deck level strain profile for the loads considered. The longitudinal strain values on the top surface of the joint for different loads are presented in Table 5.4. The same results are presented graphically in Fig. 5.23. 


\section{CHAPTER 6}

\section{CONCLUSIONS AND RECOMMENDATIONS}

\subsection{INTRODUCTION}

The Prodeck 4 is an FRP bridge deck. Panel to panel connection of the bridge deck is done in the field using adhesive and or mechanical joints. This research has simulated using the finite element method several joint mechanisms and analyzed them under compressive loading. This chapter contains conclusions drawn from the present finite element analysis as well as recommendations for future work.

\subsection{CONCLUSIONS}

- An accurate finite element model of a multi-panel Prodeck 4 with different joint types has been carried out successfully.

- The results in the form of strain profiles along the joint surface using the finite element model shows good correlation with that of the experiments conducted by earlier researchers.

- The strain profile in the adhesive joint indicates that the load transfer takes place at the end of the joint.

- The shear stress variation across the adhesive in the glued only joint is in good agreement with theoretical predictions.

- The apparent increase in the modulus of elasticity of a thin layer of adhesive is about $15 \%$ confirming previous findings. 
- The stress concentration around the holes in the riveted joints leads to high strain values at the middle of the riveted joints. This also indicates that the load is transferred through the rivet.

- Based on the results obtained, the glued and riveted joint would be the most efficient of the three. This is due to the fact that when loaded initially the rivet takes up the entire load and the adhesive only comes into action once the rivet fails.

\subsection{RECOMMENDATIONS}

- The joining mechanism in the panels can be optimized by studying the effect of variations in glue and rivet properties.

- A viscoelastic model of the adhesive could be incorporated in the analysis using contact elements to better understand the time-dependent behavior of the adhesive.

- Clamping pressure could be incorporated in the design for the riveted only and glued and riveted joints to better understand the stress strain state in the rivets.

- Failure analysis for all the three joint configurations could be carried out to better understand the modes of failure for the respective joint configurations.

- The finite element model could be further verified by dynamic/vibration testing. 


\section{REFERENCES}

ANSYS 10, 2007, “ANSYS theory reference manual."

Alampalli, S., Kunin, J. (2001), "Load Testing of an FRP Bridge Deck on a Truss Bridge," Applied Composite Materials, Vol. 10, pp. 85-102.

Adams, R.D., and Wake, W.C., (1984) "Structural Adhesive Joints in Engineering," Elsevier Applied Science Publishers, London.

Cope, D.A., and Lacy, T.E., (2004), “Modeling mechanical fasteners in singleshear lap joints," Journal of Aircraft, Vol. 41, pp. 1491-1497.

Clark, J.D., and McGregor, I.J., (1993) "Ultimate Tensile Stress Over a Zone: A new Failure Criteria for Adhesive Joints," Journal of Adhesion, Vol. 52, pp. 227-245.

Bank, L.C., (2006), “Composites for Construction,” John Wiley \& Sons, NY

Bank, L.C., Mosallam, A.S., and McCoy, G.T. (1994), "Design and Performance of Connections for Pultruded Frame Structures," Journal of Reinforced Plastics and Composites, Vol. 13, pp. 192-212.

Bank, L.C., and Mossallam, A.S., (1991), "Performance of Pultruded FRP Beam to Column Connections," Proceedings, $9^{\text {th }}$ ASCE Structures Congress, ASCE, NY, pp 389-392.

Barbero, E.J., (1998), “Introduction to Composite Materials Design" Taylor and Francis, Philadelphia. 
Boyapati, S.K., (2006), "Finite Element Analysis of Low Profile Bridge Decks." M.S Thesis, Dept. of Mechanical and Aerospace Engineering, WVU, Morgantown, WV.

Delale, F., Erdogan, F., and Aydinoglu, M.N., (1981) "Stresses in Adhesively Bonded Joints A Closed-Form Solution" Journal of Composite Materials, Vol.15, pp. 249-271

Doyle, J.R., (1991), "Behavior of Bolt and Adhesive Connections in Fiber Reinforced Members," M.S Thesis, Dept. of Civil and Environmental Engineering, WVU, Morgantown, WV.

Fukuoka, T., and Takaki, T., (1998), "Mechanical Behavior of Bolted Joint in Various clamping Configurations," Journal of Pressure Vessel Technology, Vol. 120, pp 226-231.

Ganga Rao, H.V.S., Whitlock, J., Shekar, V., (2004), “Develop Lightweight, Low-Cost FRP Composite Decks and Evaluate Their Responses," CFC Report to USDOT-FHWA, West Virginia University.

Gerbert, G., and Båstedt, H., (1993), “Centrically Loaded Bolted Joints," Journal of Mechanical Design, Vol. 115, pp. 701-705.

Goland, M., and Reissner, E., (1944), “The stresses in Cemented Joints," Journal of Applied Mechanics,Vol. 66, pp. A17-A27.

Hart-Smith, L.J., (1987), “Design of Adhesively Bonded Joints,” Chapter 7 in Joining Fiber-reinforced Plastics, Elsevier, London.

Hibbitt, Karlsson, and Sorensen, ABAQUS, Version 5.5, HKS Inc., 1995 
Howard, I., (2002), "Development of Lightweight FRP Bridge Deck Designs and Evaluations.” Master's Thesis, Dept. of Civil Engineering, WVU, Morgantown, WV.

Holloway, L., (1990), "Adhesively and Bonded Joints," Chapter 6 in Polymers \& Polymers Composites in Construction, Thomas Telford Ltd.

Ireman, T., (1998), "Three-dimensional stress analysis of bolted single-lap composite joints" Composite Structures, Vol. 43, pp. 195-216.

Jager, N., Pallav, P., and Feilzer, A. J., (2003), “Apparent increase of Youngs Modulus in Thin Cement Layer," Dental Material, Vol. 20, pp. 457-462

Jung, C. K., and Han, F. S., (2000), "Fatigue Life Prediction of Bolted Joints," Key Engineering Materials, Vol. 183-187, pp. 1011-1016.

Lehnhoff, T.F., and Wistehuff, W.E., (1996), "Nonlinear Effects on the Stresses and Deformations of Bolted Joints," Journal of Pressure Vessel Technology, Vol. 118, pp. 54-58.

Lin, C.C., and Lin, Y.S., (1993), "A Finite Element Model of Single-Lap Adhesive Joints," International Journal of Solids and structures, Vol. 30, pp. 16791692.

Mark .H. L., IDEAS, Master Series, SDRC Inc., 1995

Matthews, F. L., Kilty, P. F., and Godwin, E. W., (1982), “ Review of the Strength of Joints in Fiber-Reinforced Plastics- 2. Adhesively Bonded Joints," Vol. 13, pp. 29-37. 
Melhem, H.G., and Schlup, J.R., (1994), "An Assessment of the Usage of FRP Composites in Highway Structures," Proceedings, The $17^{\text {th }}$ annual Energy- Sources Technology Conference, ASME Petroleum Division, New Orleans, Louisiana .

Morsi, A., Wissman, D., and Cook, J., (1984), "Column-Base Connections of Fiber-Reinforced Plastics," Proceedings, ASCE Structures Congress, Atlanta, Georgia, May.

Mosallam, A.S., (1994), “Connections for Pultruded Composites: A Review and Evaluation," Proceedings, The Third Materials Engineering Conference, ASCE, San Diego, California, pp 1001-1017.

Oplinger, D.W., (1975), "Stress Analysis of Composite Joints" Proceedings, $4^{\text {th }}$ Army Materials Technology Conference, Newton, MA.

Oplinger, D.W., (1994), "Effects of Adherend Deflections in Single Lap Joints," International journal of Solids and Structures, Vol. 31, pp. 2565-2587.

Pratt, J.D., and Pardeon, G., (2002), “Comparative Behavior of Single-Bolted and Dual-Bolted Lap Joints," Journal of Aerospace, Vol. 15, pp. 55-63.

Prokhorov, B.F., (1965) “Joints used in Plastics and Composites Shipboards Superstructures; Deck-House, Light Bulkheads and Enclosures," Sudostroyenlye \#9, U.S Navy Translation No 2076-b.

Shankar, K., and Dhamari, R., (2002), "Fatigue Behavior of Aluminum Alloy 7075 Bolted Joints Treated with Oily Film Corrosion Compounds," Materials and Design, Vol. 23, pp. 209-216. 
Stiropoulos, S.N., (1995) "Performance of FRP Components and Connections for Bridge Deck Systems," Ph.D Dissertation, Dept. of Civil Engineering, WVU, Morgantown, WV.

Srinivas, S., (1975), “Analysis of Bonded Joints,” NASA TN-D7855, (N7521763), NASA.

Tong, L., (1994), “Bond Shear Strength for Adhesive Bonded Double Lap Joints," International Journal of Solid and Structures, Vol. 31, pp. 2919-2931.

Tsai, M.Y., and Morton, J., (1994), “An Evaluation of Analytical and Numerical Solutions to the Single-Lap Joint," International Journal of Solid and Structures, Vol. 31, pp. 2537-2563.

Vinson, J.R., (1989), “Adhesive Bonding of Polymer Composites," Polymer Engineering and Science, Vol. 29, pp.1325-1331.

Vol.kersen, O., (1938), “Die neitraftverteilung in zugbeansprunchten mit konstantten laschenquerschnitten," (in German) Luftfahrtforschung, Vol. 15, pp. 41. Winter, (1956), "Tests on Bolted Connections in Light Gage Steel," Journal of Structural Division, Vol. 82, pp. 920-1-25.

Zureick, A., (1995), “Fiber-reinforced polymeric bridge decks," Structural Engineering Review, Vol. 7, pp. 257-266

[1] http://www.pulwellpultrusions.com/applications.htm 